\title{
WestVirginiaUniversity
}

THE RESEARCH REPOSITORY @ WVU

Graduate Theses, Dissertations, and Problem Reports

2006

\section{Development and evaluation of smart materials for structural health monitoring}

Sandilya Hota

West Virginia University

Follow this and additional works at: https://researchrepository.wvu.edu/etd

\section{Recommended Citation}

Hota, Sandilya, "Development and evaluation of smart materials for structural health monitoring" (2006). Graduate Theses, Dissertations, and Problem Reports. 1751.

https://researchrepository.wvu.edu/etd/1751

This Thesis is protected by copyright and/or related rights. It has been brought to you by the The Research Repository @ WVU with permission from the rights-holder(s). You are free to use this Thesis in any way that is permitted by the copyright and related rights legislation that applies to your use. For other uses you must obtain permission from the rights-holder(s) directly, unless additional rights are indicated by a Creative Commons license in the record and/ or on the work itself. This Thesis has been accepted for inclusion in WVU Graduate Theses, Dissertations, and Problem Reports collection by an authorized administrator of The Research Repository @ WVU. For more information, please contact researchrepository@mail.wvu.edu. 


\title{
Development and Evaluation of Smart Materials for Structural Health Monitoring
}

\section{Sandilya Hota}

\author{
Thesis Submitted to the \\ College of Engineering and Mineral Resources \\ at West Virginia University \\ in partial fulfillment of the requirements \\ for the degree of

\section{Master of Science \\ in} \\ Electrical Engineering \\ Dr. Powsiri Klinkhachorn, Ph.D., Committee Chair \\ Dr. Mark A Jerabek, Ph.D. \\ Dr. Gangarao Hota, Ph.D. \\ Dr. Ruifeng Liang, Ph.D.
}

\section{Department of Electrial Engineering \\ Morgantown, West Virginia \\ 2006}

Keywords: Electrical Conductivity, Thermosetting Resin, Carbon Fibers, Graphite Powders, Health monitoring, Conductive composites, Smart (sensing) Material, Mechanical properties, Electrical properties 


\section{ABSTRACT \\ Development and Evaluation of Smart Materials for Structural Health Monitoring}

\section{Sandilya Hota}

Most neat resins, including thermoplastics and thermosets are electrical insulators. However, conductive additives or fillers (such as carbon black, carbon fibers) can be added into resins to produce electrically conductive resins and composite materials. At a specific concentration of conductive filler, electroconductive channels are formed and the insulators are turned into semi-conductors. This transformation process can be described within the framework of the percolation theory. The objective of the present study is to develop conductive polymer composites as sensors in terms of change in their electrical resistance as a function of deformation and other parameters for health monitoring and structural response detection of wide range of structural systems including air and spacecraft structures and in particular, fiber reinforced polymer (FRP) composites structures.

Researchers at CFC-WVU have developed a smart material system by adding nanomaterials to neat resins to produce conductive composite sensors (WVU patent pending). The operation of a conductive nanocomposite sensor system is based on the phenomenon that the electrical conductivity of the composite material system changes when exposed to an external stimulus. The change in conductivity/resistivity can be correlated quantitatively to the intensity of external stimulus. Preliminary evaluation demonstrates that the composite sensor developed by $\mathrm{CFC}-\mathrm{WVU}$ researchers appears to be able to detect changes in moisture and strain under mechanical loading in real time. The axial sensitivities $S_{A}$ of the conducting composites were in the range of 5-15 for different variations in the constituent materials. This is very good considering that the $\mathrm{S}_{\mathrm{A}}$ for common strain-gage alloys are in the range of 2-5. The smart material has good thermal stability and is not influenced appreciably by temperature changes up to $130 \mathrm{~F}$. Moisture has an effect (the resistance of the sample increases with increase in moisture and vice versa) on the resistance of the material. This is a limitation since we have to use a correction factor depending on the amount of moisture and the time of exposure at that particular humidity level. The resistance of the material over prolonged period of time, the effect of harsh environment (material degradation), durability have to be further investigated.

The CFC-WVU composite sensor has a great potential. It can be designed at any desired scale (dimensions) and manufactured economically. Those sensors can either be embedded into a system during manufacturing or can be grafted onto the surface of a structural component. Moreover, such a sensor can be designed and produced with electrical signal transmission capability, allowing for wireless measurements of material property changes. 


\section{ACKNOWLEDGEMENTS}

The author would like to sincerely thank Dr. Ruifeng Liang and Dr. Hota V.S. GangaRao. They provided valuable insight into all areas of the project from conducting experiments, to analyzing the test data, to philosophical viewpoints about the work. Their indispensable contributions will never be forgotten.

A special thanks to Dr. Klinkhachorn Powsiri who was the committee chairman. He provided valuable feedback during the progress of the work and also helped with providing the facilities of his lab.

The author would like to thank Dr. Mark A Jerabek for serving as an advisory member in the committee and his comments and suggestions.

Many additional students and faculty were very helpful during the course of this work, and their assistance was greatly appreciated. Among them were Liviu Magean, Steve Carpenter,

James Bowers, Shushant Agarwal, Lynne Jacobs, Aneesh Reddy, Jim Hall, Linda Rogers, Bhyrav Mutnuri and Suneetha Burla.

U. S. Department of Transportation - Federal Highway Administration (USDOT-FHWA) under the CFC Center of Excellence program provided the funding for the project. The author is grateful to Mr. Eric Munley, FHWA Project Monitor, for reviewing the progress of this research and providing timely feedback during the course of this study. 


\section{TABLE OF CONTENTS}

$\begin{array}{lc}\text { ABSTRACT } & \text { ii } \\ \text { ACKNOWLEDGEMENTS } & \text { iii } \\ \text { TABLE OF CONTENTS } & \text { iv } \\ \text { LIST OF FIGURES } & \mathbf{v} \\ \text { LIST OF TABLES } & \text { xi }\end{array}$

\section{CHAPTER 1}

INTRODUCTION 1

1.1. General background 1

1.2. Motivation for research 1

1.3. Objective 2

1.4. Scope 3

CHAPTER 2

LITERATURE REVIEW

2.1. Fiber reinforced polymer composites 3

2.2. Conductive composites 4

\section{CHAPTER 3}

MATERIALS AND SAMPLE MANUFACTURING 8

3.1. Introduction $\quad 8$

3.2. Materials 8

3.2.1. Conductive fillers $\quad 8$

3.2.2. Polymers 9

3.3. Molds 10

$\begin{array}{lr}\text { 3.4. Manufacturing of coupon samples } & 12\end{array}$ 
3.4.1 Casting of conducting composites using vinyl ester resins $\quad 12$

3.4.2 Casting of graphite/hybrid resin and other flexible resin samples $\quad 14$

3.4.3 Casting of circular disks for thermal conductivity measurements $\quad 17$

3.4.4 Casting of carbon nano tube based samples 18

\section{CHAPTER 4}

TESTING METHODS 19

4.1. Electrical resistance measurement 19

4.2. Tension test 20

4.2.1. Test specimen 20

4.2.2. Tension test setup and procedure 21

4.3. Static multi-run test 24

4.4. Evaluation of conductive composites as heating elements 25

4.4.1. Basic Theory 25

4.4.2. Experiment 26

4.5. Thermal conductivity measurement 28

4.6. Effect of moisture and water on the potential sensor 30

4.7. Effect of temperature on the potential sensor 31

\section{CHAPTER 5}

RESULTS AND DISCUSSION 33

5.1. Electrical properties 33

5.1.1. Transpo-48 epoxy based samples 33

5.1.2. Hetron 922 vinyl ester based samples 34

5.1.3. Effect of graphite particle sizes in Hetron 922

5.1.4. Other flexible resins 37

5.1.5. Derakane 8084 based samples 42

5.1.6. Effect of graphite particle sizes in Derakane 8084

5.1.7. Carbon nano tube based samples 45

5.2. Mechanical properties 46

5.2.1. Typical results from using Instron 8501 
5.2.2 Graphite /Hetron 922 based samples using Instron 568948

5.2.3. Effect of particle sizes in Hetron 922

5.2.4 A comparison between vinyl ester and epoxy based samples $\quad 60$

$\begin{array}{ll}\text { 5.2.5. Derakane } 8084 \text { based samples } & 60\end{array}$

5.2.6. Effect of particle sizes in Derakane 8084

5.2.7. Carbon nano tube (CNT) based samples $\quad 74$

5.3. Static multi-run test 75

5.4. Evaluation of conductive composites as heating elements 77

$\begin{array}{ll}\text { 5.5. Thermal conductivity } & 79\end{array}$

5.6. Effect of water and moisture on the resistance 80

5.7. Effect of temperature on the resistance 82

CHAPTER 6

CONCLUSIONS AND FUTURE WORK 84

$\begin{array}{ll}6.1 \text { Conclusions } & 84\end{array}$

6.2. Future work 85

REFERENCES 86 


\section{LIST OF FIGURES}

Figure 2.1 Experimental set-up for EIT 5

Figure 3.1 1/8th inch Aluminum mold 11

Figure 3.2 1/8th inch PTFE mold 11

Figure 3.3 HDPE mold for casting samples to measure thermal conductivity 12

Figure 3.4 A schematic of the sample with a line contact 13

Figure 3.5 Tension specimens made of graphite in vinyl ester composites $\quad 14$

Figure 3.6 A hybrid resin system consisting of vinyl ester, epoxy and 15 graphite powder

Figure 3.7 A ready-to-cast mold with electric contacts in place 15

Figure 3.8 Samples made of metallic powder in comparison with a graphite $\quad 17$ sample

Figure 3.9 HDPE mold for casting samples of circular disks 18

Figure 4.1 A schematic showing the wires being put in the mold even 20 before pouring the mixture

Figure 4.2 Meters used for resistance measurements. 20

$\begin{array}{ll}\text { Figure 4.3 Dog-bone tension test specimen } & 21\end{array}$

Figure 4.4 Tension test setup using Instron model 8501

Figure 4.5 A vinyl ester conductive composite under test 22

Figure 4.6 Tension test set-up using Instron 5689

Figure 4.7 A typical stress versus strain curve for a ductile material 24

Figure 4.8 A conductive composite sample being connected to a wire which 26 can be plugged into a domestic power outlet

Figure 4.9 Experimental setup for evaluation of conductive composites as 27 heating elements using an infrared camera model ThermaCAM

Figure 4.10 Typical thermal image generated by an infra red camera for 27 $25 \%$ graphite/ 8084 composite sample

Figure 4.11 A guarded heat flow meter. 28 
Figure 4.12 Schematic of the system arrangement for UNITHERM 2022

Figure 4.13 A controlled humidity chamber 30

Figure 4.14 Two samples immersed in water inside conical flask 31

Figure 4.15 A press used to study the effect of temperature on the sensor's 32 property.

Figure 5.1 Conducting behavior of graphite filled vinyl ester samples 34

Figure 5.2 A power data fit with logarithmic axes for the Figure 4.1 35

Figure 5.3 Variation of electrical resistance of the conducting composites 36 with the graphite particle size

Figure 5.4 SEM micrograph of graphite GP44-B in Ebond at 10wt $\%$

Figure 5.5 SEM micrograph of graphite GP44-B in Ebond at 25wt\% 39

Figure 5.6 SEM micrograph of graphite GP44-B in Ebond at 25wt\% 39

Figure 5.7 SEM micrograph of graphite GP44-B in vinyl ester at 20wt $\% \quad 40$

Figure 5.8 SEM micrograph of graphite GP44-B in vinyl ester at 20wt $\% \quad 40$

Figure 5.9 SEM micrograph of graphite GP44-B in vinyl ester at 20wt\% 41

Figure 5.10 SEM micrograph of graphite GP44-B in vinyl ester at 20wt\% 41

Figure 5.11 Electric resistance as a function of graphite concentration 44

Figure 5.12 Variation of electric resistance w.r.t. particle size in Derakane $\quad 45$

Figure 5.13 Stress and resistance as a function of time for $25 \%$ graphite/ 46 vinyl ester samples

Figure 5.14 Stress and resistance as a function of time for $40 \%$ graphite/ vinyl ester samples

Figure 5.15 Stress and resistance as a function of time for $5 \%$ graphite with

$1 \%$ carbon fiber /vinyl ester samples

Figure 5.16 Relationship between stress and resistance w.r.t strain for $8 \%$ graphite/vinyl ester samples

Figure 5.17 Relationship between stress and resistance w.r.t. strain for $10 \% \quad 50$ graphite/vinyl ester samples

Figure 5.18 Relationship between stress and resistance w.r.t. strain for $12 \% \quad 50$ graphite/vinyl ester samples 
Figure 5.19 Relationship between stress and resistance w.r.t. strain for 14\% graphite/vinyl ester samples

Figure 5.20 Relationship between stress and resistance w.r.t. strain for 15\% graphite/vinyl ester samples

Figure 5.21 Relationship between stress and resistance w.r.t. strain for $20 \%$ 52 graphite/vinyl ester samples

Figure 5.22 Guage factor vs graphite powder concentration in Hetron $922 \quad 54$

Figure 5.23 Relationship between stress \& resistance w.r.t. strain for $10 \%$ GP44-B in Vinyl ester

Figure 5.24 Relationship between stress \& resistance w.r.t. strain for $10 \%$ GP55-B in Vinyl ester

Figure 5.25 Relationship between stress and resistance w.r.t. strain for $10 \% \quad 56$ GS75-E in Vinyl ester

Figure 5.26 Relationship between stress and resistance w.r.t strain for 10\% GS150-E in Vinyl ester

Figure 5.27 Ultimate strain to failure vs particle size in Hetron 58

Figure 5.28 A schematic of graphite powder dispersion in the composites with 58 graphite powder GP44-B \& GS150-E

Figure 5.29 Guage factor vs particle size in Hetron 59

Figure 5.30 A comparison in stress versus strain curve between vinyl ester $\quad 60$ based and epoxy based samples

Figure 5.31 Stress versus strain curves for Batch I Derakane 8084 based composite samples with different graphite concentrations

Figure 5.32 Stress versus strain curves for Batch II Derakane 8084 based composite samples with different graphite concentrations

Figure 5.33 Tensile stress and electric resistance versus strain for 7.5\% graphite in Derakane 8084 resin

Figure 5.34 Tensile stress and electric resistance versus strain for 9\% graphite in Derakane 8084 resin

Figure 5.35 Tensile stress and electric resistance versus strain for 10\% graphite in Derakane 8084 resin 
Figure 5.36 Tensile stress and electric resistance versus strain for $11 \%$ graphite in Derakane 8084 resin

Figure 5.37 Tensile stress and electric resistance versus strain for $12.5 \%$ graphite in Derakane 8084 resin

Figure 5.38 Tensile stress and electric resistance versus strain for 15\% graphite in Derakane 8084 resin

Figure 5.39 Tensile stress and electric resistance versus strain for $17.5 \%$ graphite in Derakane 8084 resin

Figure 5.40 Tensile stress and electric resistance versus strain for 20\% graphite in Derakane 8084 resin

Figure 5.41 Tensile stress and electric resistance versus strain for $22.5 \%$ graphite in Derakane 8084 resin

Figure 5.42 Tensile stress and electric resistance versus strain for $25 \%$ graphite in Derakane 8084 resin

Figure 5.43 Linear modeling of stress and resistance vs strain 69

Figure 5.44 Failure strain versus graphite concentration in Derakane $8084 \quad 70$

Figure 5.45 Guage factor versus graphite concentration in Derakane 8084

Derakane 8084 resin

Figure 5.46 Ultimate failure strain vs particle size in Derakane 8084

Figure 5.47 Sensitivity vs particle size in Derakane 8084

Figure 5.48 Relationship between stress, strain and resistance data for

$0.25 \%$ CNT in Derakane 8084 resin

Figure 5.49 Multi-run static test curves for sample \# 1 till $0.5 \%$ strain

Figure 5.50 Multi-run static test curves for sample \# 2 till $0.5 \%$ strain

Figure 5.51 Maximum temperature and temperature difference at the center

versus reciprocal of resistance for graphite/ 8084 composite samples

Figure 5.52 The figure shows the variation of resistance with the number of days the sample was kept in water

Figure 5.53 A sample under water with air bubbles on the surface 81

Figure 5.54 Variation in resistance when subjected to variation in $\mathrm{RH}$

Figure 5.55 The variation of resistance with temperature 


\section{LIST OF TABLES}

Table 3.1 Properties of different types of graphite powders 9

Table 3.2 Typical properties of Derakane 8084 resin and neat resin casting $\quad 10$

Table 3.3 Compositions of vinyl ester/epoxy hybrid resin based graphite $\quad 16$ composites ( $10 \%$ by weight of graphite)

Table 4.1 Dimensions for tension test specimen

Table 5.1 Conductivity of graphite filled T-48 samples 33

Table 5.2 Conducting properties of cured composites based on flexible resins 37

Table 5.3 Comparison in properties between graphite/ epoxy and 42 graphite/ vinyl ester composites

Table 5.4 Composition of Derakane 8084 based composite samples 43

Table 5.5 Resistance of $0.25 \%$ CNT samples in Derakane 8084 resin 46

Table 5.6 Change in resistance under tension of graphite /vinyl ester samples 53

Table 5.7 Tension and electrical test results of conducting composites with $\quad 59$ different graphite particle sizes at a concentration of $10 \mathrm{wt} \%$

Table 5.8 Typical properties of Derakane 8084 based composite samples $\quad 70$

Table 5.9 Mechanical and electrical properties of Derakane samples 72

Table 5.10 Static multi-run test results 76

Table 5.11 Temperature profiles of Derakane 8084 based conductive 78 composites subjected to an $\mathrm{AC}$ voltage for 10 minutes

Table 5.12 Thermal conductivity values of vinyl ester 8084 with and without $\quad 80$ additives 


\section{CHAPTER 1 \\ INTRODUCTION}

\subsection{General background}

Structural health monitoring and damage detection including remaining service life have recently become major areas of interest for a large number of academic and commercial laboratories [Law, 1998]. The need to develop in-service and on-line health monitoring techniques is increasing because of structural safety consciousness of end users. Techniques using piezoelectric sensors allow systems and structures to be monitored for their structural integrity while in service, and are useful not only to improve performance reliability but also to reduce maintenance and inspection costs.

Smart materials are material systems with intelligence and with life features integrated in the microstructure of the material system to produce adaptive functionality [eSMART, 2005]. The applications of smart material technologies have been mostly for aerospace use. However, many researchers have been trying to apply this technology to civil and military infrastructural systems recently. New methods for structural health monitoring and damage detection using smart or intelligent materials are being investigated, herein.

\subsection{Motivation for research}

Conventional non-destructive evaluation (NDE) techniques such as ultrasonic testing, and X-radiography can provide significant details about the nature of damage. However, these techniques usually require direct access to the structure being investigated where huge amount of data need to be collected and processed. This data collection involves bulky equipment and requires careful attention by experienced technicians. Moreover, these techniques usually require the structure be out of service during the inspection and this may cause major disruptions. Thus, these techniques may be inadequate for on-line structural health monitoring. A new method for on-line structural health monitoring is very much desired. This new system should be small, non-intrusive, and must offer the possibility of being located in inaccessible areas of the structure. It must be as sensitive as conventional non-destructive evaluation techniques, i.e. it 
must be able to detect minor damages such as small cracks. It must also be able to monitor a certain minimum area of the structure as opposed to the point measurements offered by most of NDE equipment currently available for field implementation. This new method should be compatible with a much broader set of materials like steel, concrete, timber etc., and most importantly Fiber Reinforced Polymer (FRP) composites.

FRP composite bridges and structures are a very common sight nowadays. FRP bridge decks can be pultruded in modular units and then joined to make a full scale bridge. It is at those joints that a FRP bridge is vulnerable to crack growth and propagation. There is definitely a need for a technique that can detect early damage in these joints. Some of these joints are 50 feet long. The crack can initiate at any location in the joint and has to be detected. The technique should therefore cover a broader area of the structure than limit itself to a small localized area. The technique should also be an online monitoring technique that can be operated even when the structure is in service. It should also be sensitive, easy to install, operate and acquire data in the field. Finally, the production and installations costs of the developed sensor should be lower than the conventionally available techniques/sensors.

\subsection{Objective}

There are no references on conductive composites with thermoset resins as the matrix. Thermosetting polymer resins are widely used for structural applications such as bridge decks, utility poles, underground pipe lines etc. Hence they are the focus of current study. Our work is to develop thermoset resin based conductive polymer composites and evaluate them as sensors for structural health monitoring. The advantages of developing thermoset resin based conductive polymer composites include excellent compatibility with vinyl ester based composite structures, low cost, ease of manufacturing, and even in-line production through integrally embedding into part of the structures. The challenging part of the research is that no one has ever used a conductive thermoset resin for monitoring the structural health.

Another primary objective is to develop the material to be as much sensitive to strain as the existing conventional sensors like strain gages etc. There are several issues that affect the sensitivity of the sensor. Particle size, content of the filler and the type of polymer used are some of them [Park, 2003]. So we have to establish the relationship between these parameters and the sensitivity of the conductive composite. 


\subsection{Scope}

Chapter 2 contains a brief note on fiber reinforced composites and conductive composites. It also describes some of the areas conductive composites are being used. It also addresses briefly how researchers are trying to use them for damage detection and the limitations they are facing. Additional literature can be obtained from the list of references mentioned in the end of this report.

Chapter 3 discusses mainly the materials that were investigated for the development of the smart material. The properties of the fillers and the resin systems were listed. It also discusses the manufacturing technique that is employed to make the sensor. The different types of molds that were used and the reason why they were used were also discussed.

Chapters 4 describes the tests that were done on the sensors and Chapter 5 discuss the obtained results. The electrical resistance of the sensors was measured. The variation of resistance with graphite powder size, filler concentration and the type of the resin were established. The sensitivity of the sensors is also evaluated as a function of the above parameters. Tension tests were performed on the sensors to correlate mechanical property to their electrical property and obtain a relationship between them. The mechanical properties of the sensor were found to vary with graphite powder's concentration and their size. A static multi-run test was performed to verify the consistency of the sensor in the linear range of the stress-strain curve. The conductive composites were further evaluated as heating elements. Thermographs were taken to see how the generated heat is distributed along the sensors. Thermal conductivities were measured for the conducting composites. Effects of moisture and temperature on the sensor were also investigated.

Chapter 6 describes the conclusions and the future work that need to be carried out to further develop and evaluate these sensors. 


\section{CHAPTER 2}

\section{LITERATURE REVIEW}

\subsection{Fiber Reinforced Polymer Composites}

As the name implies, polymer composites are primarily made of fiber fabric reinforcements and polymeric resin systems including fillers and additives. The fibers provide the necessary reinforcement in terms of increased stiffness and strength. The resin offers interlaminar shear transfer and binds the fibers together through cured resin which is referred to as matrix. The fillers serve to reduce cost and shrinkage and enhance processability. The additives help improve different properties like mechanical, thermal and physical properties.

The fiber is an important constituent in composites. A great deal of research and development has been taking place with a wide range of fibers. The fibers generally occupy $30 \%-70 \%$ of the matrix volume in a composite. The fibers can be chopped, woven, stitched, and/or braided. They are usually treated with sizings such as starch, gelatin, oil or wax to improve bondability between resin and fiber. In addition, sizing improves the handling of fibers. The most common types of fibers used in advanced composites for structural applications are glass, aramid, and carbon. The glass fiber is the least expensive reinforcement and carbon being the most expensive. The cost of aramid fibers is about the same as the lower grade carbon fibers [Tang, 1997].

The resin is another important constituent in composites. One of the oldest ways of classifying polymers is based on their response to heat - thermoplastics and thermosets. Thermoplastic resins or polymers 'melt' on heating and solidify on cooling. The heating and cooling cycles can be applied several times without affecting the properties. Thermoset resins come in liquid form. During the initial heating, thermoset polymer is cured; thereafter, it does not melt on reheating but degrades [Kumar, 2003]. The linear long-chain thermoplastics do not chemically cross link. Because they do not crosslink permanently, they are less desirable for structural application. Conversely, a thermosetting resin will cure permanently by irreversible cross linking at elevated temperatures. This characteristic makes thermoset resin based composites highly desirable for structural applications. The most common thermoset resins used 
in composites are the unsaturated polyesters, epoxies, and vinyl esters; the less common ones are polyurethanes and phenolics. However, urethane resins are gaining popularity in mass application due to various reasons [PTM\&W, 2005].

Three basic manufacturing techniques (there are several other variations and patented processes) in producing composite structural products are: 1) The pultrusion process that involves a continuous pulling of fiber rovings or fabrics and mats through a resin bath and then into a heated die. The elevated temperature inside the die cures the composite matrix into a structural shape; 2) The filament winding process that can be automated to wrap resin-wetted fibers around a mandrel to produce circular or polygonal shapes; and 3) The hand layup process that engages a hand or machine buildup of mats of fibers that are held together permanently by a resin system. This method enables numerous layers of different fiber orientations to be built up to a desired sheet thickness and product shape.

\subsection{Conductive composites}

Electrically conductive plastics are commonly made by adding conductive fillers such as metallic powders or carbon black into neat resins. For example, when particulate additives are mechanically mixed with molten polymers, particle chains may be formed by chance as a result of the random positions of individual particles. Such chains, or networks, provide conducting pathways. High shear rate flows, which characterize ordinary compounding methods, such as extrusion or batch mixing, lead to random and nearly uniform particle distributions. The likelihood for extended conducting pathways to form is accordingly low at small particle concentrations. If the particle concentration is higher than a certain value called the percolation threshold, these associations among particles yield a network that spans the material and the solidified composite becomes electrically conductive [Danescu, 2002].

The concept of conductive composites is not new at all. There have been a huge number of references on conductive composites and their applications. However, they are mostly concerned about thermoplastic resin based conductive polymer composites instead of thermosetting resin based conductive composites as covered in the present study.

Triton Systems, Inc., in cooperation with NASA/Glenn Research Center, has successfully addressed the problem of shielding electronic devices in space from EM1 (electro-magnetic interference) - with lower weight conductive composite shields compared to presently used 
metallic shields [Gaier, 1992]. Resins with an electrical resistivity of approximately $10^{\circ} \mathrm{ohm}-\mathrm{cm}$ or less can be used for electromagnetic and radio frequency interference shielding applications [Krueger, 2003].

Conducting polymers also have a wide variety of applications in microelectronics [Angelopoulos, 2001]. Conducting polymers are effective discharge layers in electron beam lithography. They also find applications in metallization of plated through-holes for printed circuit board technology, provide excellent electrostatic discharge protection for packages and housings of electronic equipment, provide excellent corrosion protection for metals, and may have applications in electromagnetic interference shielding.

Conductive composites using carbon fiber are being proposed as tools for health and usage monitoring of structures. Since this is an area which is being investigated, there are very few references and publications. Researchers have explored the conductivity of carbon fiber reinforced plastics (CFRP) and are considering them a self monitoring material without any need for additional sensing elements [Schueler, 1997]. However for this to become a reality the conductivity map of the entire structure need to be constructed and relationship between the conductivity and various usage and damage related variables need to be established. The method is very tedious and requires lot of skill for extracting and interpreting the data. The results of their experiments are based on the fact that internal damage, such as fiber fracture and delamination, decreases the conductivity of the composite laminates.

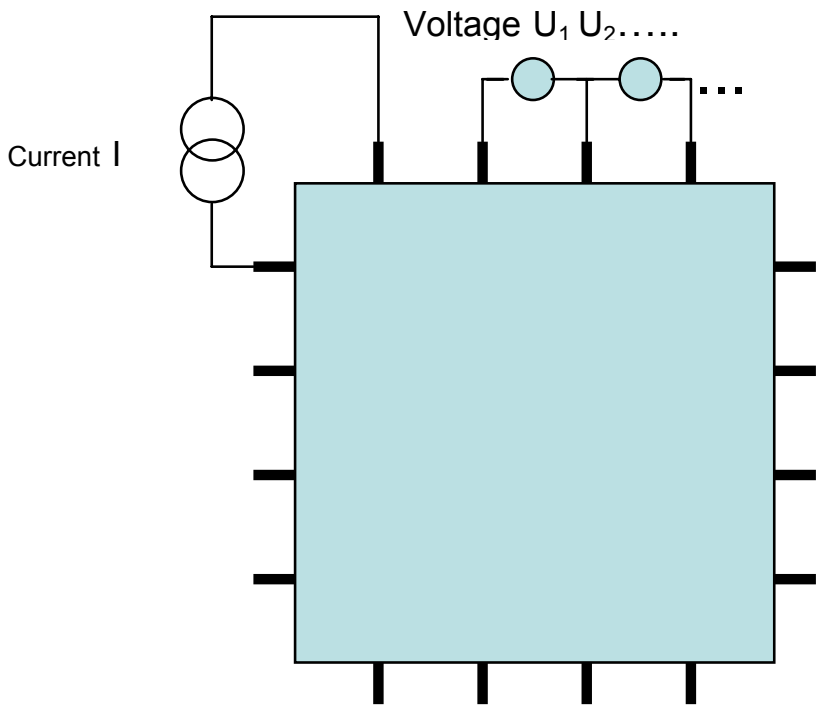

Figure 2.1 Experimental setup of EIT applied to a quadratic specimen using the adjacent data collection strategy [Ruediger 1997]. 
A possible experimental setup is shown in Figure 2.1. An electric current is injected via the two electrodes and the potential difference between all other neighboring electrodes is measured. By taking various combinations of current injecting electrodes and repeating the potential difference measurements, the resistivity distribution inside the sample can be obtained. The change in the resistivity profile can be attributed to the damage in the specimen. Technological and manufacturing hurdles are barriers in the implementation of the technique in addition to those mentioned in the preceding paragraphs. 


\section{CHAPTER 3}

\section{MATERIALS AND SAMPLE PREPARATION}

\subsection{Introduction}

Most polymers or plastics after curing are insulators of heat and electricity. They can be made to conduct both heat and electricity by adding conductive fillers into the resin systems before curing. These fillers have to be added in controlled amounts so that they do not affect adversely the mechanical properties of the polymer.

In this research, we dealt mainly with thermosets (vinyl ester, epoxy) as our polymer resins and the conductive fillers were chopped carbon fiber and graphite powder. Carbon nano tubes were also used as the conductive fillers. Descriptions of the materials, manufacturing of coupons and testing procedure are provided in the following sections.

\subsection{Materials}

\subsubsection{Conductive fillers}

For casting the conductive composite samples we need the polymer as well as the conductive filler. The conductive fillers used in this research and their properties are as follows.

Four kinds of graphite powders of different sizes were supplied by UCAR Carbon Company, Clarksburg, WV. These graphite powders were used to establish how both the conductivity, sensitivity (ratio of the increase in resistance due to stress to the original resistance when no stress is applied) \& mechanical properties of the sensor change with particle size of the conductive filler. The properties of different graphite powders are given in Table 3.1.

We have also used metallic powders as the conductive fillers, including powdered aluminum (steel grey) and powdered copper (reddish brown). The sizes of these powders were of the order of 100 microns and have densities of 2.7 and $8.9 \mathrm{~g} / \mathrm{cc}$ respectively.

Carbon fibers supplied by Zoltec, have a density of $1.81 \mathrm{~g} / \mathrm{cc}$ and a resistivity of 0.00155 Ohm-cm. They were chopped into strands of length $\sim 5 \mathrm{~mm}$ for use as conductive fillers to produce conductive composites. 
Table 3.1 Properties of different types of graphite powders

\begin{tabular}{|l|c|c|c|c|}
\hline \multirow{2}{*}{ Properties } & \multicolumn{4}{|c|}{ Graphite powder } \\
\cline { 2 - 5 } & GP44-B & GP55-B & GS75-E & GS150-E \\
\hline Ash & $0.2 \% \mathrm{max}$ & $0.2 \% \mathrm{max}$ & $0.2 \% \mathrm{max}$ & $0.5 \% \mathrm{max}$ \\
\hline Moisture & $0.5 \% \mathrm{max}$ & $0.5 \% \mathrm{max}$ & $0.5 \% \mathrm{max}$ & $0.5 \% \mathrm{max}$ \\
\hline Density & $2.25 \mathrm{~g} / \mathrm{cc}$ & $2.24 \mathrm{~g} / \mathrm{cc}$ & $2.25 \mathrm{~g} / \mathrm{cc}$ & $2.24 \mathrm{~g} / \mathrm{cc}$ \\
\hline Surface Area & $8.9 \mathrm{sq} \cdot \mathrm{m} / \mathrm{g}$ & $8.0 \mathrm{sq} \cdot \mathrm{m} / \mathrm{g}$ & - & - \\
\hline Particle Size & $100 \%<75 \mathrm{microns}$ & $98.5 \%<75 \mathrm{microns}$ & $99 \%<75 \mathrm{microns}$ & $90 \%<100 \mathrm{microns}$ \\
Distribution & $90 \%<45 \mathrm{microns}$ & $90 \%<50 \mathrm{microns}$ & $90 \%<70$ microns & $83 \%<75$ microns \\
$50 \%<19 \mathrm{microns}$ & $50 \%<23$ microns & $50 \%<32$ microns & $50 \%<55$ microns \\
\hline $\begin{array}{l}\text { Average } \\
\text { Particle Size }\end{array}$ & $44 \mathrm{microns}$ & 55 microns & 75 microns & 150 microns \\
\hline
\end{tabular}

\subsubsection{Polymers}

A resin system known as Hetron 922 L25 vinyl ester was supplied by Ashland Company. It is a promoted RTM grade resin catalyzed using MEKP peroxide at a concentration of $2 \%$. The resin has a viscosity of $275 \mathrm{cps}$ and an elongation to failure of $\sim 5 \%$.

Derakane 8084 resin (Ashland Chemicals) is an elastomer-modified epoxy vinyl ester designed to offer increased adhesive strength, superior resistance to abrasion and severe mechanical stress, while giving greater toughness and elongation. Typical properties of the resin and neat resin casting are given in Table 3.2. This resin has a tensile elongation of $8-10 \%$, two times larger than that of Hetron 922 L25, and is a good candidate for developing conductive composites with greater tensile strain to failure.

An epoxy resin, consisting of two parts, Part A and Part B, which have to be mixed at a ratio of 1:1 by volume is also used. It has a viscosity of $350 \mathrm{cps}$ and an elongation to failure of 15\%. Other resins, including Polycarb Flexogrid Mark 163 (urethane modified epoxy) and Transpo 48 (T-48 polysulphide modified epoxy) were also investigated in order to obtain larger elongation to failure. T 48 is a low modulus, polysulphide modified epoxy, with a viscosity 1500 cps and a mixing ratio Part $\mathrm{A}$ : Part $\mathrm{B}=2: 1$. A urethane (polyol blend) resin consisting of two parts Bayer Baydur 646 Component A and Bayer NB \# 877514 supplied by Nautilus Composites LLC was also used. 
Table 3.2 Typical properties of Derakane 8084 resin and neat resin casting

\begin{tabular}{|l|c|}
\hline \multicolumn{2}{|l|}{ Typical liquid resin properties } \\
\hline Dynamic viscosity @ $25^{\circ} \mathrm{C}\left(77^{\circ} \mathrm{F}\right), \mathrm{mPa} . \mathrm{s}$ & 360 \\
\hline Styrene content, $\%$ & 40 \\
\hline Density @ $25^{\circ} \mathrm{C}\left(77^{\circ} \mathrm{F}\right), \mathrm{g} / \mathrm{ml}$ & 1.02 \\
\hline Shelf life, dark, @ $25^{\circ} \mathrm{C}\left(77^{\circ} \mathrm{F}\right)$, months & 6 \\
\hline Typical properties of resin clear castings \\
\hline Tensile strength, $\mathrm{MPa} / \mathrm{psi}$ & $76 / 11,000$ \\
\hline Tensile modulus, $\mathrm{GPa} / 10^{5} \mathrm{psi}$ & $2.9 / 4.2$ \\
\hline Tensile elongation, $\%$ & 8 to 10 \\
\hline Flexural strength, $\mathrm{MPa} / \mathrm{psi}$ & $132 /$ \\
\hline Flexural modulus, $\mathrm{GPa} / \mathrm{unit} 10^{5} \mathrm{psi}$ & $3.3 / 4.8$ \\
\hline Density, g/cm3 & 1.14 \\
\hline $\begin{array}{l}\text { Heat distortion temperature, }{ }^{\circ} \mathrm{C}\left(\mathrm{F}^{\circ}\right) \text { at } \\
\text { 264 psi }\end{array}$ & $82 / 180$ \\
\hline Izod impact, unnotched, J/m / ft.lbf/inch & $480 / 8.9$ \\
\hline Barcol hardness & 30 \\
\hline
\end{tabular}

\subsection{Molds}

All the samples were prepared by hand molding. Two different kinds of moulds were used for the casting of conductive composite samples as shown in Figures 3.1 and 3.2. The first mold was made out of a 0.125 -inch aluminum sheet with two rectangular cavities. The samples were found difficult to demold even with using a releasing agent. Moreover, the failure pattern exhibited by these samples is not a tension type of failure (failing in the guage section of the sample).

The other mold was made of 0.125 inch PTFE sheet supplied by McMaster Carr. Since we were testing all the samples under tension, all moldings had dog bone shapes. This PTFE mold has 10 cavities. Both molds were made in house. 


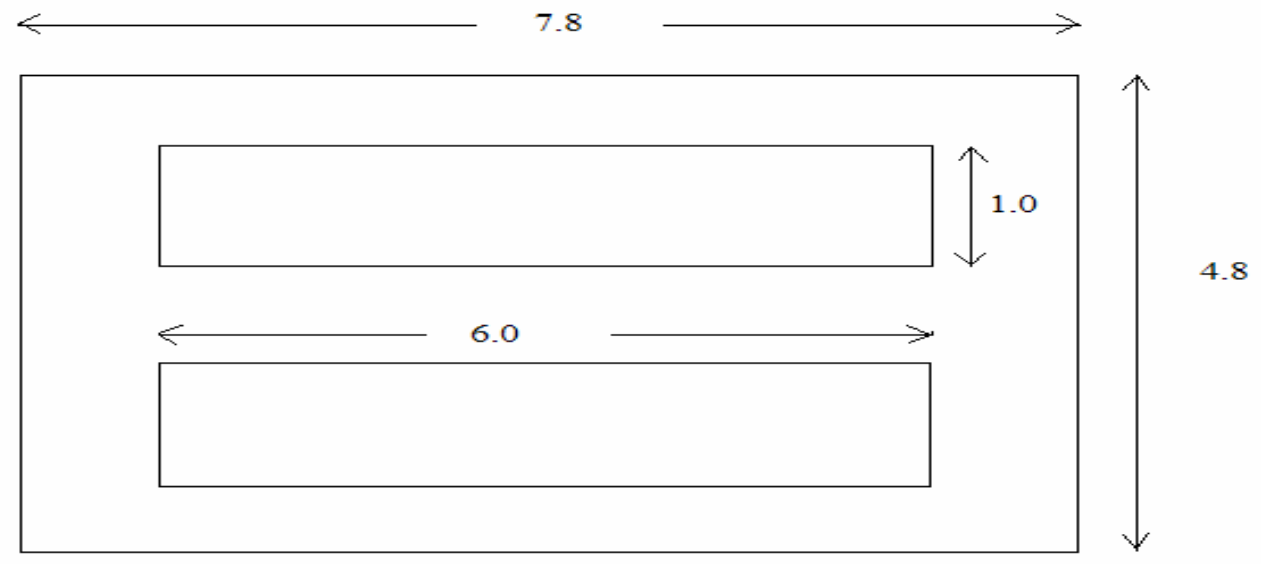

Fig $3.11 / 8^{\text {th }}$ inch Aluminum mold (all dimensions are in inches)

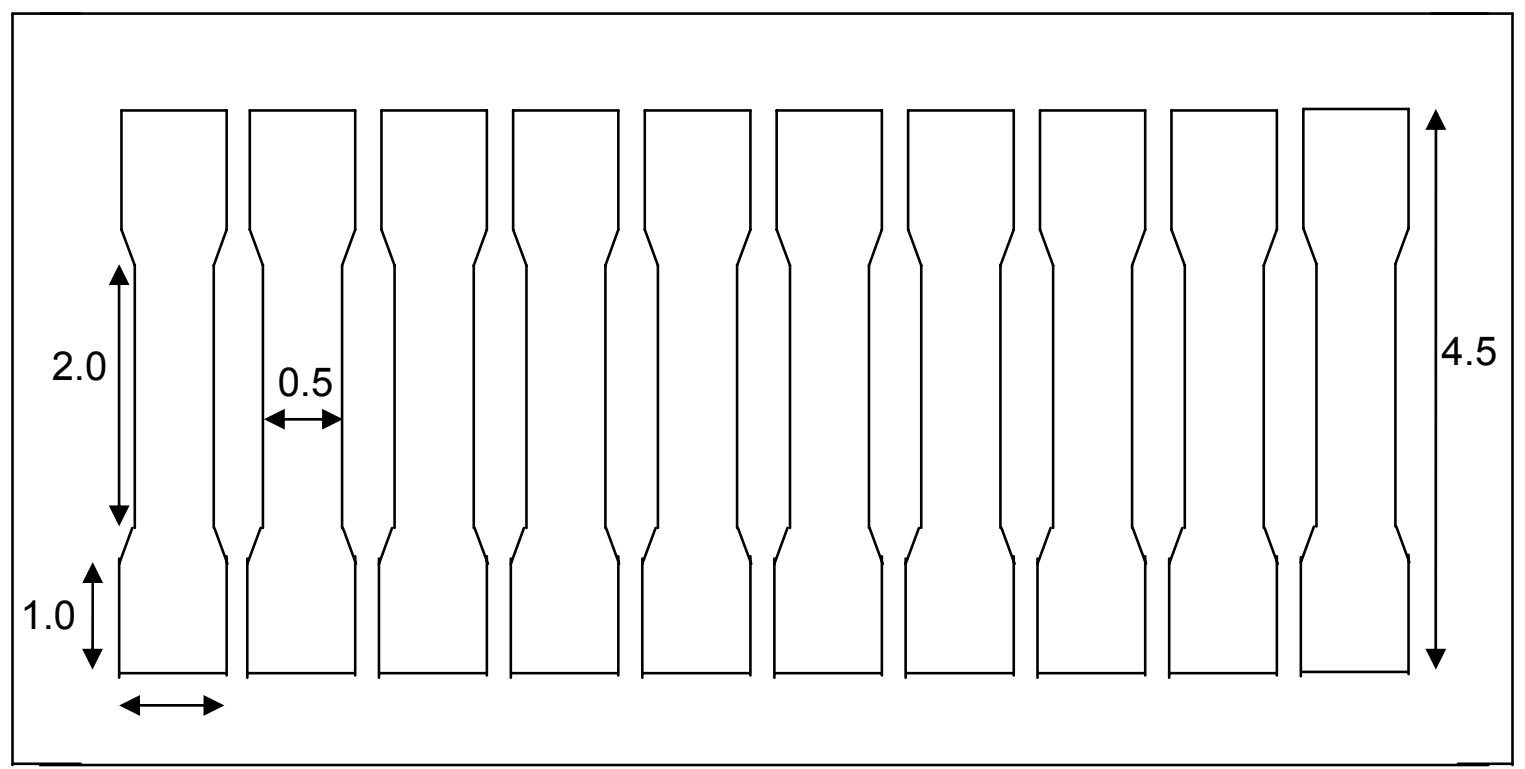

Fig $3.21 / 8^{\text {th }}$ inch PTFE mold (all dimensions are in inches)

For thermal conductivity measurements, we need to cast circular discs with required thickness. We had a mold made out of a High Density Polyethylene (HDPE) block which was 7 x 4 x 0.75 inches. Two circular cavities of diameter 2 inches were drilled through the block. Figure 3.3 shows the HDPE mold used for casting samples to determine thermal conductivity. 


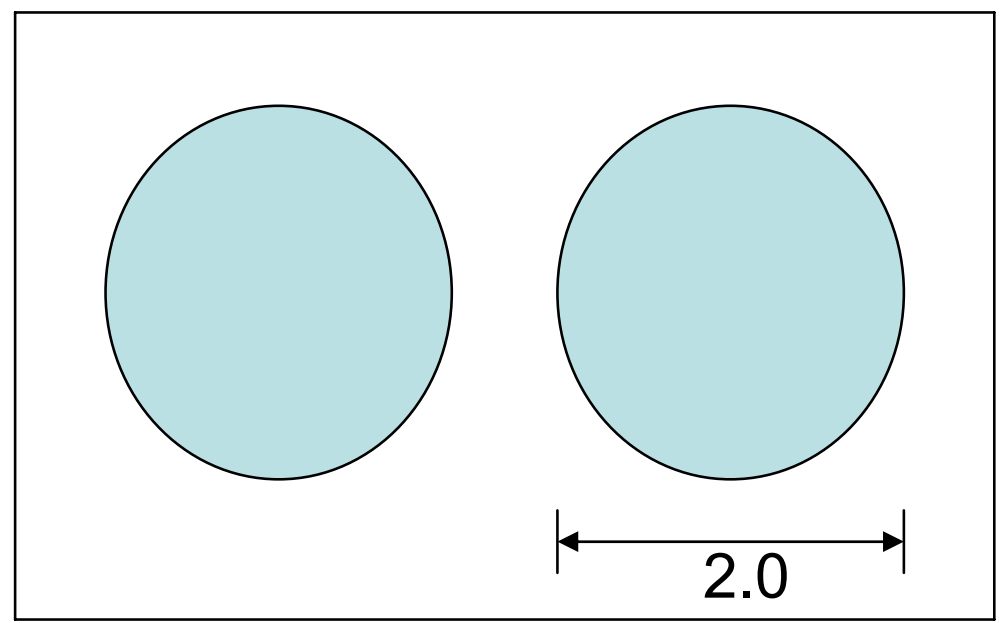

Fig 3.3 HDPE mold for casting samples to measure thermal conductivity

\subsection{Manufacturing of coupon samples}

\subsubsection{Casting of conducting composites using vinyl ester resin}

All the samples were prepared by hand cast-molding. There had been several improvements with different batches of composite samples. First, all samples cast had perfect dog bone shapes, which eliminates or reduces the high stress concentration points from the earlier molds. Secondly, line electrodes (see Fig. 3.4) were used instead of point contact (see Fig. 4.1) inside the moldings, which significantly improve conducting stability and give consistent, reliable resistance readings. Thirdly, compression molding was done to replace the previous topopen casting so that samples of a uniform cross section were obtained. Fourthly, nonconductive end tabs were bonded onto test specimens, which not only provide insulation from conducting through the testing machine but also make test samples to fail absolutely in the gage section.

The mold was first placed on a flat surface, which was covered with a thin sheet of aluminum foil. Electric contacts were accomplished by embedding two bared copper rods, at each end of the mold cavity, which were connected to extended fine copper wires. These contacts were placed inside the mold prior to pouring of the mixture into the mold. Then polymer matrix and the conductive filler were weighed respectively and mixed thoroughly and manually in a container for 5 minutes at a particular weight ratio ranging from $0-40 \%$ wt. It was observed that with the increase in particle size it became difficult to disperse them uniformly in the resin. The bottom layer was graphite rich and the top layers turned out to be resin rich as the size of 
graphite particles increased. Proper care was taken to remove any sort of air bubbles. The mixture of the polymer resin with the conductive filler was poured into the mold and was allowed to set for 24 hours and then de-molded.

In order to have a uniform thickness along both the width and length of the sample, the mold was covered with another plate with small openings on either side of the cavities which allow to pour the resin into the mold. Some weight was placed on the top plate so that the mold was subject to a slight pressure while the resin was curing. This improvement gave tension specimens smooth surfaces on both sides and uniform cross sections, instead of a concave shape (meniscus) from a top-open casting.

We first used copper wires as contacts inside the samples (see fig. 4.1). It was observed that this kind of contacts presented a problem. The resistance of the sample was changing with time erratically even before applying any stress. The problem was solved by using a line contact (see fig. 3.4) instead of a point contact. The line contacts (electrodes) were made of bared copper rods of a diameter of 1/8" inch (supplied by Mc Master Carr company). The as-received copper rods were first cut into smaller rods of about $3 / 4$ inch in length. Then conducting extension wires were soldered onto these copper rods. Last, the rods with extension wires were placed at both ends of mold cavities. A schematic of the final assembly is shown in Figure 3.4. It was identified that samples of line contacts gave very stable, consistent readings in electrical resistance, demonstrating that the type of contacts would greatly affect the stability of the sensor.

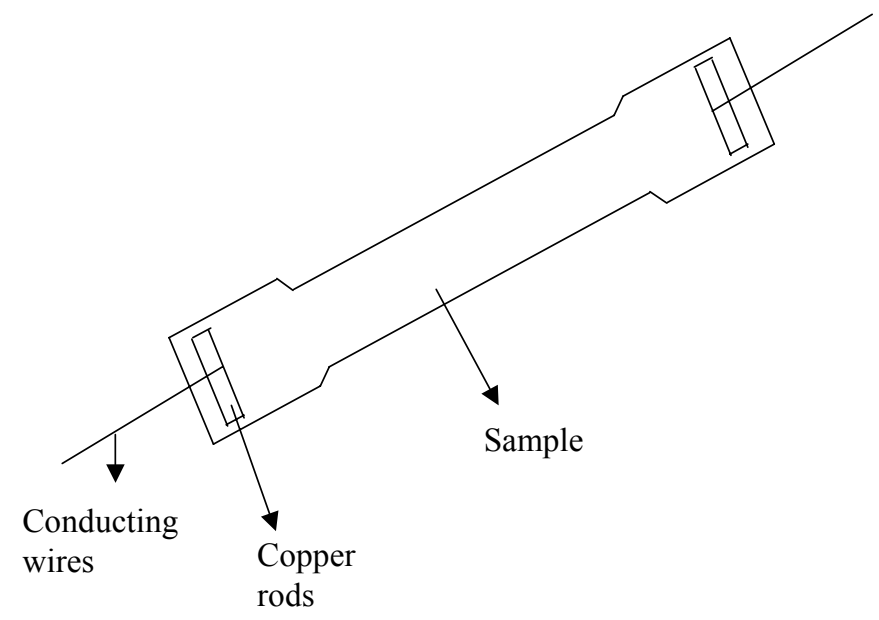

Figure 3.4 A schematic of the sample with a line contact 


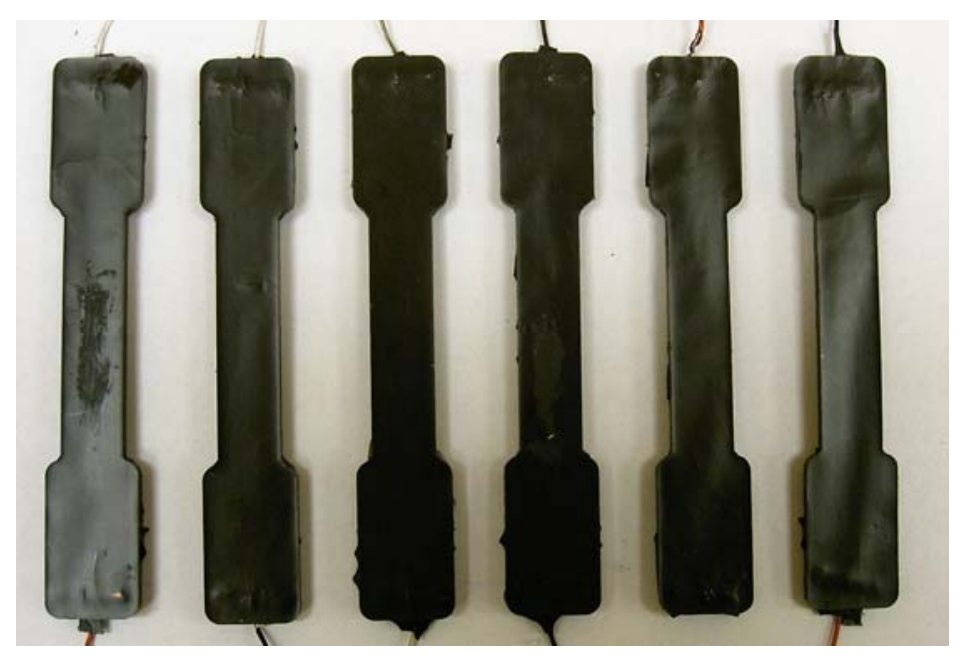

Figure 3.5 Tension specimens made of graphite in vinyl ester composites

The samples after demolding were heated for $3 \mathrm{hrs}$ uniformly from both sides for 3 hours at a temperature of 185 degrees F. The temperature was chosen such a way that it was around 15 degrees $\mathrm{F}$ below the glass transition temperature of the polymer. The samples were then taken out of the oven and are ready to be tested.

Figure 3.5 shows some of the tension specimens made of graphite powder in vinyl ester composites. These samples were first tested for their resistivity and then bonded with end tabs for tension tests.

\subsubsection{Casting of graphite/hybrid resin composite samples}

The idea of developing hybrid resin composites is to develop a flexible resin system that will lead to conductive composites of large elongation to failure, thus yielding a wider sensing window and higher sensitivity of the potential conductive composite sensors. As described in the previous section, the conductive composite samples were cast using graphite powder as fillers dispersed in a conventional vinyl ester resin (Ashland Hetron 922 L25). The elongation to failure for those samples was about 1\%. It was also identified that samples comprised of a flexible epoxy resin (E-Bond 526) showed large elongation to failure $(\sim 15 \%)$ but could not show electric conductivity even though the graphite concentration in the sample was up to $25 \%$ by weight. Therefore, it was intended to develop a flexible hybrid resin system by mixing both the vinyl ester and epoxy resins in a controllable manner. Significant amount of time and effort was directed towards formulating the hybrid resin that might be electrically conductive and 
mechanically ductile. Indeed, we have achieved a flexible system based on this hybrid method. Some samples are shown in Figure 3.6. However, they were found non-conductive.
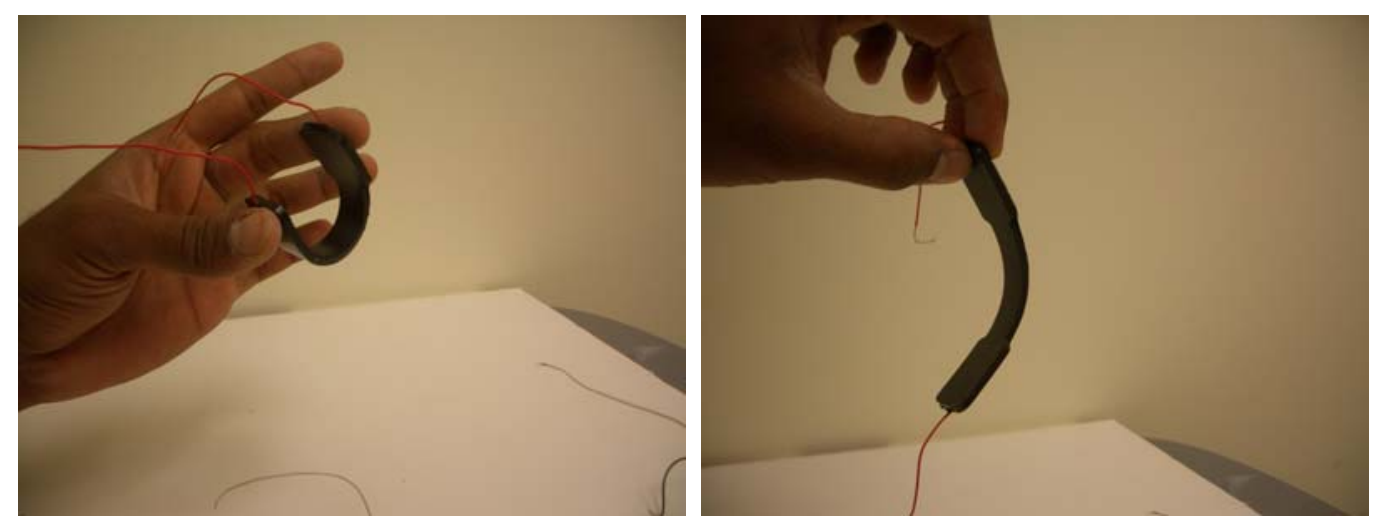

Figure 3.6. A hybrid resin system consisting of vinyl ester, epoxy and graphite powder

Similarly, the PTFE mold was used to cast dog-bone shaped samples. The mold was placed on a flat surface, which was covered with a thin aluiminum foil. Electric contacts were established by using two bare copper rods at the end of each cavity as shown in Figure 3.7. The two types of resins and the conductive filler were weighed separately and mixed manually for 5 minutes in a specific order at a particular weight ratio in a container for 5 minutes. Table 3.3 shows the details of each sample including weights of each component in the sample. The samples were designated in terms of epoxy concentrations (wt \%).

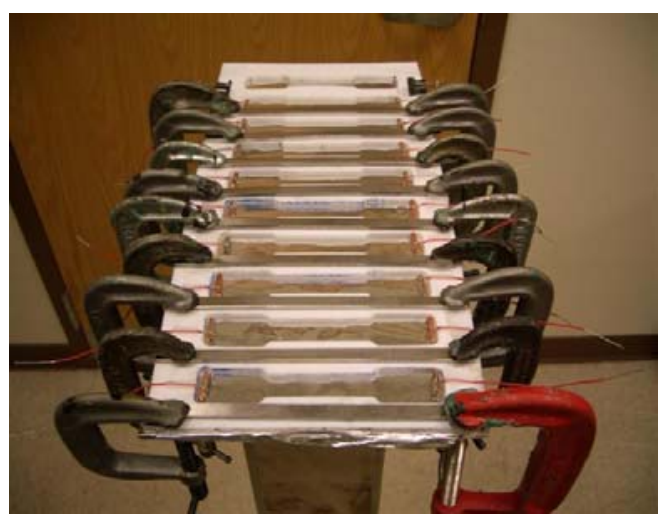

Figure 3.7 A ready-to-cast mold clamped to the flat surface covered with aluminum foil, and with electric contacts in place 
Table 3.3 Compositions of vinyl ester /epoxy hybrid resin based graphite composites ( $10 \%$ by weight of graphite)

\begin{tabular}{|c|c|c|c|c|c|c|c|}
\hline $\begin{array}{c}\text { Epoxy } \\
\text { wt \% }\end{array}$ & $\begin{array}{c}\text { Graphite } \\
\text { gram }\end{array}$ & $\begin{array}{c}\text { VE }+ \\
\text { Epoxy, } \\
\text { gram }\end{array}$ & $\begin{array}{c}\text { Epoxy } \\
\text { Gram }\end{array}$ & $\begin{array}{c}\text { Epoxy } \\
\text { Part A } \\
\text { Gram }\end{array}$ & $\begin{array}{c}\text { Epoxy } \\
\text { Part B } \\
\text { Gram }\end{array}$ & $\begin{array}{c}\text { Vinyl } \\
\text { Ester } \\
\text { gram }\end{array}$ & $\begin{array}{c}\text { MEKP } \\
\text { Gram }\end{array}$ \\
\hline 0 & 1 & 9 & 0 & 0 & 0 & 9 & 0.27 \\
\hline 5 & 1 & 9 & 0.45 & 0.241 & 0.209 & 8.55 & 0.2565 \\
\hline 10 & 1 & 9 & 0.9 & 0.481 & 0.418 & 8.1 & 0.243 \\
\hline 15 & 1 & 9 & 1.35 & 0.722 & 0.627 & 7.65 & 0.2295 \\
\hline 20 & 1 & 9 & 1.8 & 0.963 & 0.837 & 7.2 & 0.216 \\
\hline 25 & 1 & 9 & 2.25 & 1.203 & 1.046 & 6.75 & 0.2025 \\
\hline 30 & 1 & 9 & 2.7 & 1.444 & 1.256 & 6.3 & 0.189 \\
\hline 35 & 1 & 9 & 3.15 & 1.684 & 1.465 & 5.85 & 0.1755 \\
\hline 40 & 1 & 9 & 3.6 & 1.925 & 1.674 & 5.4 & 0.162 \\
\hline 45 & 1 & 9 & 4.05 & 2.166 & 1.883 & 4.95 & 0.1485 \\
\hline 50 & 1 & 9 & 4.5 & 2.407 & 2.093 & 4.5 & 0.135 \\
\hline 100 & 1 & 9 & 9 & 4.814 & 4.186 & 0 & 0 \\
\hline
\end{tabular}

As seen in Table 3.3, a hybrid resin is comprised of 5 constituents. Considering that the sequence of mixing one constituent with another might affect the reactivity and thus curing of resin system components, the following batches of samples were prepared in terms of mixing sequence of constituents in a container:

Batch 1: 1) first add graphite powder; 2) then add vinyl ester followed by MEKP; 3) add epoxy Part A and epoxy Part B; 4) last mix all thoroughly for 5 minutes.

Batch II: 1) first mix vinyl ester and MEKP thoroughly in a container; 2) mix epoxy Part A and Part B in another container; 3) allow vinyl ester resin to mix with graphite powder thoroughly; and 4) add already-mixed epoxy and mix for 5 minutes.

Batch III: similar to Batch II except that graphite powder is first wet with already-mixed epoxy and then with vinyl ester.

Batch IV: similar to Batch II except that vinyl ester with MEKP is mixed with epoxy first and then with graphite powder. 
The curing of the hybrid resin systems was monitored visually from time to time and was found incomplete at room as well as elevated temperatures for hybrid resins with low concentrations of epoxy even after a couple of days.

\section{Other samples}

Several metallic fillers were also used to cast the conductive composite samples using epoxy as a matrix. Figure 3.8 shows some samples made with different types of metallic fillers in comparison with a graphite sample. Surprisingly, those metallic samples were found non conductive.

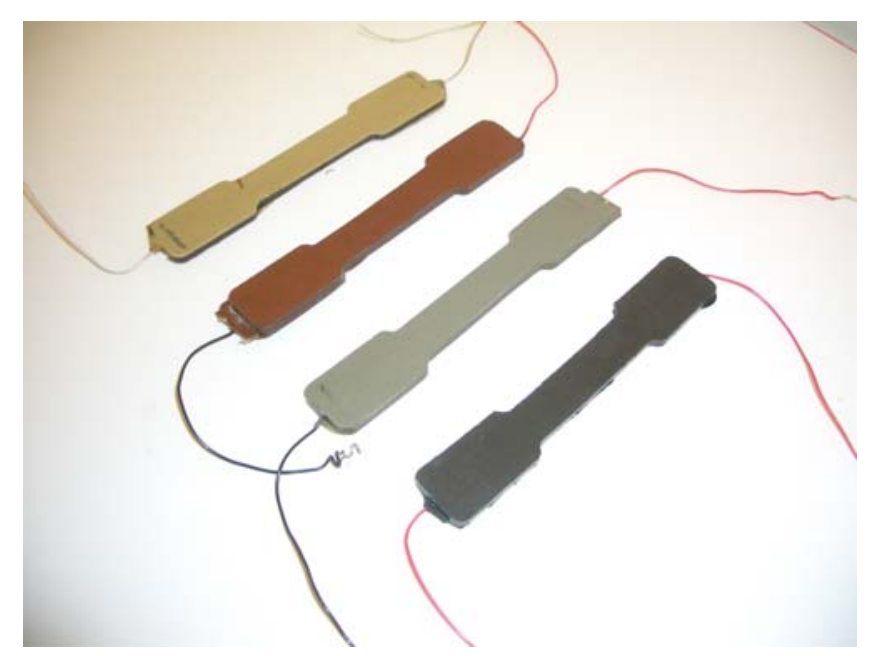

Figure 3.8. Samples made of metallic powder in comparison with a graphite sample. From top to bottom: Al (green) filled epoxy, Cu (reddish brown) filled epoxy, Al (grey) filled epoxy and Graphite (black) filled epoxy

\subsubsection{Casting of circular disks for thermal conductivity measurements}

For thermal conductivity measurements of the conductive composites, circular specimens were cast with required thickness. This was achieved using the mold shown in Figure 3.9. The mold was placed on a flat surface, which was covered with a thin film of aluminum foil. Mold filling and releasing agents were applied to the mold for a smooth demolding process. The polymer (Derakane 8084) and the conductive filler (both graphite and carbon nano tubes) were weighed respectively and then mixed manually and thoroughly in a container for 5 minutes at a particular weight ratio. 2\% of MEKP (Methyl Ethyl Ketone Peroxide) was then added to catalyze the reaction. The mixture was stirred for another 5 minutes. Proper care was taken to remove 
any sort of air bubbles. The mixture of the polymer resin with the conductive filler together with the catalyst was poured into the mold and was allowed to set for 24 hours and then de-molded. Post curing was done by heating the samples from both top and bottom sides uniformly at a temperature of 185 degrees $\mathrm{F}$ for $3 \mathrm{hrs}$.

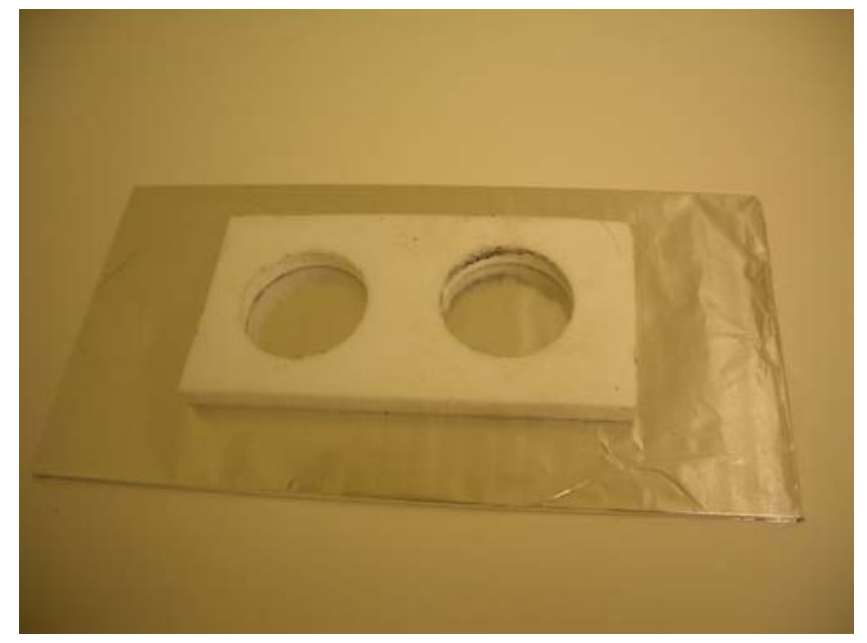

Figure 3.9 HDPE mold for casting samples of circular disks

\subsubsection{Casting of carbon nano tube based samples}

Carbon nano tubes (CNT) which are dispersed in styrene at a concentration of $0.5 \%$ were obtained from Bedford Reinforced Plastics, Bedford, PA. It was then mixed with Derakane 8084 resin to cast moldings of a CNT concentration $0.25 \%$.

In this experiment, equal amount of CNT solution was weighed and added to the resin. 3 $w t \%$ MEKP was added to the total mixture. All the contents were mixed together in a container for about $\sim 10$ minutes. This mixture was poured into the molds described earlier to get dog bone shaped samples for tension and electrical resistance measurements and circular disks for thermal conductivity measurements as described in sections 4.1 and 4.5 . 


\section{CHAPTER 4}

\section{TESTING METHODS}

\subsection{Electrical resistance measurement}

Electrical resistance is a measure of the degree to which a material opposes the passage of an electric current. The SI unit of electrical resistance is the Ohm. Its reciprocal quantity is electrical conductance, measured in Siemens. Polymers generally have a very huge resistance.

They are very good insulators of hear and electricity and their resistivity is of the order of $\sim 10^{10}$ Ohm-Meters. Conductive polymer composites can be made by adding conductive fillers to polymers in their uncured states and then curing them using the catalysts. By varying the concentration of the fillers ( $\sim 20 \%$ by weight for graphite powder and $\sim 1 \%$ by weight for CNT) in the polymer we can tailor the resistivity of the conducting composite samples to as low as $10^{0} \mathrm{Ohm}-$ Meters.

We have measured resistance of all the samples using the two wire measurements. The electric resistance of those samples was measured using a Radioshack 24 Range LCD digital multimeter. This multimeter also has an RS 232 port through which it can be interfaced to a PC for monitoring the resistance of the samples at periodic intervals of time. A more sensitive and also more sophisticated Wayne Kerr Automatic LCR meter model 4270 was also used when the former was out of range.

The samples were prepared in such a way that the wires were put in the mold even before pouring the uncured resin system into the mold. After the resin with fillers and conductive material in the mold was cured and the samples were de-molded, the wires were a part of the test samples. As schematically shown in Figure 4.1, there are two wires coming out of the sample.

A multi-meter was then connected to the wires across the sample as shown in Figure 4.2. It gave the resistance of the sample. The resistivity can be found out if we know the cross sectional area and the length between the two points of contact. It was observed that this method was not able to give a stable resistance value for the sample and the obtained resistance through the meter was fluctuating from time to time because of point contacts used. Later, a new type of contacts, i.e. line contacts, was introduced in the sample as schematically shown in Figure 3.4. Instead of using the point contacts, the wires were soldered to a copper rod which is of 0.125 
inches in diameter. Then this copper rod was placed in the mold perpendicular to the axial direction (length). This cylindrical type contact gave a stable and non fluctuating resistance.

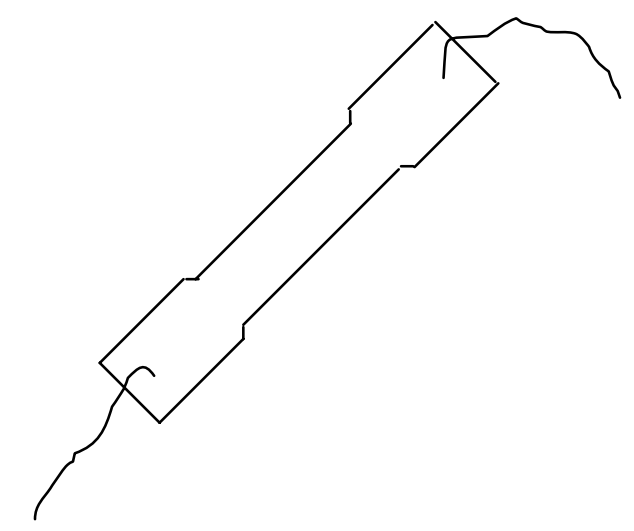

Figure 4.1 A schematic showing the wires being put in the mold
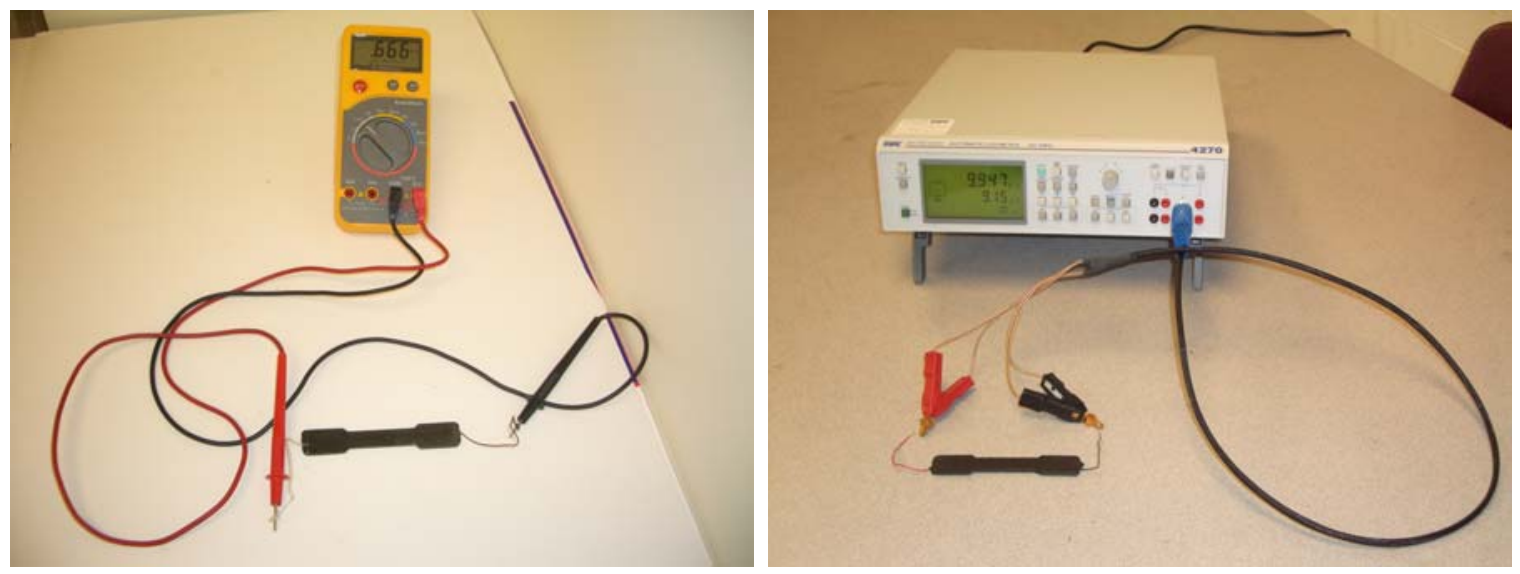

Figure 4.2 Meters used for resistance measurements. Left:RS-24. Right:Wayne-Kerr LCR

\subsection{Tension test}

\subsubsection{Test specimen}

For correlating the mechanical properties to the electrical properties of the sensor we need to perform several mechanical tests. Tension test is a method for determining behavior of materials under axial loading. Data from test are used to determine elongation, modulus of elasticity, tensile strength, yield point, yield strength and mechanical properties. Dimensions of the tension test specimens are listed in Table 4.1 with the nomenclature identified in Figure 4.3. 
Table 4.1 Dimensions for tension test specimen

\begin{tabular}{|l|r|}
\hline Width of narrow section (W) & $0.5^{\prime \prime}$ \\
\hline Width overall (Wo) & $0.75^{\prime \prime}$ \\
\hline Length overall (Lo) & $4.5^{\prime \prime}$ \\
\hline Thickness (T) & $0.125^{\prime \prime}$ \\
\hline Guage length (L) & $2.0^{\prime \prime}$ \\
\hline Center section length (D) & $2.5^{\prime \prime}$ \\
\hline
\end{tabular}

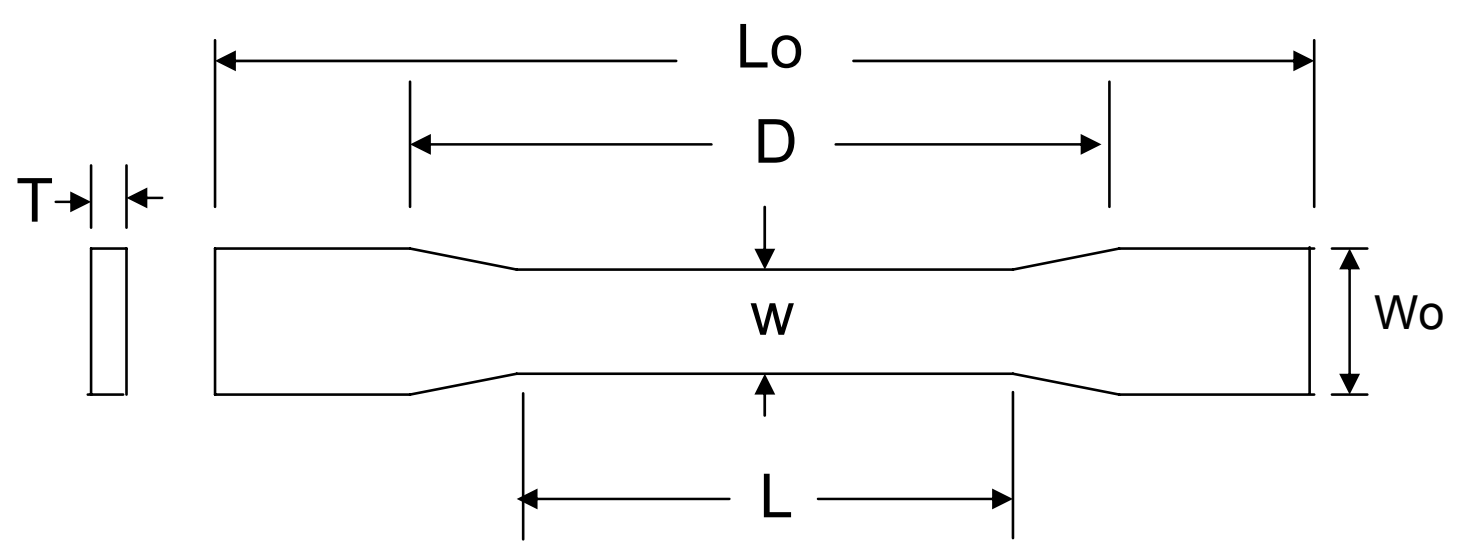

Figure 4.3 Dog-bone shaped tension test specimen

\subsubsection{Tension test setup and procedure}

Tension test was carried out first on an Instron machine model 8501. The Instron model 8501 is a dynamic testing system designed to test mechanical properties of a wide range of materials. Using a hydraulic actuator, tensile load was applied to the test specimen to monitor tensile strain or deflection of the specimen by observing the position of the hydraulic actuator in response to the applied load. The load is also monitored under the applied strain.

Tension test was conducted with a position control mode at a stretching rate of 0.05inch/minute ASTM standard D-638. During a test, the electric resistance was measured along with the variation in applied stress. The measured resistance values were recorded by a computer through an RS 232C interface. Two cables were used for connecting the sample to the multimeter. The electric resistance was monitored with a Radio Shack 24-range LCD digital multimeters. The entire test setup is shown in Figure 4.4. Figure 4.5 shows a close-up view of a vinyl ester composite specimen under tension. 


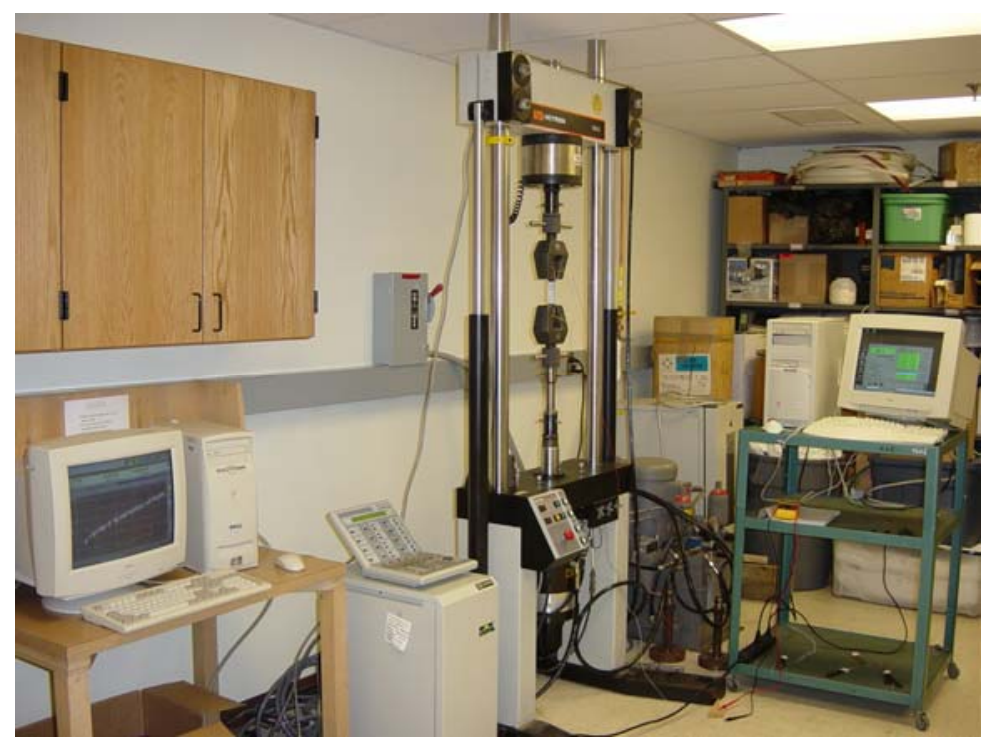

Figure 4.4 Tension test setup using Instron model 8501

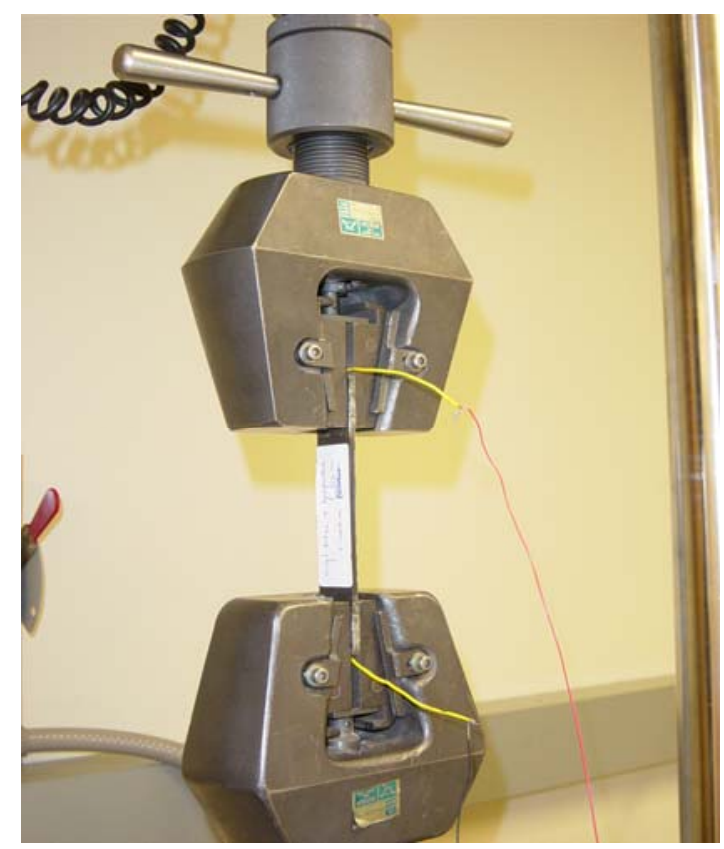

Figure 4.5 A vinyl ester conductive composite under tension

Instron machine 8501 was not very sensitive for small loads, since our samples failed at a maximum load of $1500 \mathrm{~N}$. Therefore, results reported hereafter were obtained on the Instron machine 5689. This table top load frame model is a state of the art instrument for testing a wide range of materials in tension or compression. It evaluates the materials under investigation by applying a tensile or compressive load on the specimen between the rigid frame and the moving 
crosshead. It carries three load cells ranging $10 \mathrm{~N}, 1 \mathrm{KN}$ and $50 \mathrm{KN}$. A supply of house air is required during normal operation. The instrument is operated from a separate fused $110 \mathrm{~V} \mathrm{AC}$ line, capable of 30A service.

The entire test setup is shown in Figure 4.6. The test was conducted with a position control mode at a stretching rate of $0.1 \mathrm{~mm} / \mathrm{min}$. During the test electrical resistance was measured along with applied load and strain. This was accomplished using Radio Shack 24 Range LCD digital multimeters. Two extension cables were used to connect the test sample to the multimeters. The measured resistance values were automatically recorded on a computer through an RS 232C interface.

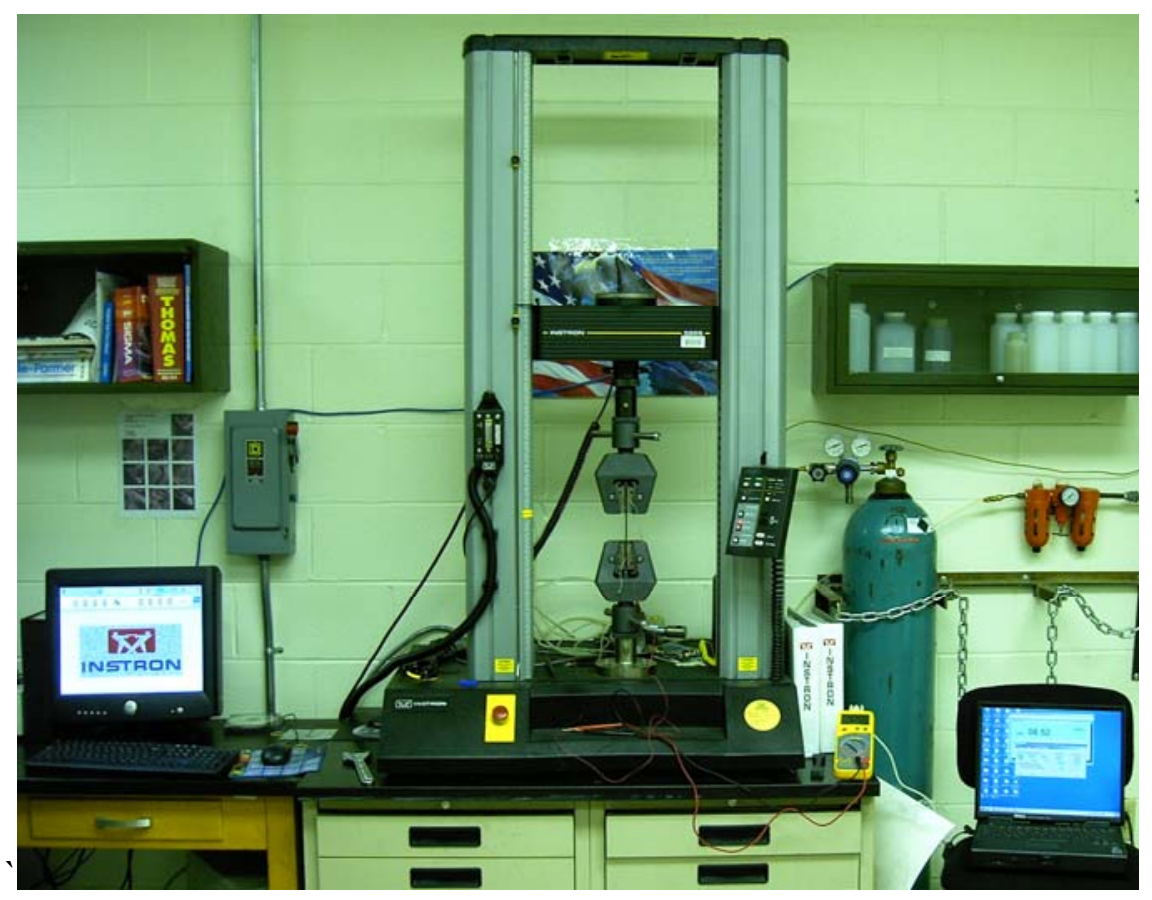

Figure 4.6 Tension test set-up using Instron 5689 


\subsection{Static multi-run test}

Hooke's law of elasticity states that if a force $(F)$ is applied to a prismatic rod (with length $L$ and cross section $A$ ), its extension is linearly proportional to its tensile stress $\sigma$ and reciprocal to its modulus of elasticity $(E)$ :

$$
\begin{aligned}
& \sigma=E \cdot \varepsilon \\
& \text { or } \\
& \Delta L=\frac{1}{E} \times F \times \frac{L}{A}=\frac{1}{E} \times L \times \sigma
\end{aligned}
$$

For most materials, the law holds up to a limit, called the elastic limit, or limit of elasticity, after which the materials will enter a condition of 'yield' and suffer plastic deformation up to the plastic limit or limit of plasticity, after which they will eventually break if the force is further increased or may move into strain hardening phase as in most metals. A typical stress versus strain curve for a plastic material is shown in Figure 4.7.

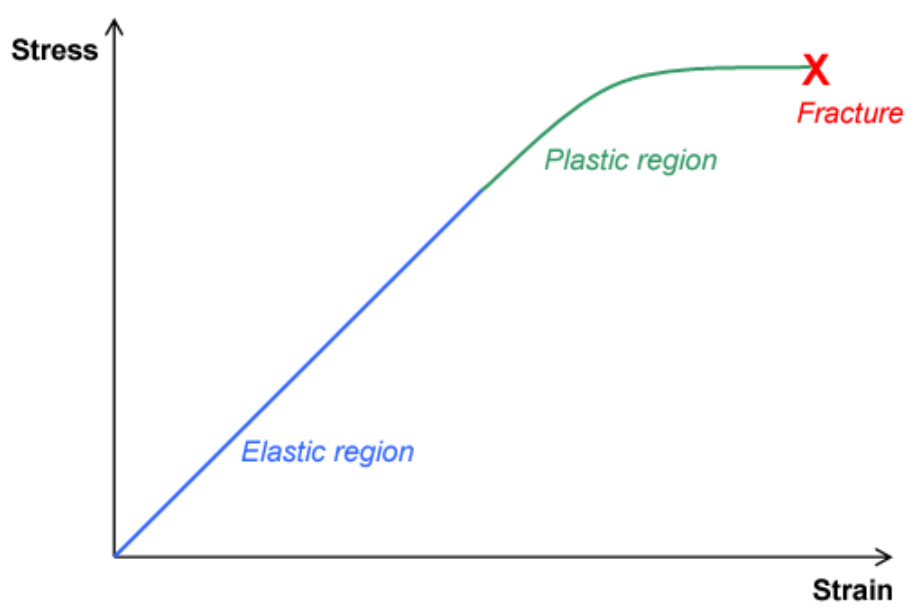

Figure 4.7 A typical stress versus strain curve for a ductile material

The developed conductive composite sensor is most likely to be operated in the linear, elastic region where the sensor does not undergo plastic deformation so that the sensor after being subjected to certain magnitude of loading will return back to the initial state, after the release of the load.

To prepare the static (multi-run) test, we first perform a tension test on a conductive composite sensor sample to failure. We will then know from the stress vs strain curve, the 
elastic region and the plastic region. The remaining samples will be subjected to the load that will take the sample to $\sim 95 \%$ of its elastic limit. The load will then be released from the sample. The sample then comes back to its normal state since its being operated in its elastic region. This loading and relaxing is repeated a number of times, simultaneously monitoring the resistance of the sample. This is a test for the reproducibility of our sensor in the region of interest.

A tabletop load frame model Instron 5689, was used for conducting the test. The sample was loaded between the two tension grips firmly. A load was applied keeping in mind the before mentioned criterion. The machine was stopped after that was achieved. The sample was removed from the grips. The machine was then brought to its initial state by pressing the return button on the control panel of the machine. The sample was again loaded and this was repeated for 5 times for each sample. The resistance was also continuously monitored using another computer. The data were plotted and the reproducibility was studied.

\subsection{Evaluation of conductive composites as heating elements}

The objective is to preliminarily evaluate conductive composites as heating elements. Upon connecting the two ends of conductive composite samples to a supply of AC voltage, the electric current passing through the sample should generate heat. One of the potential applications for this function is to heat a highway bridge deck for de-icing (to melt ice) in winter when these smart composites are embedded into FRP bridge decks.

\subsubsection{Basic Theory}

Upon connection to a supply of voltage, a resistor is to generate heat. If the resistor has a resistance $\mathrm{R}$ and is subjected to $\mathrm{AC}$ voltage $\mathrm{V}$, the current passing through the resistor, $\mathrm{I}$, can be determined using the formula:

$$
\mathrm{I}(\text { Amps })=\mathrm{V} \text { (Volts) / R (Ohms) }
$$

Then, the power $\mathrm{P}$ is

$$
\mathrm{P}(\text { Watts })=\mathrm{V}(\text { Volts }) * \mathrm{I}(\text { Amps })=\mathrm{V}^{2} / \mathrm{R}
$$

The heat generated, $Q$ for a period of time $(t)$ is

$$
\mathrm{Q}(\text { Joules })=\mathrm{P}(\text { Watts }) * \mathrm{t}(\mathrm{Sec})=\left(\mathrm{V}^{2} / \mathrm{R}\right) * \mathrm{t}
$$

For an AC voltage, $\mathrm{V}=\mathrm{V}_{0} / \sqrt{2}$, giving the amount of heat generated as

$$
\mathrm{Q}=0.5 *\left(\mathrm{~V}_{0}^{2} / \mathrm{R}\right) * \mathrm{t}
$$


For a conductive composite sample under investigation, if the material has a specific heat capacity $\mathrm{Cp}$ and the sample has a mass $\mathrm{M}$, the heat required, $\mathrm{Q}$ to create a temperature increment $\Delta \mathrm{T}$ will be

$$
\mathrm{Q}(\text { Joules })=\mathrm{Cp}(\mathrm{J} / \mathrm{g} . \mathrm{K}) * \Delta \mathrm{T}(\mathrm{K}) * \mathrm{M}(\mathrm{g})
$$

Combining Equations 4.6 and 4.7 gives a relationship between the resistance and temperature difference:

$$
\Delta \mathrm{T}=0.5 *\left(\mathrm{~V}_{0}^{2} / \mathrm{R}\right) * \mathrm{t} *(1 / \mathrm{Cp} * \mathrm{M})
$$

Thus, the temperature change is inversely proportional to the resistance.

\subsubsection{Experiment}

For a conductive composite sample that has a resistance $\mathrm{R}$, when the terminals of the sample are connected to a voltage the sample will generate heat just like any other resistor. In the experiment, the conductive composite samples with Derakane 8084 and graphite powder are subjected to AC voltage (110V-regular). This is accomplished by connecting the embedded wires to the AC voltage using a two pin connector as shown in Figure 4.8.

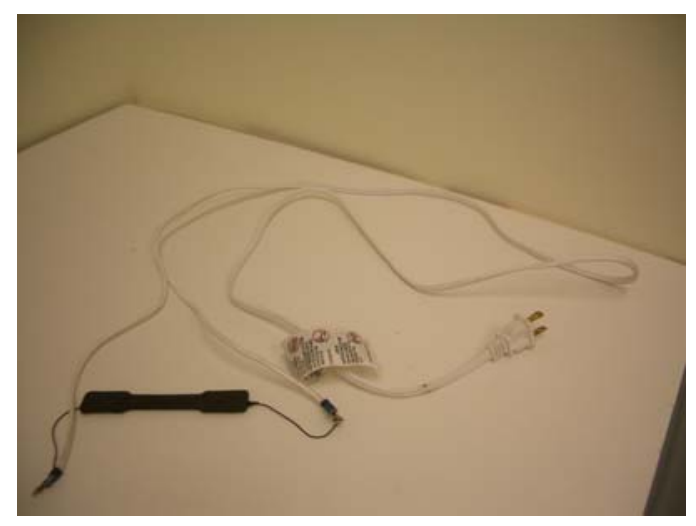

Figure 4.8 A conductive composite sample ready to plug into a power outlet.

The sample was placed on a wooden block so that the heat generated would not be lost to the object in contact with the sample. The amount of time the voltage supplied to the samples was kept constant as 10 minutes during all measurements. The temperature profile of the sample under investigation was observed using an infrared camera (ThermaCAM S60) and the temperature was recorded as a function of time. The entire experimental setup is shown in Figure 4.9. The test was conducted at room temperature $(\sim 70 \mathrm{~F})$. A typical infrared image of the sample is shown in Figure 4.10 


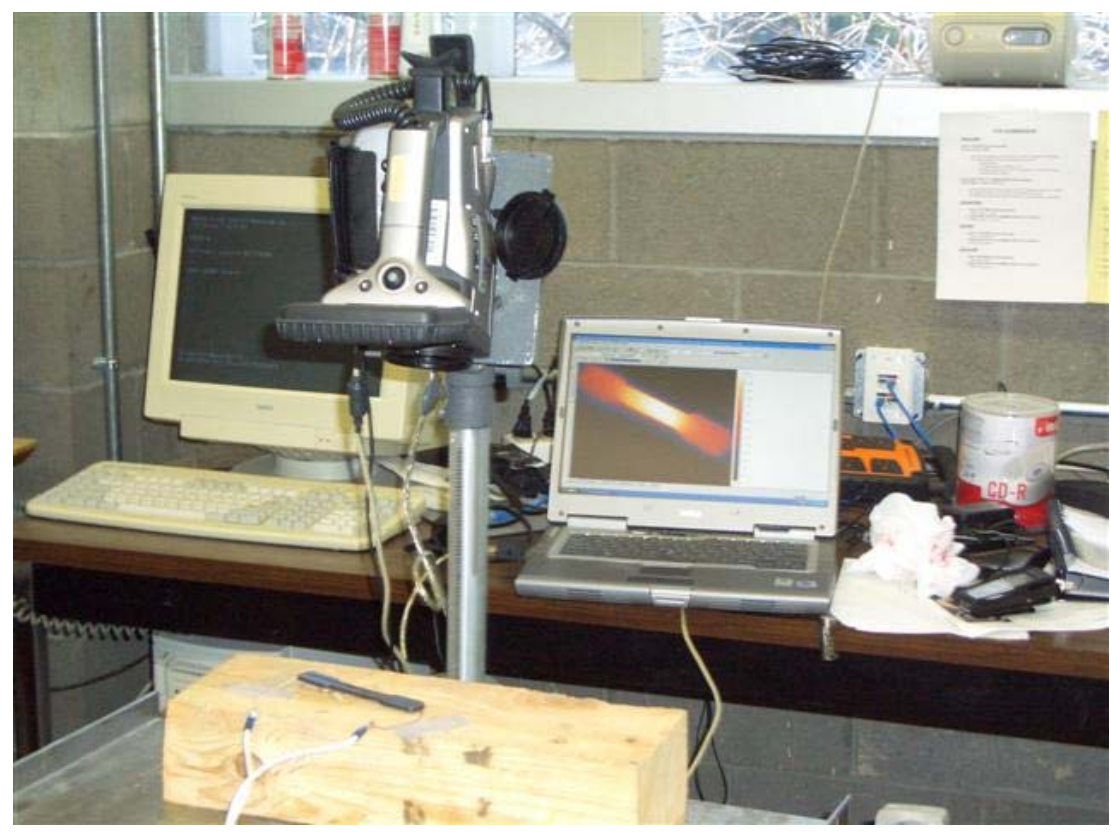

Figure 4.9 Experimental setup for evaluation of conductive composites as heating elements using an infrared camera model ThermaCAM
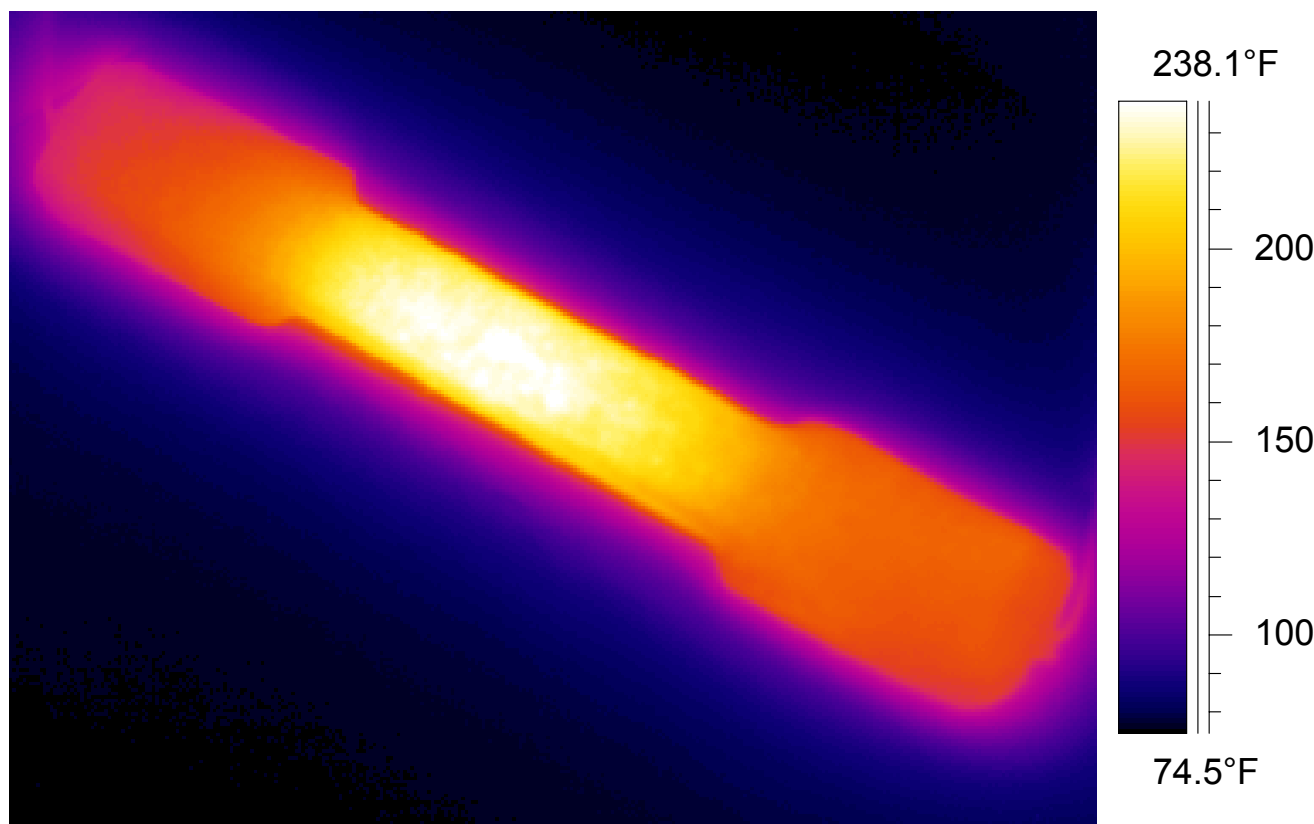

$74.5^{\circ} \mathrm{F}$

Figure 4.10 Typical thermal image generated by an infra red camera for $25 \%$ graphite/ 8084 composite sample 


\subsection{Thermal conductivity measurement}

As mentioned earlier, most plastics are insulators of heat and electricity. The addition of conductive fillers can make them better in terms of both electrical and thermal conductivity. Herein, thermal conductivity measurements of some conductive composites were carried out.

The samples were tested for thermal conductivity using a testing system shown in Figure 4.11. This system is a UNITHERM-Model 2022 from ANTER Corp., Pittsburgh, PA. This model measures the thermal conductivity of materials in the range 0.1 to $100 \mathrm{~W} / \mathrm{mK}$ according to ASTM E1530 guarded heat flow meter method. A sample of the material to be tested is compressed in between two polished surfaces, each controlled at different temperatures. A schematic picture shown in Figure 4.12 represents the system functioning in detail.
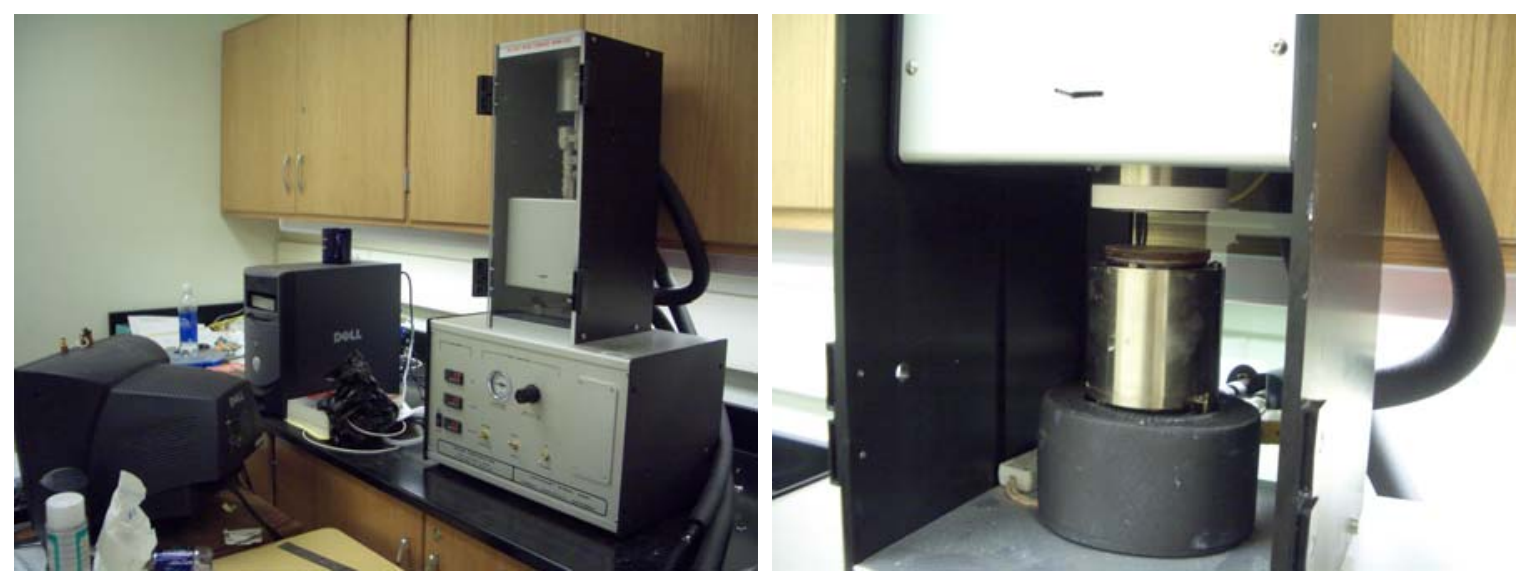

Figure 4.11 A guarded heat flow meter. Left: a computerized UNITHERM-Model 2022 system. Right: sample loading into between the two plates.

This assembly is a stack of parts with different functionalities. The heaters on top and bottom helps to maintain steady state heat transfer through the sample, two polished surfaces on top and bottom of the sample transfer heat from top and bottom heaters with reduced thermal resistance through surface. A reference calorimeter is placed under the lower plate, which acts as a heat flux transducer. The heat sink at the bottom avoids excessive temperature from the system. The sample is compressed in between the polished surfaces, each controlled at different temperatures, using pneumatic load. The pressure is maintained at 10 psi using pressurized air supply. As an option for coolant, water is circulated through heat sink. A circular low 
temperature heat insulation ring is wrapped around the lower stack of the assembly to restrain heat flow to outside atmosphere. The entire system is maintained in a thermally insulated glass chamber. UNITHERM is completely automatic while testing as the apparatus is completely controlled by a computer. The test system is hooked to the computer by means of an USB cable.

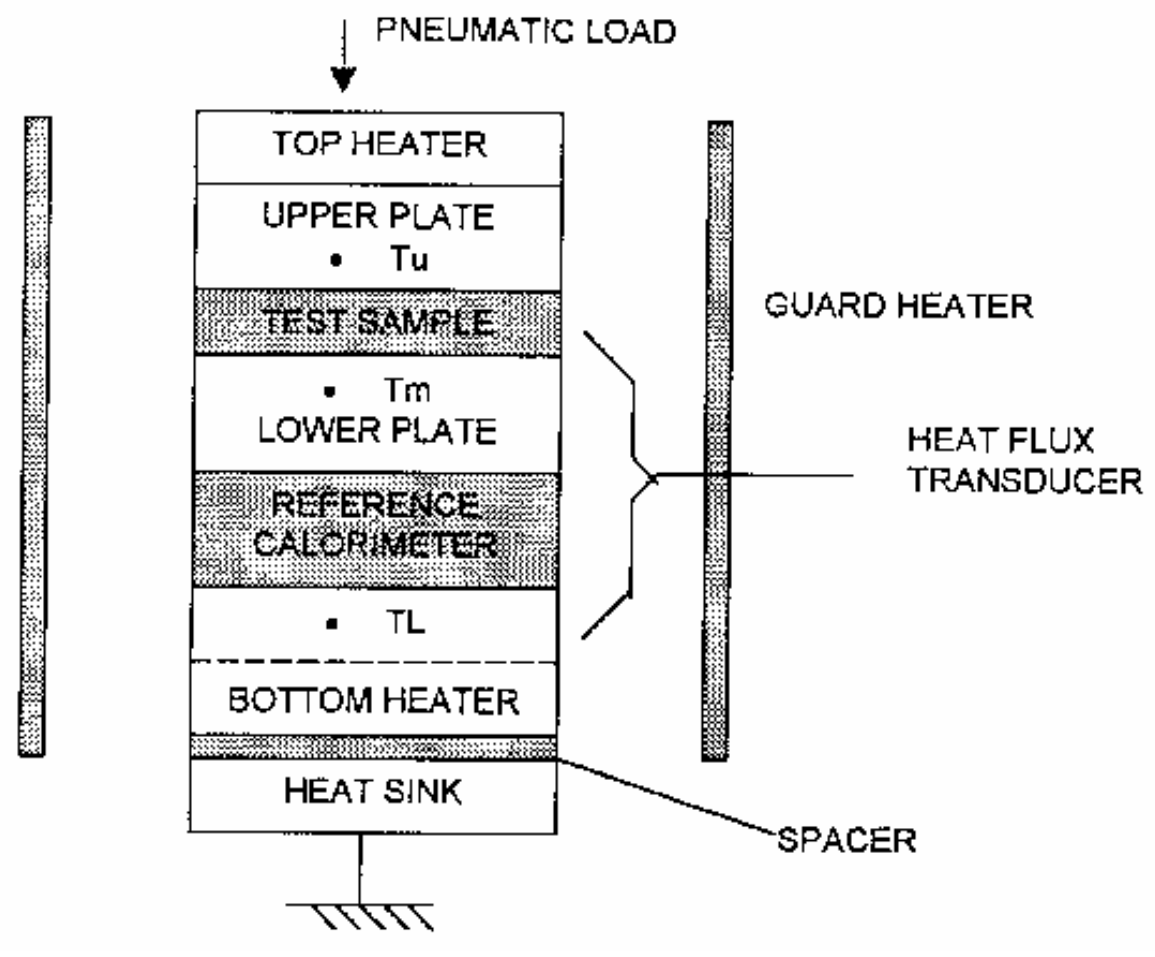

Figure 4.12 Schematic of the system arrangement for UNITHERM 2022 heat flow meter

Considering the working of the system, the sample to be tested is prepared into a flat surface on both sides and thermal compound is applied on the sample to reduce thermal resistance caused due to surface roughness. Then the prepared sample is placed in between two polished surfaces and a pneumatic pressure of $10 \mathrm{psi}$ is applied on the top portion of the stack. The sample can be tested in the temperature range from $20^{\circ} \mathrm{C}$ to $300^{\circ} \mathrm{C}$. For steady state heat transfer, the user can divide the testing into different zones, called as set point temperatures. In this work the testing was divided into three temperature zones i.e. $60,80,100^{\circ} \mathrm{C}$. For higher thermal conductivity materials a difference of 50 degrees was recommended for the machine (between the zones). At every set point temperature, the system checks for steady state heat flow through the sample and thermal conductivity is measured. 


\subsection{Effect of moisture and water immersion on the potential sensor}

As a sensor, the conductive composite will be subjected to heat, UV light, moisture and other natural weathering forces in addition to loading. These might affect the resistance of the sensor and need to be investigated. Therefore it is important to understand how the sensor behaves when it is exposed to the different weathering forces individually and integrally.

The effect of moisture on the sensor was studied by putting the sample in a controlled humidity chamber as shown in Figure 4.13. The chamber was supplied by Fisher Scientific., including a 0 to 100 scale hygrometer with a $21 / 4 \mathrm{in}$. $(57 \mathrm{~mm})$ dial mounted in door to measure relative humidity inside. The dessicant Drierite Indi 8 mesh was also supplied by Fisher Scientific. It absorbs $10-14 \%$ by wt of moisture and is reusable. The door of the chamber has a rubber lining to improve the seal. Initially the $\mathrm{RH}$ in the chamber was around 45 which is approximately the $\mathrm{RH}$ of the lab.
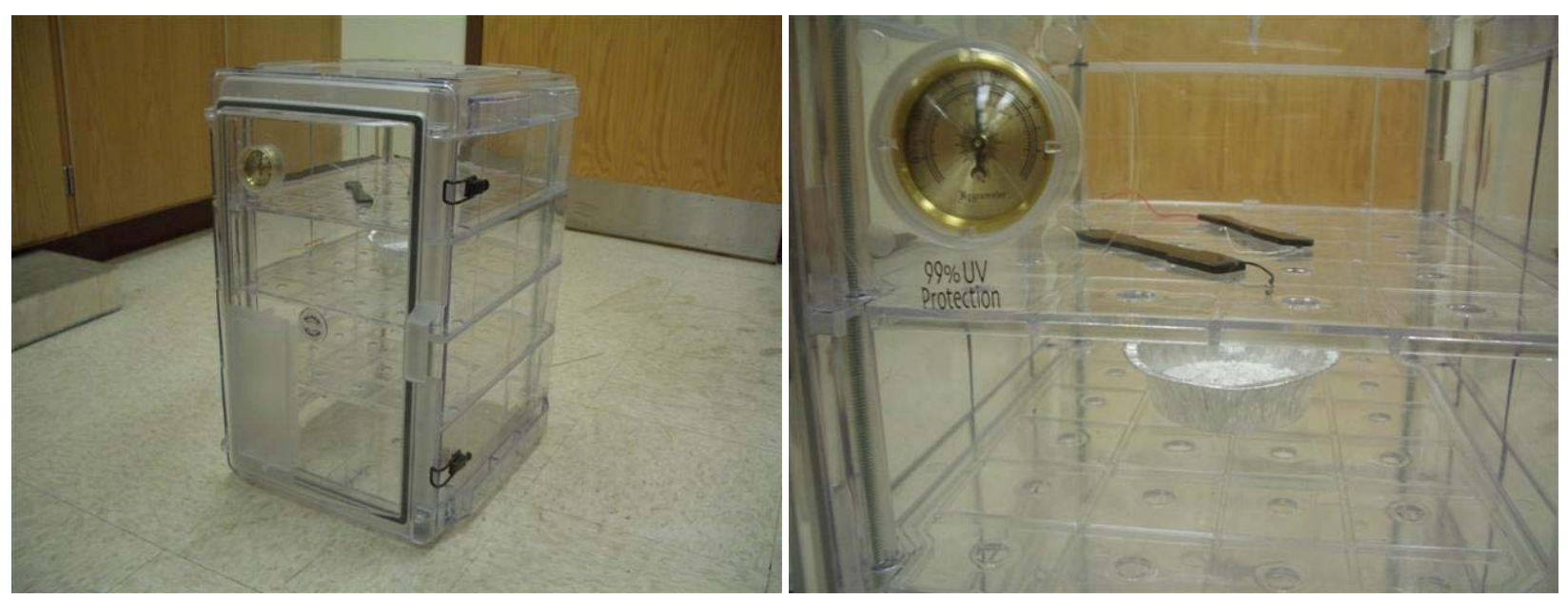

Figure 4.13 Humidity chamber with the samples, dessicant and rubber lining

The $\mathrm{RH}$ of the chamber is brought down from the ambient $\mathrm{RH}$ to 10 using the dessicant. The dessicant was pre-treated at $218^{\circ} \mathrm{C}\left(425^{\circ} \mathrm{F}\right)$ for one hour in the oven and is then placed in the chamber to lower the RH. This process is repeated to get the chamber's RH to 10 . The RH in the chamber was varied from 10 to 90 and then it was brought back to 10 . The RH was increased by replacing the dessicant with a dish of water. The electric resistance of the sample was monitored along with the humidity in the container.

The effect of immersion in water on the sample was found by placing the sample in a conical flask that was filled with water as shown in Figure 4.14. The sample was completely 
immersed in water. The resistance of the sample was recorded on a daily basis. While measuring the resistance care was taken to wipe the surface of the sample with a cloth so that there was no water on the surfaces of the sample. After taking the measurement of the resistance the sample was again put back into the flask. This process was repeated for 25 days and the variation of resistance was studied as a function of wetting time. The results indicated moisture effect on the resistance of the conductive composite sensor.

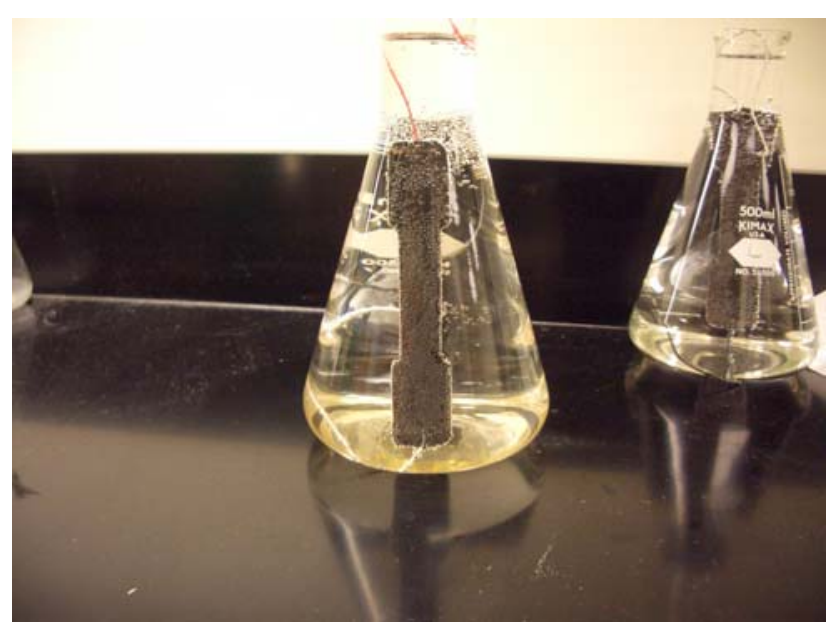

Figure 4.14 Two samples immersed in water inside conical flasks

The second part of the experiment was to study the reversible nature of the above process. The sample was taken out of the flask after 25 days and was kept at room temperature. The resistance of the sample was monitored at a daily basis.

\subsection{Effect of temperature on the potential sensor}

The sensor will be subjected to the heating of the sun during the day and the cooling during the night. It is very important to know how the resistance of the conductive composite varies with temperature. A preliminary test was done to examine the temperature effect on the resistance of a sample.

The electric resistance of a typical metal conductor increases linearly with the temperature as follows:

$$
R=R_{0}+a T
$$


The electric resistance of a typical semiconductor decreases exponentially with the temperature as follows:

$$
R=R_{0}+e^{a / T}
$$

Therefore, a material (a conductor or a semiconductor) will undergo resistance fluctuations with temperature fluctuations. The typical temperatures in which our sensor will operate is from 0 to $110 \mathrm{~F}$.
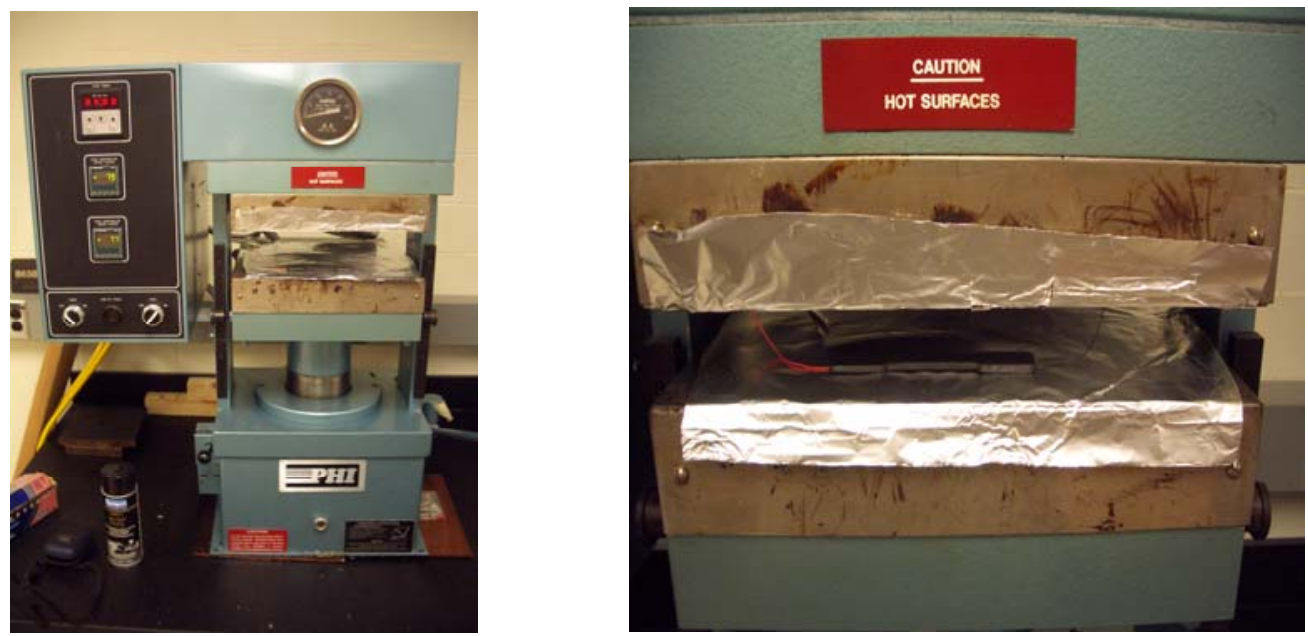

Figure 4.15 A press used to study the effect of temperature on the sensor's property.

We placed the sample in between the two plates of a compression molding machine as shown in Figure 4.15. The plates of the compression molding machine can be maintained at different temperatures. The plates are then brought close in contact with the sample from both sides. A pressure of 5 psi was applied on the sample. The temperature of the plates can be varied from 80 to $500 \mathrm{~F}$, but we are interested in the region of $80-120 \mathrm{~F}$. During the test, the temperature of the bottom and top plate was first set to $80 \mathrm{~F}$. The machine took about 5 minutes to attain that temperature. After the temperature was attained, we maintained the temperature for $\sim 30$ minutes. Then the sample was removed and the resistance was noted. The sample was then loaded back and the temperature was increased to $90 \mathrm{~F}$ on both the plates. The same procedure was repeated with increments of 10 in temperature till 130F. The resistance was monitored at each temperature. 


\section{CHAPTER 5 \\ RESULTS AND DISCUSSION}

Results from various test procedures as described in Chapter 4 on conductive composite samples prepared as per the description Chapter 3 are presented and analyzed in this chapter.

\subsection{Electrical resistance}

\subsubsection{Transpo-48 resin based specimens}

Transpo-48 (T-48) is a low modulus, polysulphide modified epoxy, with a viscosity of $1500 \mathrm{cps}$ and a mixing ratio by volume of Part A to Part B is 2. T-48 was selected in this study because of its long elongation to failure. The disadvantage was the difficulty of mixing the fillers in it due to its high viscosity. Graphite powder GP 44-B supplied by UCAR carbon company was used as the conductive filler. All the test samples were prepared by hand molding. The procedure was similar to that described in Section 3.4.1, except that there was no need of adding any catalyst. After mixing both the parts together, the graphite filler was weighed and added to the resin system and was thoroughly mixed. After the samples were de-molded, they were tested for their conductivity using the Wayne-Kerr instrument as described in Section 4.1. The results of the samples are listed in Table 5.1

Table 5.1 Conductivity of graphite filled T-48 samples

\begin{tabular}{|c|c|c|}
\hline $\begin{array}{c}\text { Graphite powder } \\
\text { concentration by weight }\end{array}$ & Ease of casting & Electrical conducting behavior \\
\hline $1 \%$ & Easy & No conductance observed \\
\hline $5 \%$ & Easy & No conductance observed \\
\hline $25 \%$ & Very viscous, difficult & No conductance observed \\
\hline $33 \%$ & Very viscous, difficult & No conductance observed \\
\hline $40 \%$ & Highly viscous, very difficult & No conductance observed \\
\hline
\end{tabular}

Surprisingly, no electrical conductance was observed even for the samples at a graphite concentration of $40 \%$ by weight. However, the mixture of $40 \%$ graphite in T- 48 was already of extremely high viscosity, resulting in casting difficulties. In addition, high graphite concentration samples were very difficult to de-mold. The result indicated that the T-48 resin was able to 
uniformly coat or cover graphite particles and thus-formed insulating resin layers surrounding the particle surfaces inhibited electric conductance. Therefore the conducting behavior of a composite not only depends on the filler (type, concentration) but also depends on the type of polymer matrix used.

\subsubsection{Hetron 922 vinyl ester resin based samples}

The manufacturing of Hetron 922 L25 vinyl ester resin based samples with graphite powder GP 44-B is described in Section 3.4.1. Vinyl ester is an engineering resin which finds many applications in structural and civil engineering. The reason to choose this resin is due to the fact that most of the FRP bridge decks are made of this polymer reinforced with glass fiber, thereby giving a higher degree of compatibility. After de-molding and post curing, the samples were tested for their conductivity as described in Section 4.1. Their electric resistance data were plotted as a function of graphite concentration ranging from $0-40 \mathrm{wt} \%$ in Figure 5.1.

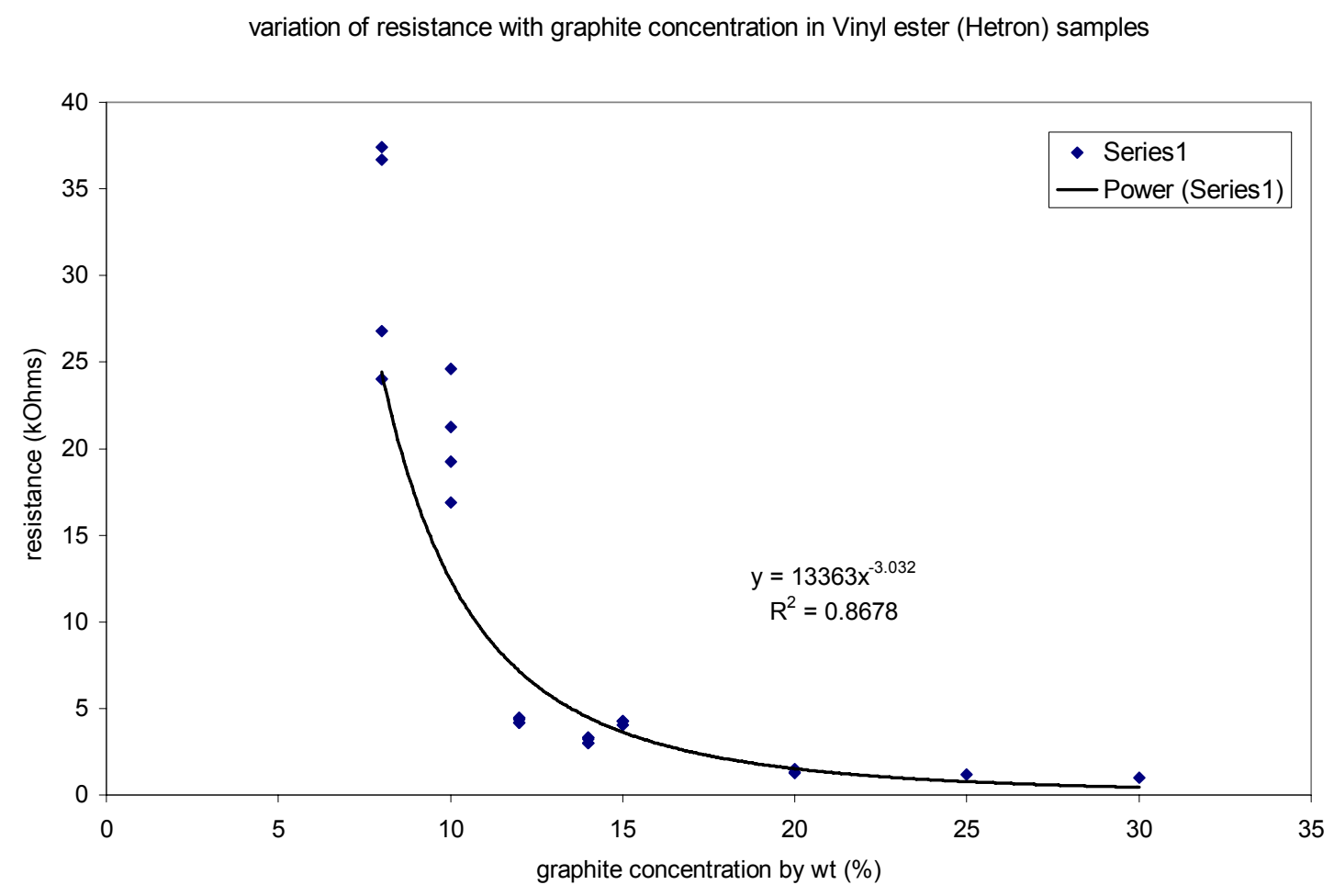

Figure 5.1 Conducting behavior of graphite filled vinyl ester samples 
Neat vinyl ester resin is non-conductive and thus has very high resistance. Figure 5.1 shows that as more and more graphite powder is needed into the resin, the sample is becoming increasingly conductive. Since the resistance data of the samples appeared to have an exponential relationship with graphite concentration, the data were replotted in a log-log scale and presented in Figure 5.2. As seen from Figure 5.2, the relationship between resistance and graphite powder concentration becomes linear in a log-log chart. Data fitting demonstrates that the resistance is reciprocal of graphite concentration with a power index of approximately 3 . For carbon fiber reinforced composites, the resistance is only reciprocal of carbon fiber weight, i.e. with a power index of 1.0 [Wang 2004].

Variation of resistance with graphite concentration for Vinyl Ester (Hetron) samples

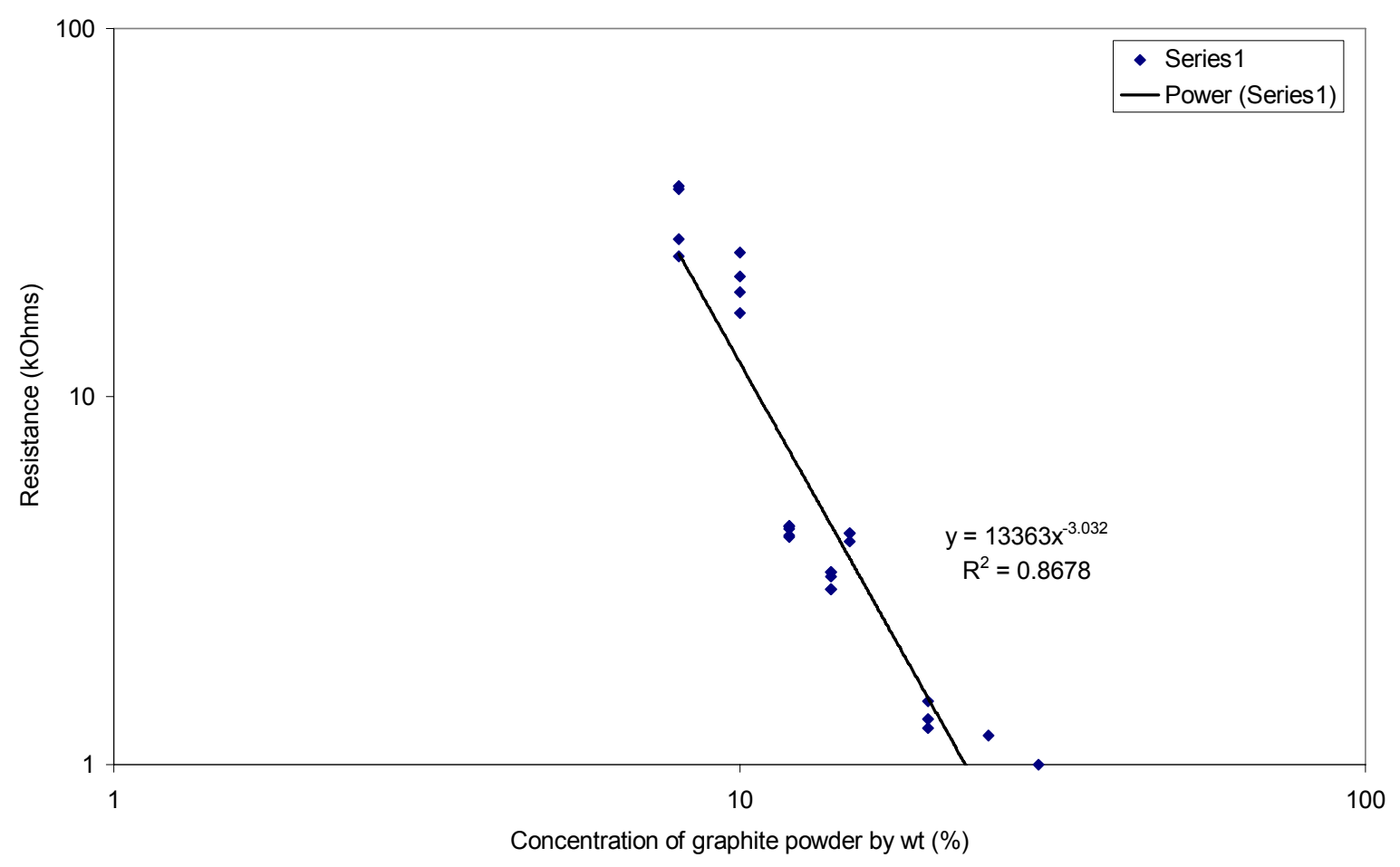

Figure 5.2 A power data fit with logarithmic axes for the Figure 4.1

In order to reduce the graphite concentration, carbon fiber was introduced into the vinyl ester/graphite systems for trial. Carbon fiber was added at 1\% into a mixture of 5\% graphite powder in vinyl ester. Two samples were cast and were found conducting. This demonstrated that a conductive network was already formed when only 5\% graphite powder was used in combination with chopped carbon fibers. 


\subsubsection{Electrical resistance as a function of graphite particle size}

In order to find the effect of particle size on the resistance of the sample, we have cast Hetron 922 L25 vinyl ester based samples with $10 \%$ by weight of graphite powder with different particle sizes. The graphite powders of different sizes were obtained from UCAR carbon company and their properties were described in Table 3.1. The casting procedures were exactly same for all the powders.

The electric resistivity data for $10 \%$ graphite in vinyl ester were plotted as a function of graphite particle size in Figure 5.3. Figure 5.3 shows that the resistance of the sample increases with the particle size till 75 microns but then decreases in the case of graphite powder of 150 microns, while the composites made of GP44-B have similar electrical resistance to those made of GP55-B. The reason why the composites consisting of GS150-E have lowest resistance is not clear. Surface properties of these powders may be needed from the manufacturer in order to interpret this interesting result.

variation of resistance vs particle size in Hetron 922L

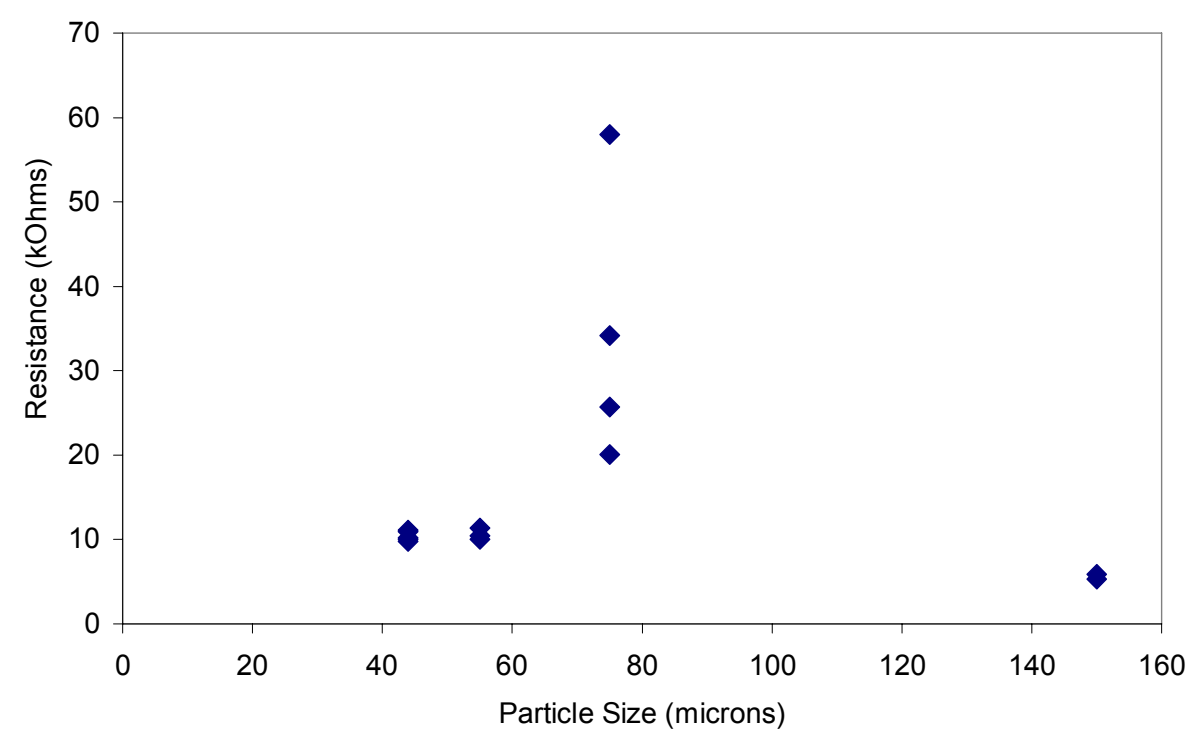

Figure 5.3 Electrical resistance vs graphite particle size 


\subsubsection{Other flexible resins}

Hetron 922 L25 vinyl ester resin has an elongation of 4-5\%. In order to develop a conductive composite that offers large elongation-to-failure, several flexible resin systems were evaluated for their applicability, including Polycarb Flexogrid Mark 163 (an urethane modified epoxy), Transpo 48 (a polysulphide modified epoxy), E-Bond 526 (an epoxy), and a polyol blend based polyurethane resin. The composite samples were prepared in the same way as described previously. Table 5.2 is a summery of conducting properties of composites prepared using different types of flexible resins. Ideally, we would like to identify a flexible resin which offers large elongation to failure but does not hinder the conducting property of the graphite networks in the composite. Unfortunately, as indicated in Table 5.2, all composites based on either epoxies or polyurethane resin are non-conducting.

Table 5.2 Conducting properties of cured composites based on flexible resins

\begin{tabular}{|l|c|c|c|c|c|}
\hline Polymer Matrix & $\begin{array}{c}\text { GP44-B } \\
(0 \mathrm{wt} \%)\end{array}$ & $\begin{array}{c}\text { GP44-B } \\
(10 \mathrm{wt} \%)\end{array}$ & $\begin{array}{c}\text { GP44-B } \\
(15 \mathrm{wt} \%)\end{array}$ & $\begin{array}{c}\text { GP44-B } \\
(20 \mathrm{wt} \%)\end{array}$ & $\begin{array}{c}\text { GP44-B } \\
(25 \mathrm{wt} \%)\end{array}$ \\
\hline Polycarb 163 & $\begin{array}{c}\text { Non } \\
\text { conducting }\end{array}$ & $\begin{array}{c}\text { Non } \\
\text { conducting }\end{array}$ & $\begin{array}{c}\text { Non } \\
\text { conducting }\end{array}$ & $\begin{array}{c}\text { Non } \\
\text { conducting }\end{array}$ & $\begin{array}{c}\text { Non } \\
\text { conducting }\end{array}$ \\
\hline Transpo 48 & $\begin{array}{c}\text { Non } \\
\text { conducting }\end{array}$ & $\begin{array}{c}\text { Non } \\
\text { conducting }\end{array}$ & $\begin{array}{c}\text { Non } \\
\text { conducting }\end{array}$ & $\begin{array}{c}\text { Non } \\
\text { conducting }\end{array}$ & $\begin{array}{c}\text { Non } \\
\text { conducting }\end{array}$ \\
\hline E-Bond 526 & $\begin{array}{c}\text { Non } \\
\text { conducting }\end{array}$ & $\begin{array}{c}\text { Non } \\
\text { conducting }\end{array}$ & $\begin{array}{c}\text { Non } \\
\text { conducting }\end{array}$ & $\begin{array}{c}\text { Non } \\
\text { conducting }\end{array}$ & $\begin{array}{c}\text { Non } \\
\text { conducting }\end{array}$ \\
\hline Polyurethane & $\begin{array}{c}\text { Non } \\
\text { conducting }\end{array}$ & $\begin{array}{c}\text { Non } \\
\text { conducting }\end{array}$ & $\begin{array}{c}\text { Non } \\
\text { conducting }\end{array}$ & $\begin{array}{c}\text { Non } \\
\text { conducting }\end{array}$ & $\begin{array}{c}\text { Non } \\
\text { conducting }\end{array}$ \\
\hline
\end{tabular}

It is surprising to observe that graphite powder dispersed in vinyl ester makes a conductive composite but graphite powder dispersed in epoxy makes an insulator. This fact implies that a conducting graphite network is formed in graphite/ vinyl ester system, but not formed in graphite / epoxy system. In order to provide an understanding, both the cured samples were studied under a scanning electron microscope (SEM) so as to observe their morphology. Typical micrographs were shown in Figures 5.4- 5.10.

As clearly revealed in Figures 5.4- 5.6, graphite powder is very well dispersed in epoxy resin and epoxy resin acts as an insulating coating on graphite particle surfaces so that no 
conducting graphite channel or network is formed. Instead, Figures 5.7- 5.10 indicates that graphite powder is poorly dispersed in vinyl ester resin in a microscopic scale and graphite particles remain in the form of aggregates. There are many conducting graphite channels and network in the composite. The distinction in morphology between graphite/ epoxy and graphite/ vinyl ester is attributed to graphite's compatibility with epoxy and incompatibility with vinyl ester.

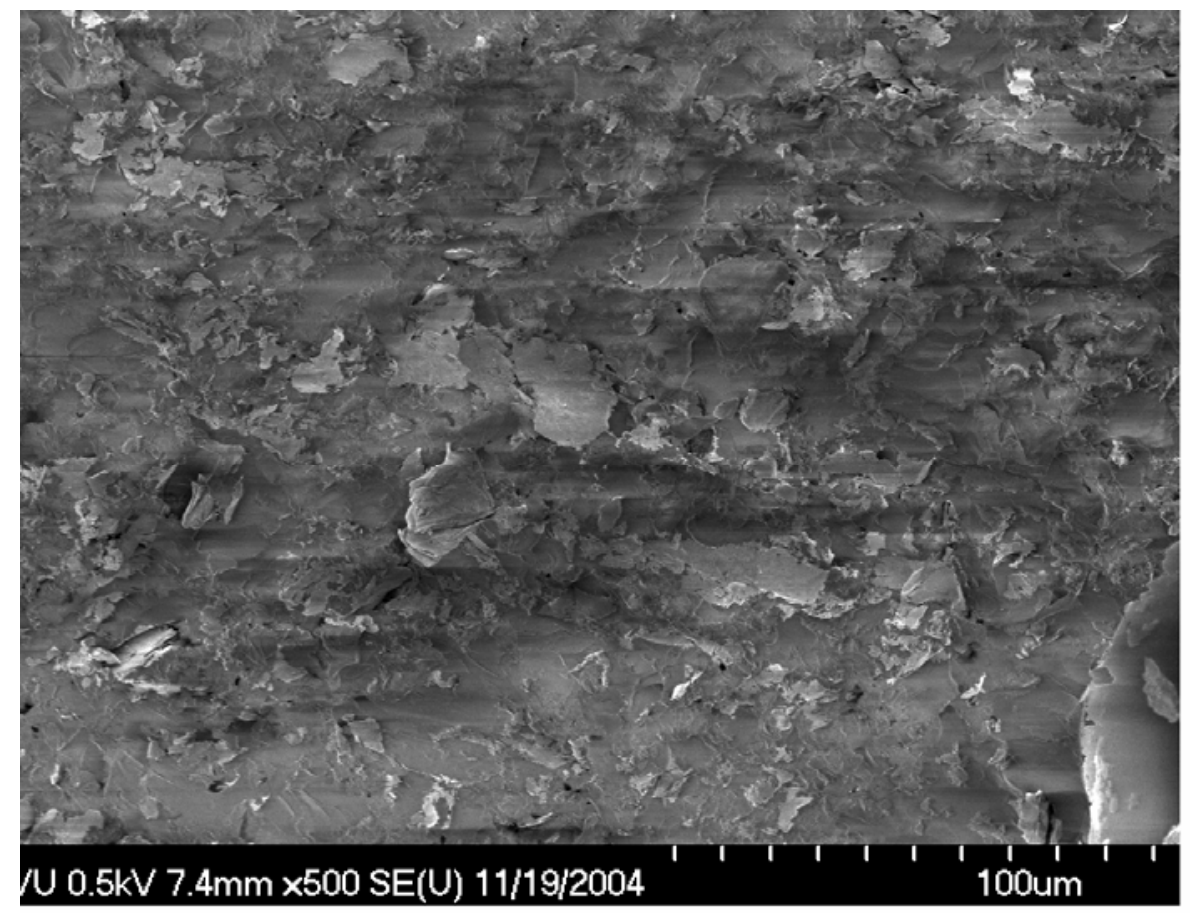

Figure 5.4 SEM micrograph of graphite GP44-B in E-Bond at 10wt \% 


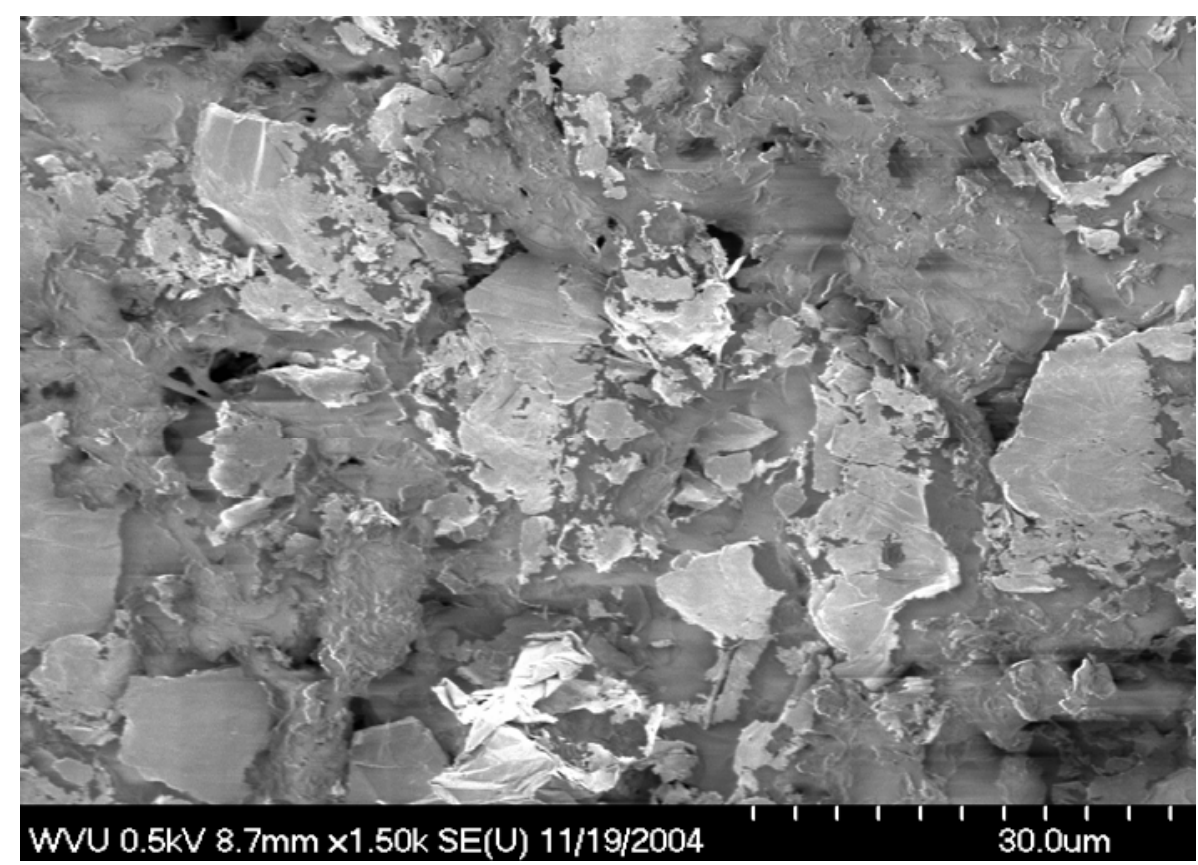

Figure 5.5 SEM of graphite GP44-B in E-Bond at 25wt\%

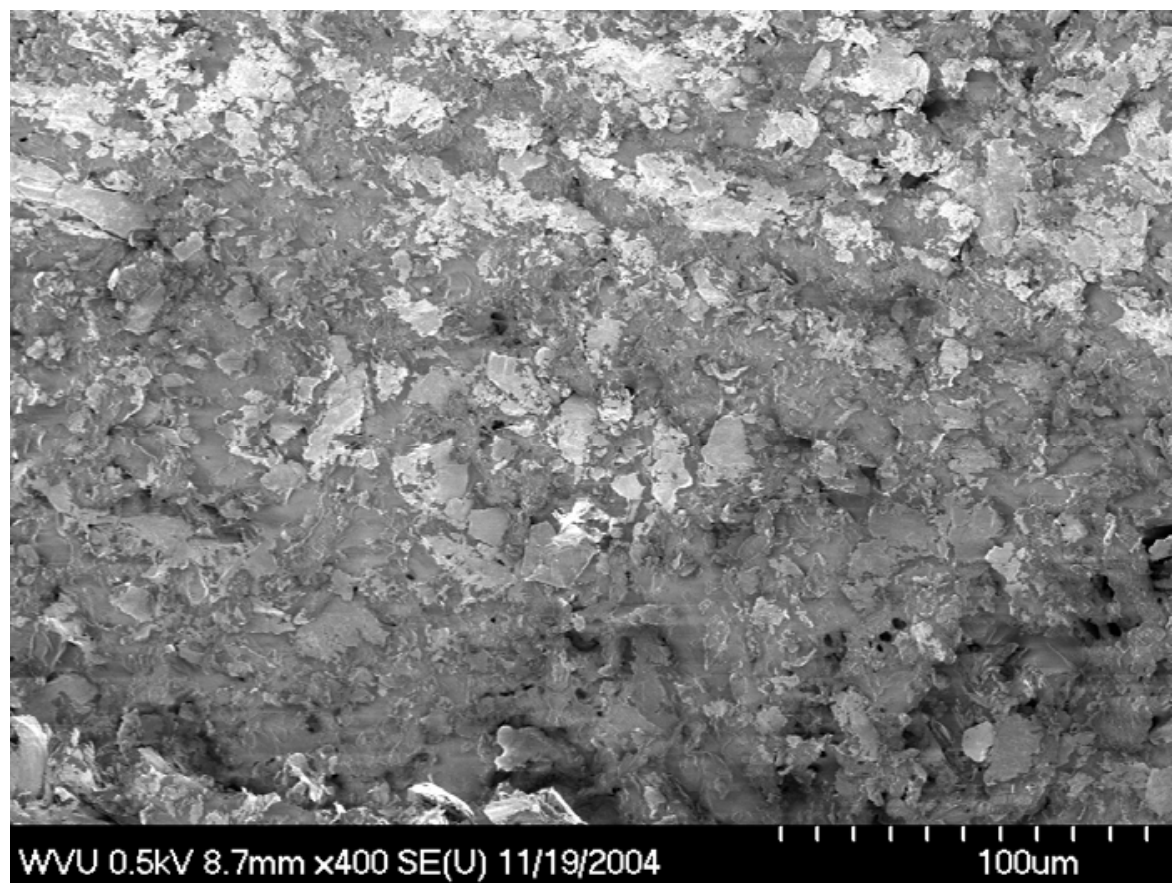

Figure 5.6 SEM of graphite GP44-B in E-Bond at 25wt\% 


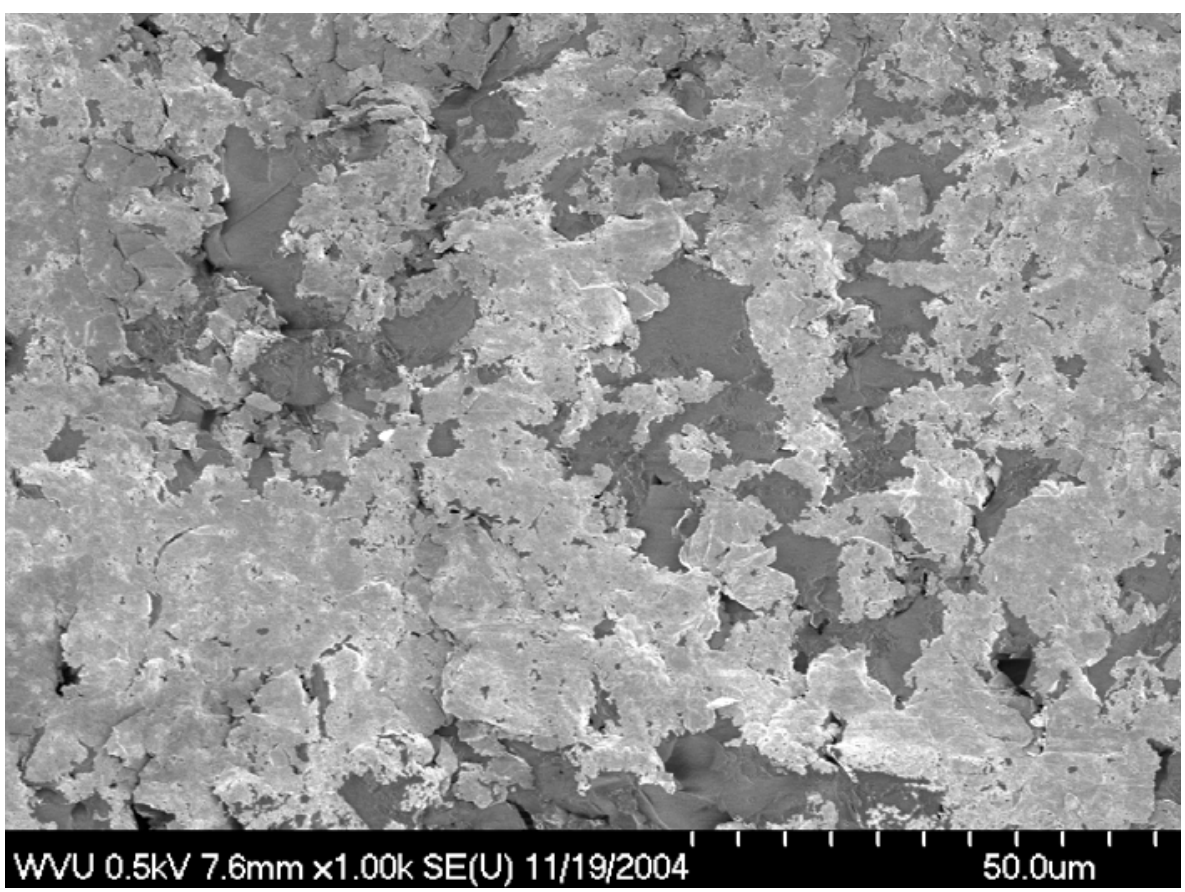

Figure 5.7 SEM of graphite GP44-B in vinyl ester at 20wt\%

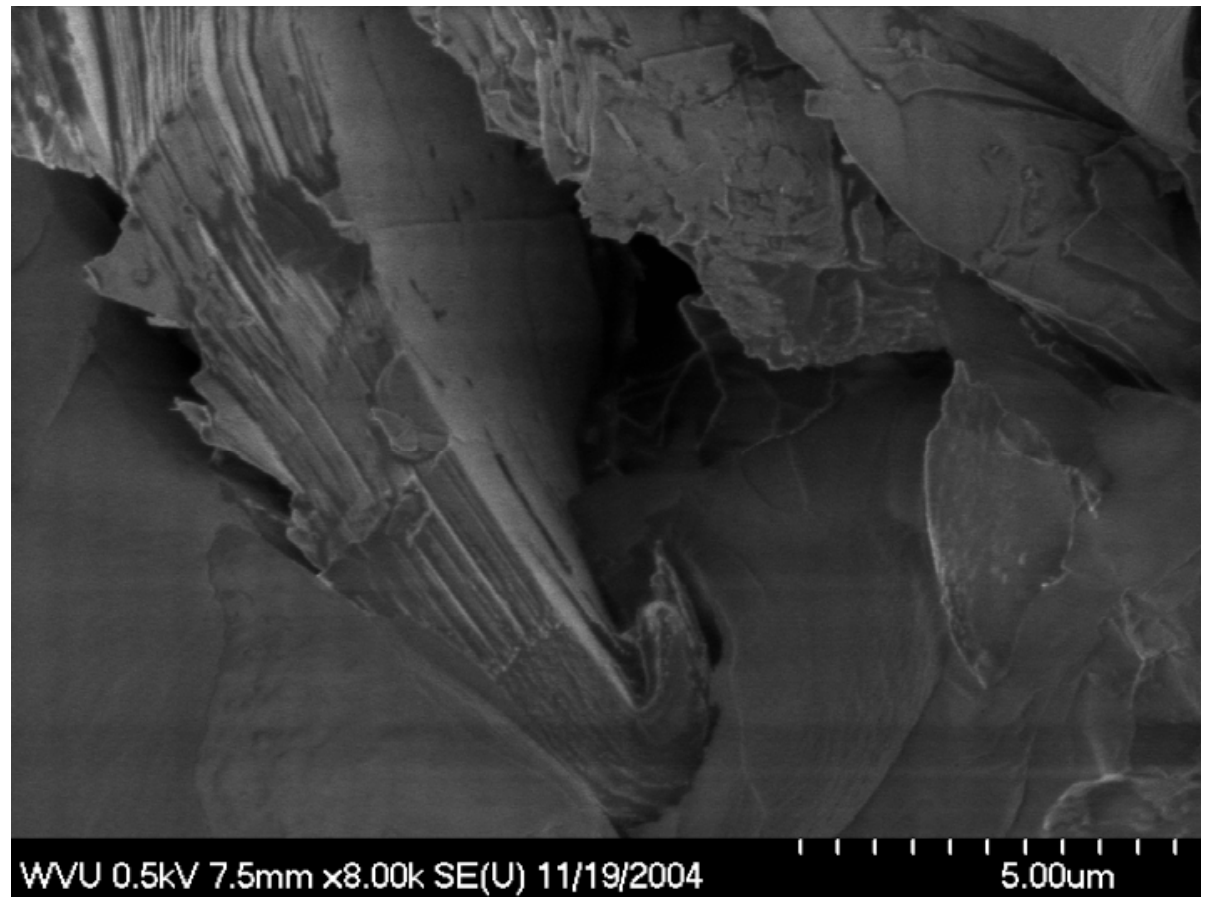

Figure 5.8 SEM of graphite GP44-B in vinyl ester at 20wt\% 


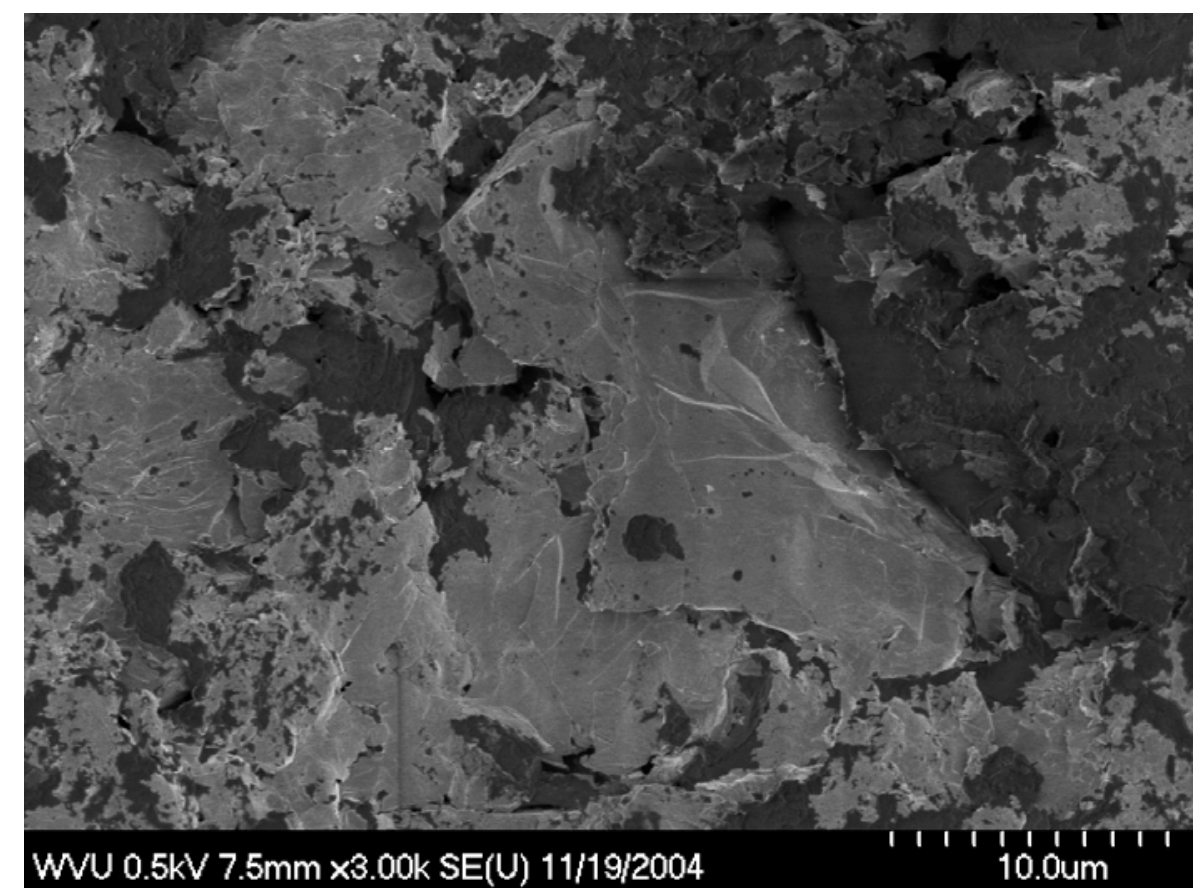

Figure 5.9 SEM of graphite GP44-B in vinyl ester at 20wt\%

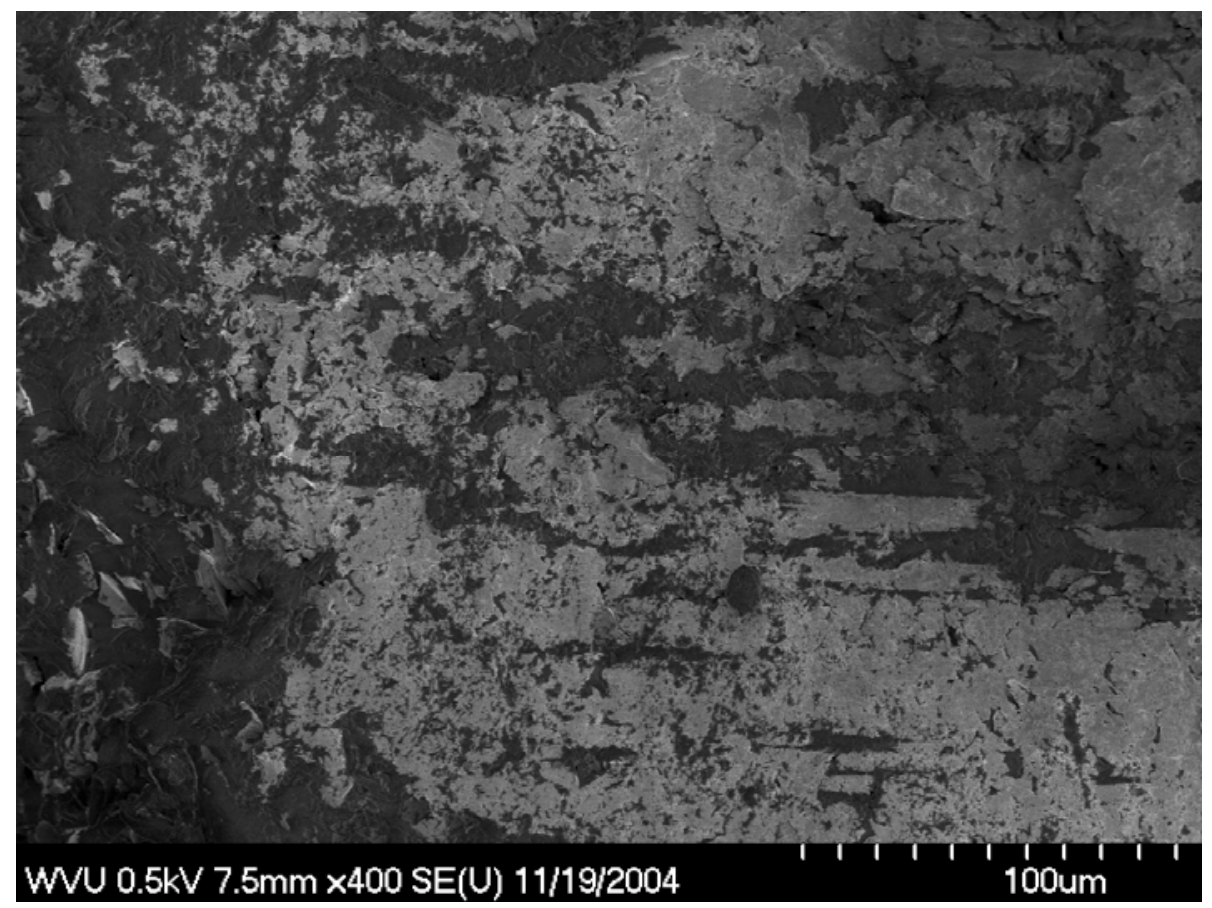

Figure 5.10 SEM of graphite GP44-B in vinyl ester at 20wt \% 
Therefore, SEM morphological micrographs provide direct information for understanding the conducting behavior of the composites. A comparison in properties between graphite /epoxy and graphite /vinyl ester is listed in Table 5.3.

Table 5.3 Comparison in properties between graphite/ epoxy and graphite/ vinyl ester composites

\begin{tabular}{|c|c|}
\hline Graphite / epoxy & Graphite / vinyl ester \\
\hline High elongation to failure $\sim 30 \%$ & Low elongation to failure $\sim 1 \%$ \\
\hline Graphite particles well dispersed in epoxy resin & $\begin{array}{r}\text { Graphite particles poorly dispersed in vinyl } \\
\text { ester resin }\end{array}$ \\
\hline Graphite particles insulated by epoxy resin & Graphite particles not wet by vinyl ester \\
\hline No conductive channel or network formed & Many conductive channels or network formed \\
\hline Non conducting even at $25 \mathrm{wt} \%$ graphite & $\begin{array}{r}\text { Conducting as low as } 8 \mathrm{wt} \% \text { graphite and } \\
\text { conductivity increasing with graphite } \\
\text { concentration }\end{array}$ \\
\hline
\end{tabular}

\subsubsection{Derakane 8084 based samples}

Derakane 8084 resin is an elastomer-modified epoxy vinyl ester designed to offer increased adhesive strength, superior resistance to abrasion and severe mechanical stress, while giving greater toughness and elongation. Typical properties of the resin and neat resin casting are given in Table 3.2 .

The conductive samples were cast exactly as described in Section 3.4.1. Derakane 8084 and the conductive filler were weighed separately and then mixed thoroughly in a container before pouring it into the mold. Two batches (Batch I, Batch II) of samples were cast at different concentrations of graphite powder as shown in the Table 5.4. Proper care was taken to remove any sort of air bubbles. The samples were allowed to cure at room temperature for 24 hours and then post cured for 3 hours in an oven at $185 \mathrm{~F}$. 
Table 5.4 Composition of Derakane 8084 based composite samples

\begin{tabular}{|c|c|c|c|}
\hline $\begin{array}{c}\text { \% of } \\
\text { Graphite }\end{array}$ & $\begin{array}{c}\text { Derakane } 8084 \\
\text { gram }\end{array}$ & $\begin{array}{c}\text { Graphite } \\
\text { gram }\end{array}$ & $\begin{array}{c}\text { MEKP } \\
\text { gram }\end{array}$ \\
\hline 5 & 11 & 0.579 & 0.33 \\
\hline 7.5 & 11 & 0.892 & 0.33 \\
\hline 9 & 11 & 1.088 & 0.33 \\
\hline 10 & 11 & 1.222 & 0.33 \\
\hline 11 & 11 & 1.360 & 0.33 \\
\hline 12.5 & 11 & 1.571 & 0.33 \\
\hline 15 & 11 & 1.941 & 0.33 \\
\hline 17.5 & 11 & 2.333 & 0.33 \\
\hline 20 & 11 & 2.750 & 0.33 \\
\hline 22.5 & 11 & 3.194 & 0.33 \\
\hline 25 & 11 & 3.667 & 0.33 \\
\hline
\end{tabular}

The electric resistance data of Derakane 8084 based composite samples are plotted as a function of graphite concentration and shown in Figure 5.11. The resistance of the samples decreases remarkably with increase in graphite concentration. A power-law fit is used to represent the variation of resistance with graphite concentration and is also shown in Figure 5.11. For Derakane 8084 based composites, the resistance decreases reciprocally at an approximately 3rd power of graphite concentration, consistent to that of Hetron 922 L25 based composites. This result indicates that graphite particles play the same role in forming conducting networks in Derakane 8084 based as well as Hetron 922 L25 based composites. 


\section{Variation of resistance w.r.t. graphite concentration in vinyl ester \\ (Derakane) samples}

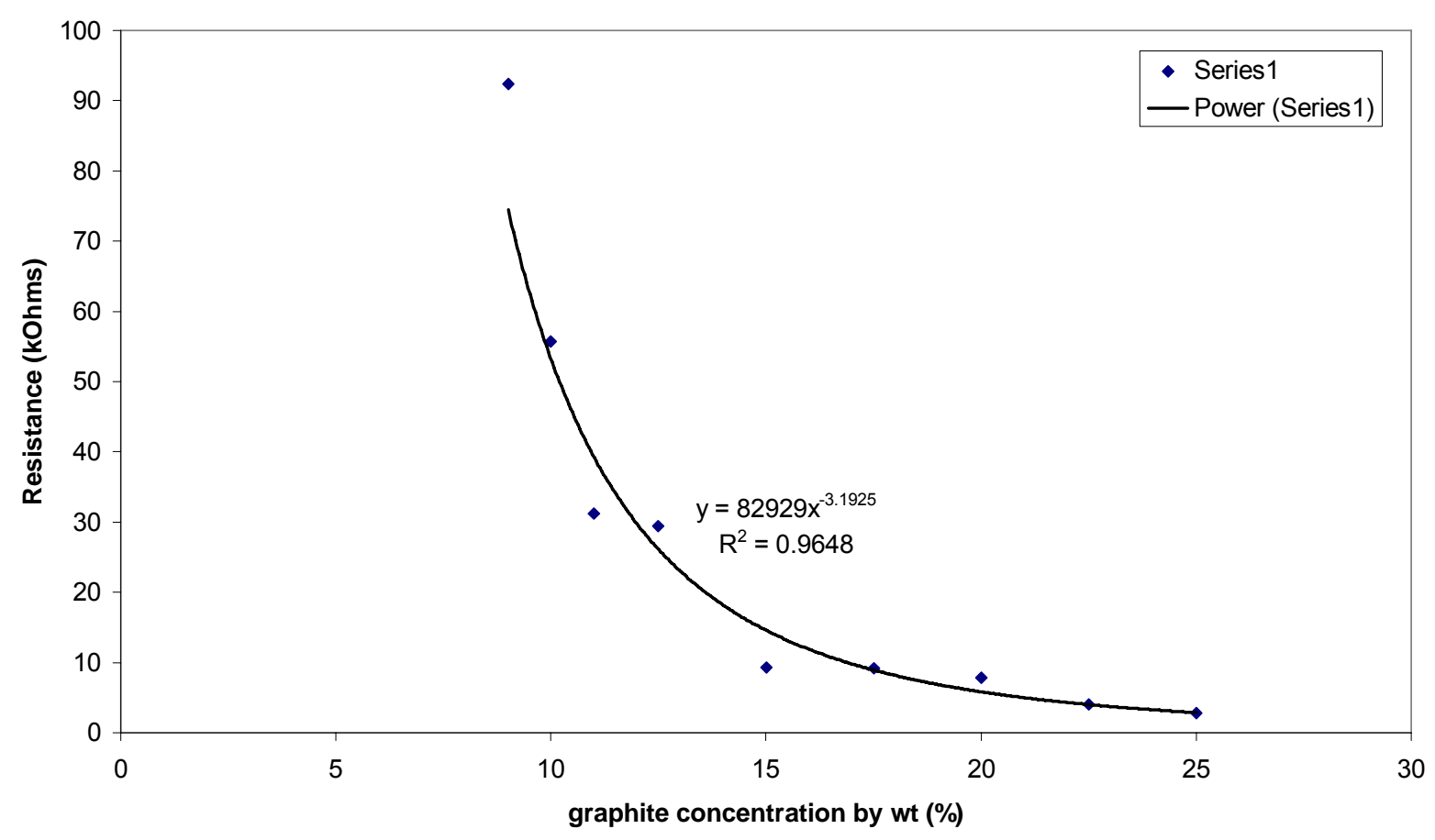

Figure 5.11 Electric resistance as a function of graphite concentration

\subsubsection{Electrical resistance as a function of graphite particle size in Derakane 8084}

To find the effect of particle size on the resistance of the Derakane based samples, graphite powders of different sizes from UCAR carbon company were used. The samples were cast at a concentration of $10 \%$ by weight of graphite powder in Derakane 8084 vinyl ester resin. The properties of the powders were given in Table 3.1. The electric resistance data were plotted as a function of graphite particle size in Figure 5.12. It can be observed that the resistance of the samples was increasing with particle size. The resistance of the samples with GS150-E is huge and cannot be shown on the graph.

For the same $\mathrm{wt} \%$ of graphite powder, the smaller the particle size the greater is the surface area of all the particles in it. The surface area plays a key role in forming more conductive chains or network. Therefore the powders with low particle size show more conductivity than those with a bigger particle size. 
Variation of resistance w.r.t graphite particle size

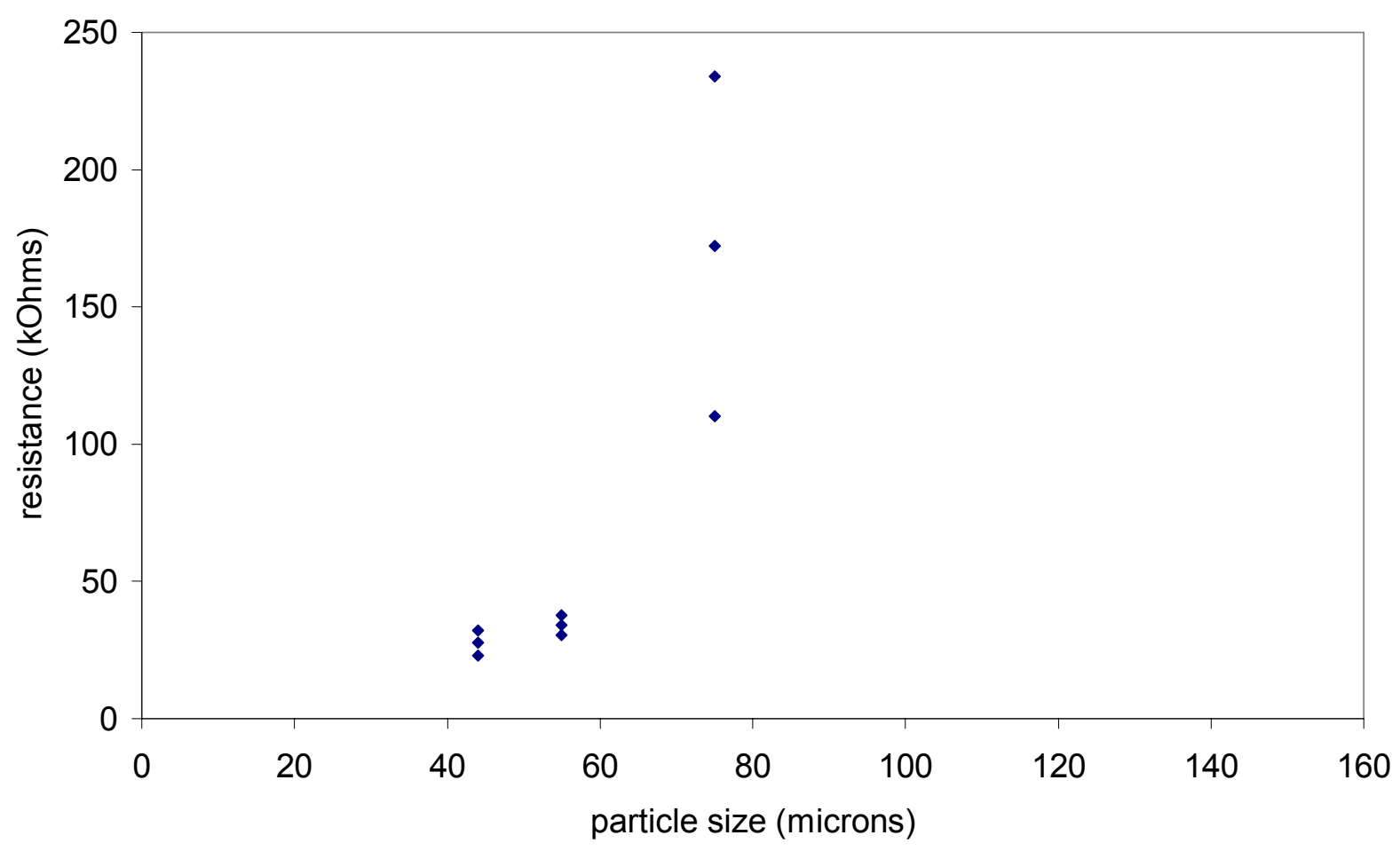

Figure 5.12 Electrical resistance of the conducting composites vs graphite particle size in Derakane 8084

\subsubsection{Carbon nano tube based samples}

Carbon nano-tubes are nano sized carbon tubes which are highly conductive, having resistivities of the order of $10^{-12}$. Their tubular structure might also enhance the mechanical properties of the resulting composite. The received carbon nano tubes were dispersed in styrene at a concentration of $0.5 \%$. CNT styrene solution offers an advantage that can be mixed at ease with vinyl ester resin since vinyl ester has $45 \%$ of styrene as reacting monomers.

CNT based samples were cast for electrical conductivity measurements, thermal conductivity measurements and mechanical tests. The cast samples had a CNT concentration of $0.25 \%$ in Derakane 8084 . Their resistance data are given in Table 5.5. 
Table 5.5 Resistance of $\mathbf{0 . 2 5 \%}$ carbon nano tube samples in Derakane 8084 resin

\begin{tabular}{|c|c|c|}
\hline Sample No. & Resistance (kOhms) & Resistivity (Ohm-m) \\
\hline 1 & 45.9 & 18.216 \\
\hline 2 & 39.0 & 15.478 \\
\hline 3 & 41.4 & 16.430 \\
\hline 4 & 40.0 & 15.875 \\
\hline
\end{tabular}

\subsection{Mechanical properties}

\subsubsection{Typical results from Instron 8501}

Tension tests were carried out initially on an Instron machine model 8501 using a position control mode at a stretching rate of $0.05 \mathrm{inch} / \mathrm{minute}$. During a test, the electric resistance was measured along with stress as described in Section 4.2.2. Synthesizing the stress and resistance data as a function of time gives the relationship between these two properties. Typical results were graphically shown in Figures $5.13-5.15$.

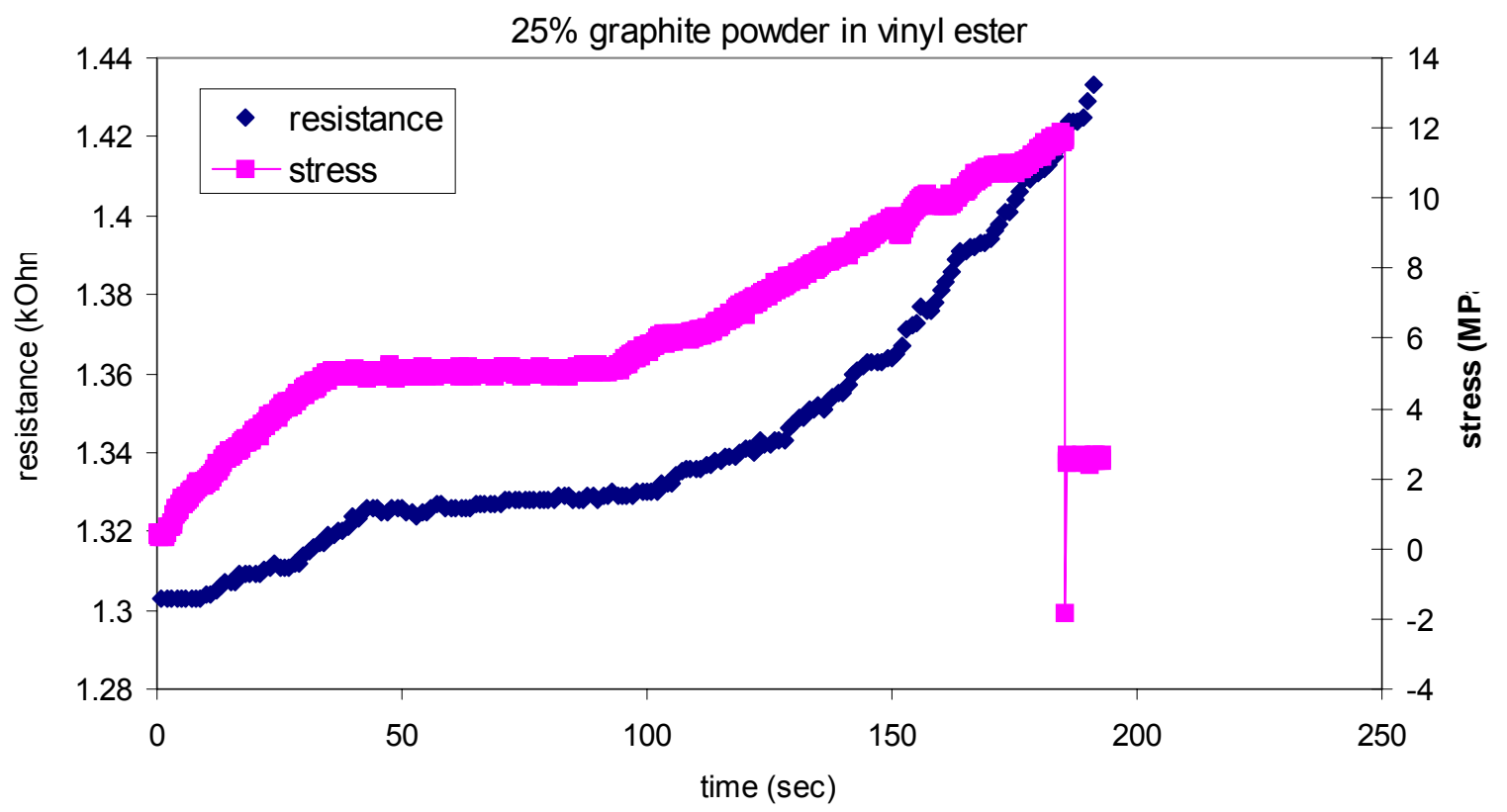

Figure 5.13 Stress and resistance as a function of time for $25 \%$ graphite/vinyl ester sample 
$40 \%$ graphite in vinyl ester

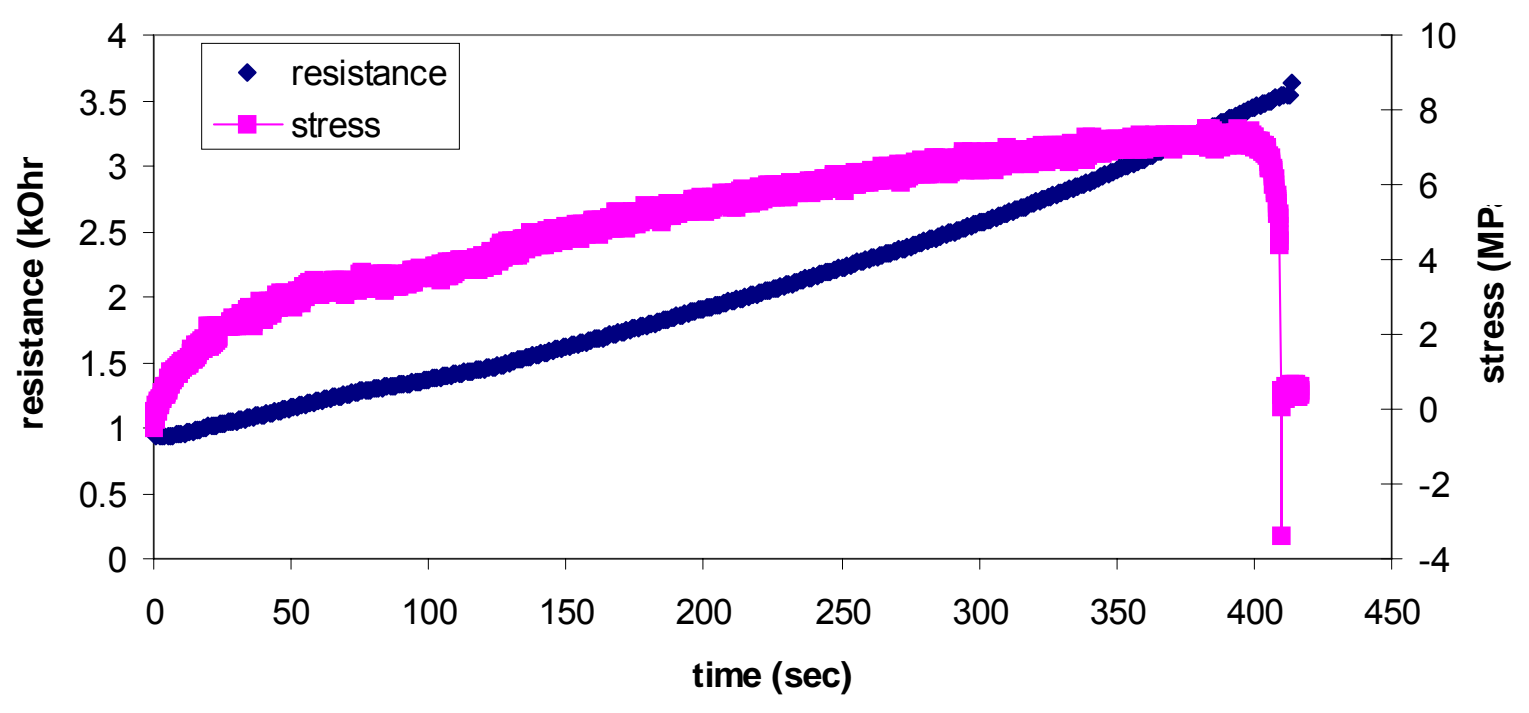

Figure 5.14 Stress and resistance as a function of time for $40 \%$ graphite/vinyl ester sample

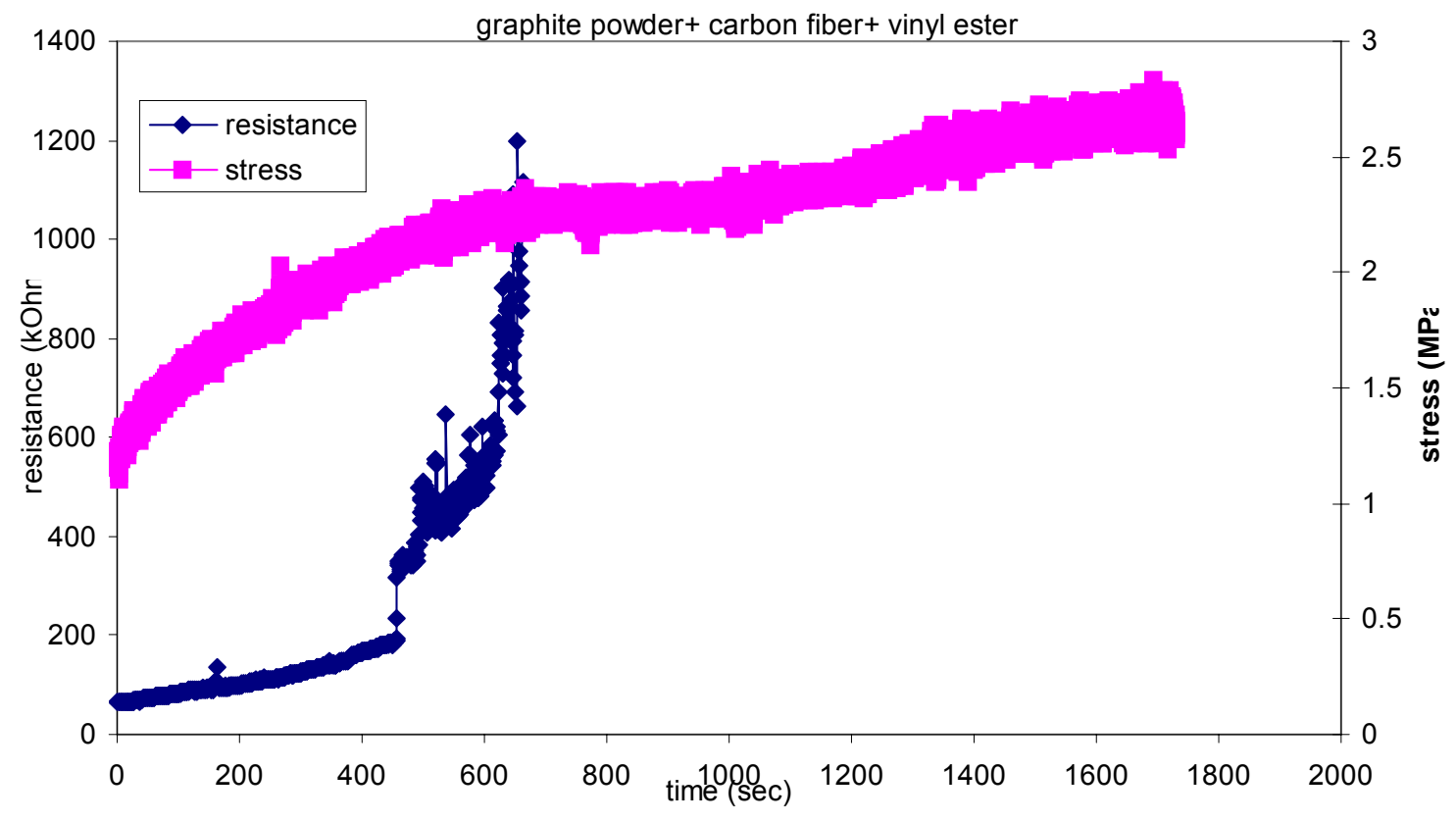

Figure 5.15 Stress and resistance as a function of time for $5 \%$ graphite with $1 \%$ carbon fiber /vinyl ester sample 
Figures $5.13-5.14$ demonstrate that the resistance of the sample increases monotonically with stress for graphite/vinyl ester samples. At the beginning, the resistance gradually increases with stress but suddenly shoots up to infinity as the sample is approaching failure. This is like a single stage process. However, for 5\% graphite/ 1\% carbon fiber/vinyl ester sample, Figure 5.15 shows a two-stage process. Initially the resistance increases linearly due to stretching of the individual fibers. When the stress reaches a certain value, the fiber starts breaking and the distance between the chopped fibers grows. At this stage, the conductivity of the sample can be attributed to the presence of graphite powder in the matrix. So, a jump in the resistance occurs instead of going to infinity. Then the sample behaves as a graphite/vinyl ester composite and the resistance increases with stress and eventually shoots to infinity at the failure of the sample.

The above results demonstrate a great potential of using a conductive composite as a strain sensor for the non-destructive testing of civil structures. However, Instron 8501 carries a loadcell of range up to $100 \mathrm{KN}$ while the sample typically fails at $1.5 \mathrm{KN}$. A more sensitive Instron machine to improve initial section data accuracy is very much desired. In addition, stress and resistance data should be correlated directly with strain. Therefore, majority of mechanical properties data presented in this report are generated on Instron 5689.

\subsubsection{Graphite /Hetron 922 vinyl ester system using Instron 5689}

Samples of graphite powder dispersed in Hetron 922 vinyl ester resin were tested under tension using an Instron machine (model) 5689 as shown in Figure 4.6. The entire test procedure is described in Section 4.2.2. The results were graphically shown in Figures 5.16 - 5.21 where the stress and the resistance data are plotted as a function of tensile strain. Overlapping curves represent different replication samples.

In all cases, the resistance and the stress on test samples was increasing with strain until failure. The stress versus strain curves from replication samples overlap each other and show good consistency and reproducibility while the consistency and reproducibility for the resistance versus strain curves from replication samples improves as the graphite powder concentration increases. The resistance scatter is the strongest with graphite concentration of $\sim 8 \%$.

The strain sensitivity of a sensor can be defined as $S=\frac{d R / R}{\varepsilon} \approx \frac{\Delta R / R}{\varepsilon}$ 
Where $\mathrm{R}$ is the initial resistance when no strain is applied; $\Delta \mathrm{R}$ or $\mathrm{dR}$ is the change in resistance in the sample when subjected to a strain of $\varepsilon$. From the Figures 5.16-5.21 and the other tension test results we have clearly observed that there is a linear relationship between stress and strain upto a strain value of $0.5 \%$. So the sensitivity of the sensor is computed in this region taking the strain to be $0.5 \%$ instead of taking the final strain to failure. In order to use as a sensor, the material needs to demonstrate as high sensitivity as possible. The sensitivity ratio or else known as guage factor is also listed in Table 5.6 for all samples.

stress and resistance versus strain

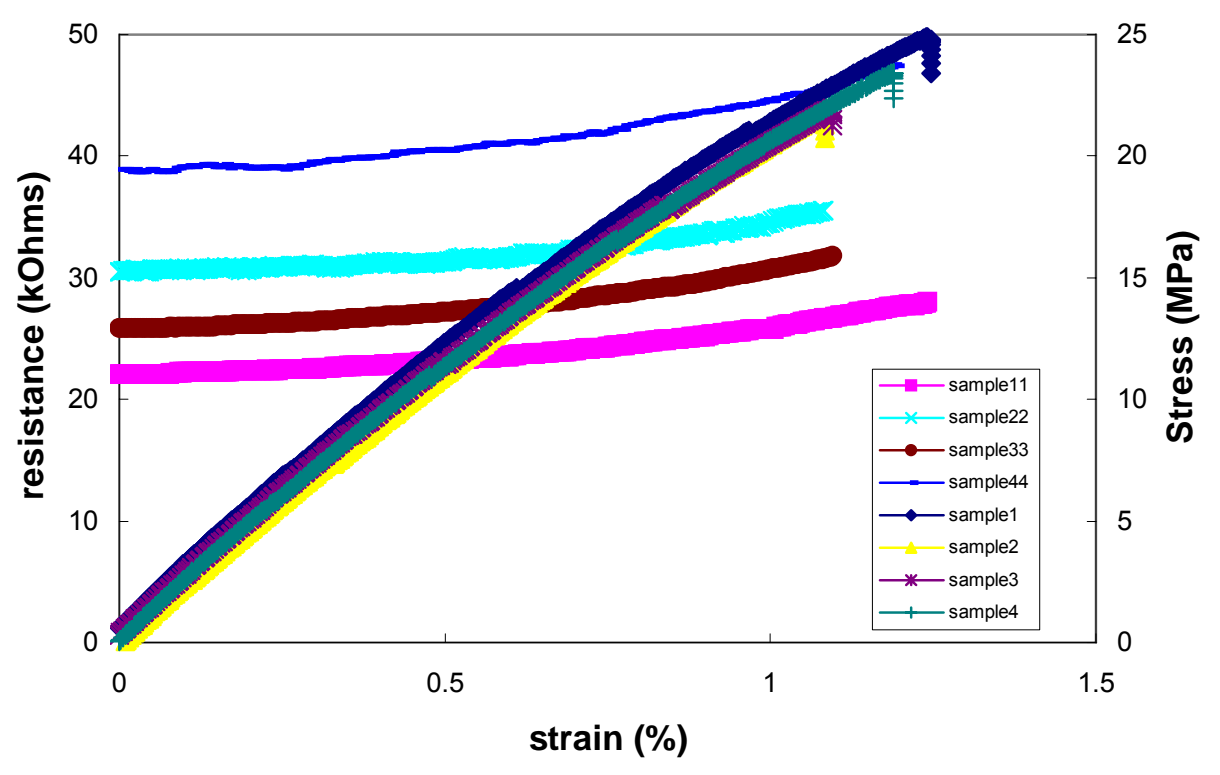

Figure 5.16 Stress and resistance w.r.t. strain for $8 \%$ graphite/vinyl ester samples 
Stress and resistance versus strain

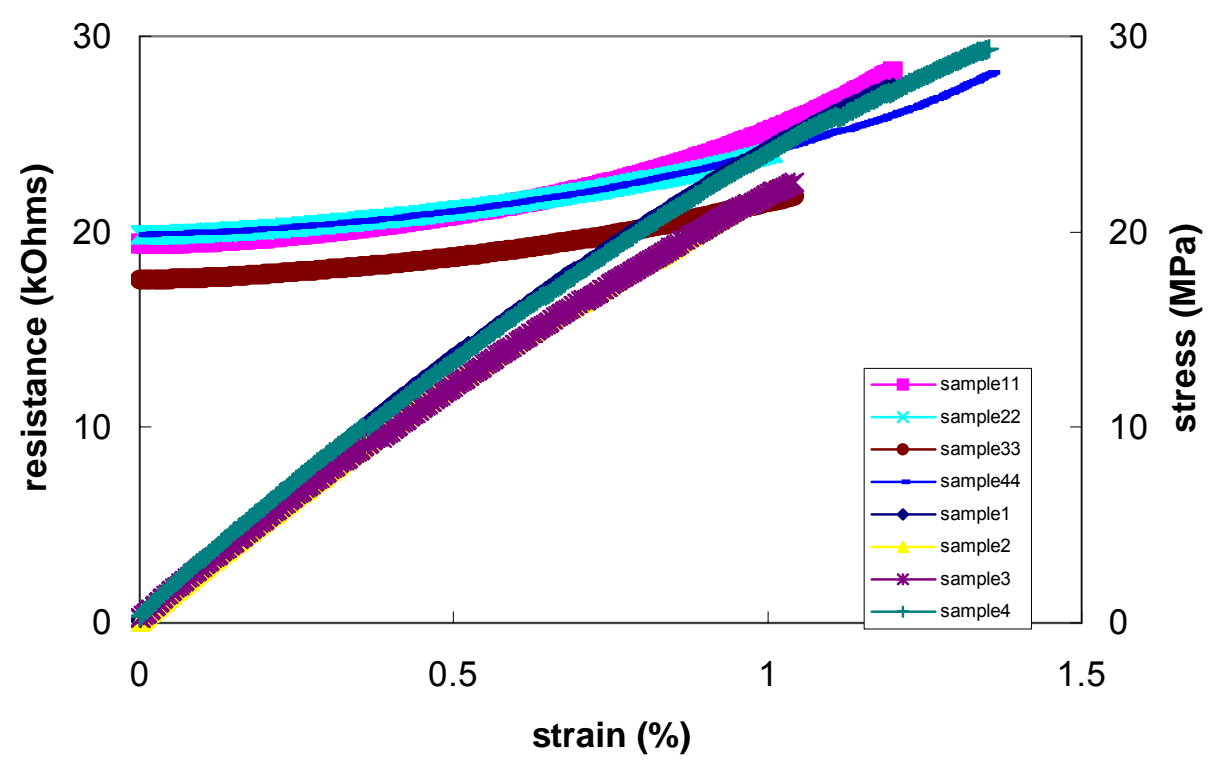

Figure 5.17 Stress and resistance w.r.t. strain for $10 \%$ graphite/vinyl ester samples Stress and resistance versus strain

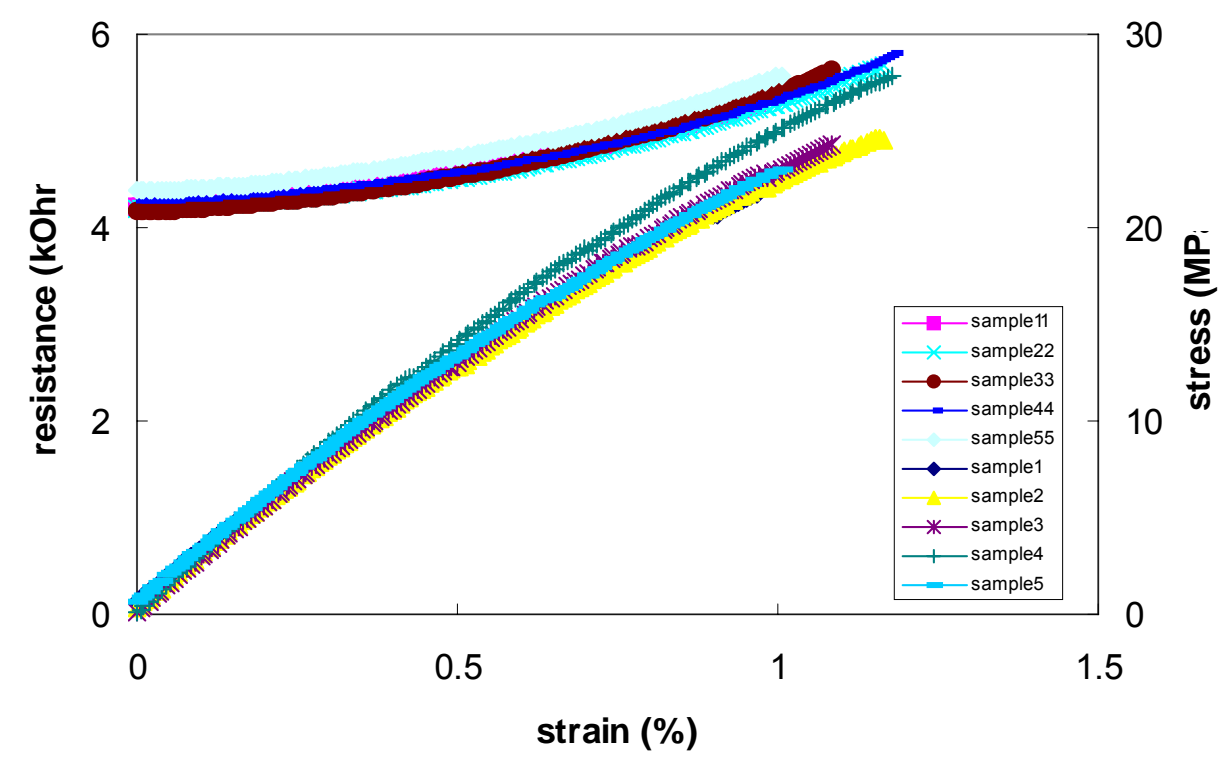

Figure 5.18 Stress and resistance w.r.t. strain for 12\% graphite/vinyl ester samples 
stress and resistance versus strain

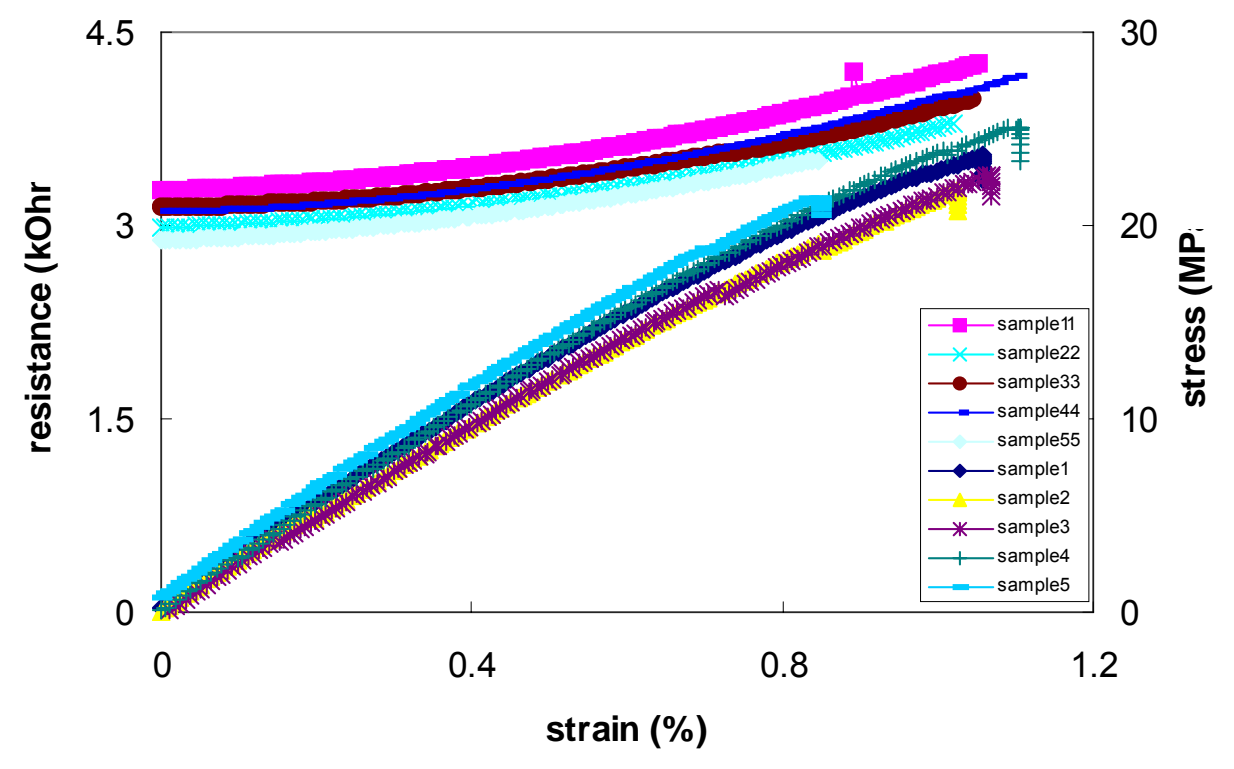

Figure 5.19 Stress and resistance w.r.t. strain for 14\% graphite/vinyl ester samples stress and resistance versus strain

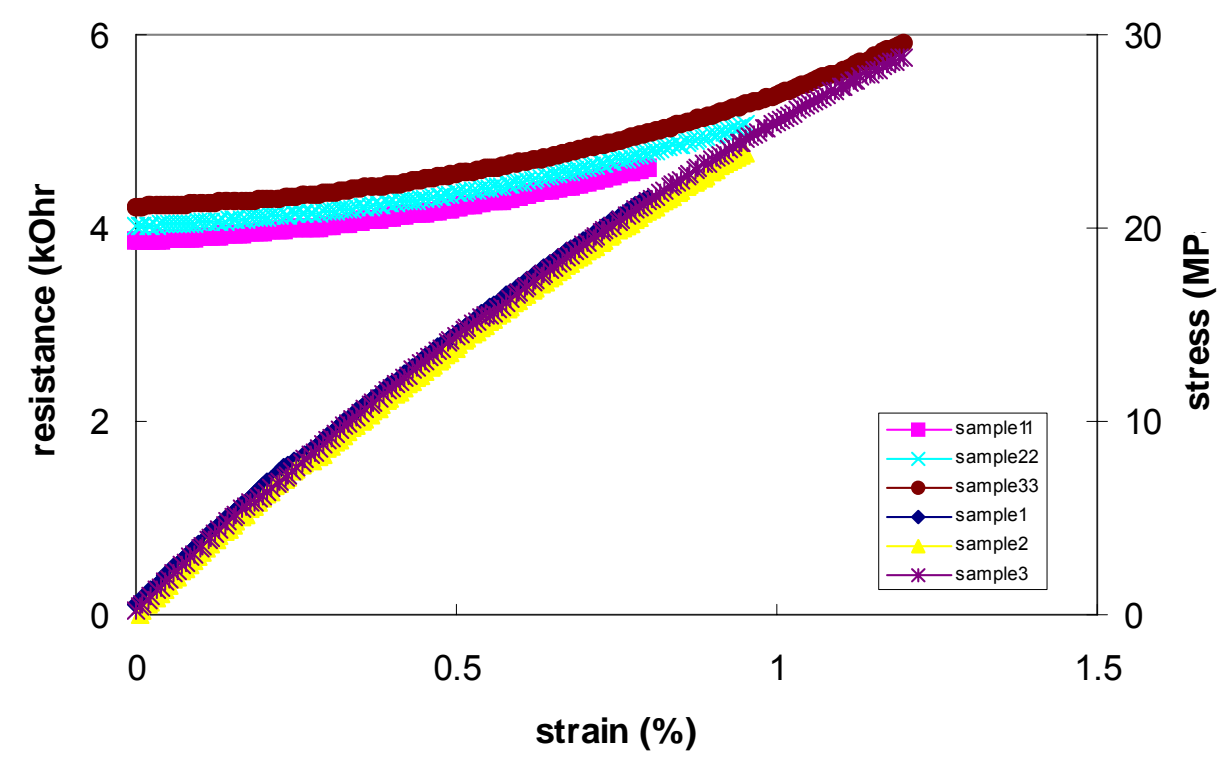

Figure 5.20 Stress and resistance w.r.t. strain for 15\% graphite/vinyl ester samples 


\section{stress and resistance versus strain}

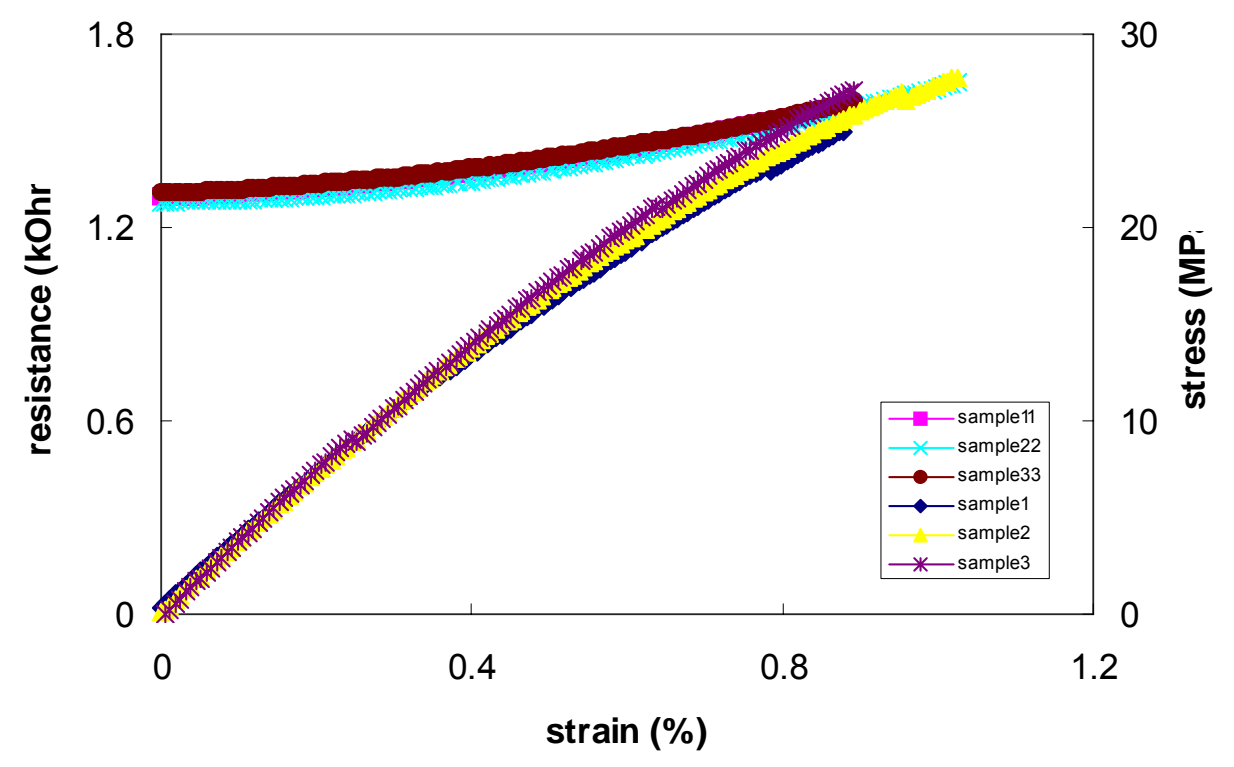

Figure 5.21 Stress and resistance w.r.t. strain for $20 \%$ graphite/vinyl ester samples

The result indicates that $8 \%$ to $10 \%$ graphite in vinyl ester samples have lower sensitivity ratios when compared to other graphite powder concentrations. A general trend appears to be that the change in resistance increases with decreasing in the graphite powder concentration as seen in Table 5.6. This can be explained as follows. Graphite powder forms conductive channels inside the vinyl ester matrix. If there are more graphite powder particles in the matrix, the particles will be more closely packed. Increase in resistance can be attributed to the separation of graphite particles from each other. If the particles are loosely packed at lower graphite concentrations, it will be easier to separate them, leading to a larger change in resistance. However, if the graphite concentration is too low as in the case of $8 \%$, the initial resistance becomes large which also depresses the sensitivity. The variation of gage factor with concentration of graphite powder is shown in Figure 5.22. 
Table 5.6 Change in resistance under tension of graphite /vinyl ester samples

\begin{tabular}{|c|c|c|c|c|c|}
\hline $\begin{array}{l}\text { Graphite } \\
\text { concentration, } \\
\%\end{array}$ & $\begin{array}{l}\text { Sample } \\
\#\end{array}$ & $\begin{array}{c}\text { Initial } \\
\text { resistance, } \\
\text { R (kOhms) }\end{array}$ & $\begin{array}{c}\text { Change in } \\
\text { resistance } \\
, \Delta \mathrm{R} \\
(\mathrm{kOhms})\end{array}$ & $\Delta \mathrm{R} / \mathrm{R}$ & $\begin{array}{l}\text { Guage factor } \\
(\Delta \mathrm{R} / \mathrm{R} / \mathrm{strain})\end{array}$ \\
\hline 20 & 1 & 1.26 & 0.104 & 0.08254 & 16.50 \\
\hline 20 & 2 & 1.331 & 0.111 & 0.083396 & 16.67 \\
\hline 20 & 3 & 1.486 & 0.109 & 0.073351 & 14.67 \\
\hline 20 & Average & $1.36 \pm 0.12$ & 0.108 & 0.079762 & 15.95 \\
\hline 15 & 1 & 4.26 & 0.35 & 0.08216 & 16.43 \\
\hline 15 & 2 & 4.05 & 0.33 & 0.081481 & 16.29 \\
\hline 15 & 3 & 4.02 & 0.34 & 0.084577 & 16.91 \\
\hline 15 & Average & $4.11 \pm 0.13$ & 0.34 & 0.082739 & 16.54 \\
\hline 14 & 1 & 3.332 & 0.226 & 0.067827 & 13.56 \\
\hline 14 & 2 & 2.999 & 0.263 & 0.087696 & 17.53 \\
\hline 14 & 3 & 3.24 & 0.267 & 0.082407 & 16.48 \\
\hline 14 & 4 & 3.003 & 0.24 & 0.07992 & 15.98 \\
\hline 14 & 5 & 3.334 & 0.265 & 0.079484 & 15.89 \\
\hline 14 & Average & $\begin{array}{c}3.182 \pm \\
0.169\end{array}$ & 0.2522 & 0.079467 & 15.89 \\
\hline 12 & 1 & 4.44 & 0.31 & 0.06982 & 13.96 \\
\hline 12 & 2 & 4.38 & 0.35 & 0.079909 & 15.98 \\
\hline 12 & 3 & 4.16 & 0.37 & 0.088942 & 17.78 \\
\hline 12 & 4 & 4.19 & 0.33 & 0.078759 & 15.75 \\
\hline 12 & 5 & 4.45 & 0.36 & 0.080899 & 16.17 \\
\hline 12 & Average & $4.32 \pm 0.14$ & 0.344 & 0.079666 & 15.93 \\
\hline 10 & 1 & 21.26 & 1.26 & 0.059266 & 11.85 \\
\hline 10 & 2 & 19.23 & 1.52 & 0.079043 & 15.80 \\
\hline 10 & 3 & 16.89 & 1.18 & 0.069864 & 13.97 \\
\hline 10 & 4 & 24.59 & 1.2 & 0.0488 & 9.76 \\
\hline 10 & Average & $\begin{array}{c}20.49 \pm \\
3.26\end{array}$ & 1.29 & 0.064243 & 12.84 \\
\hline 8 & 1 & 24.02 & 1.14 & 0.04746 & 9.49 \\
\hline 8 & 2 & 37.4 & 1.6 & 0.042781 & 8.55 \\
\hline 8 & 3 & 26.8 & 1.37 & 0.051119 & 10.22 \\
\hline 8 & 4 & 36.69 & 0.82 & 0.022349 & 4.46 \\
\hline 8 & Average & $\begin{array}{c}31.23 \pm \\
6.82\end{array}$ & 1.2325 & 0.040928 & 8.18 \\
\hline
\end{tabular}


variation of Gauge factor with graphite concentration

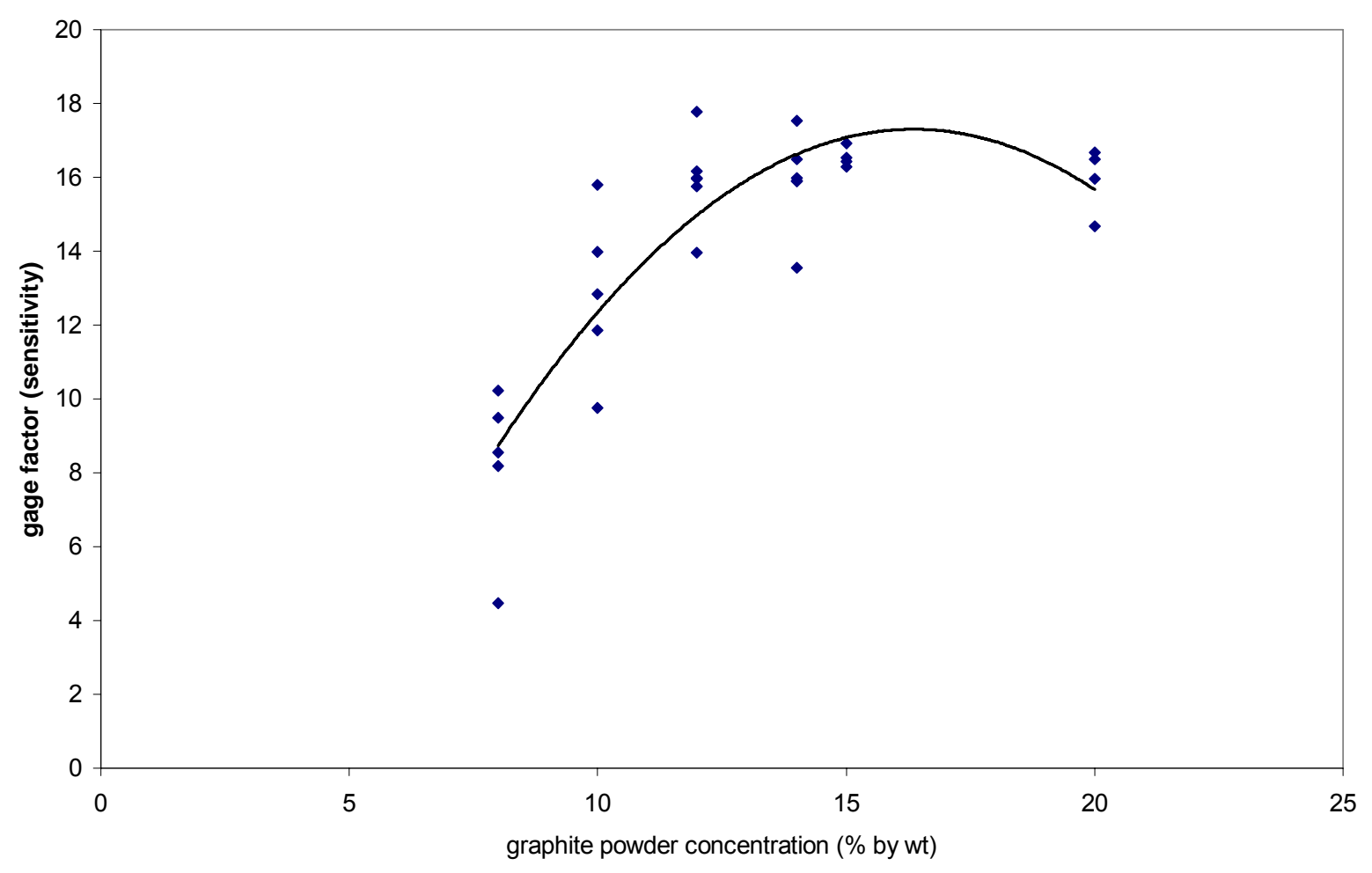

Figure 5.22 Variation of gage factor w.r.t graphite powder concentration

It can be seen clearly from Figure 5.22 that the sensitivity of the sensor is maximum at $\sim 12 \%$ by weight of graphite. The gage factor of the sensor is a function of change in resistance as well as the initial resistance (resistance of the sample with no applied strain). The sensitivity ratio also depends on the particle size. Smaller the particle size, greater its surface area will be per unit weight concentration. This surface area is proportional to the number of conductive channels. Smaller the particle size, lower the resistance. In order for the change in resistance to be high, the particle size has to be optimized. The sensitivity ratio is also a function of the polymer matrix used. The more ductile a polymer, the more strain it gives upon failure. Higher the resin's elongation to failure, the greater the change in resistance will be, leading to a larger sensitivity ratio. There are many other parameters affecting the sensitivity ratio, such as mixing efficiency, that will also be explored. 


\subsubsection{Effect of particle sizes in Hetron 922}

In order to study the effect of particle sizes on both the mechanical and electrical properties, the samples were cast at $10 \%$ by weight of graphite powder in vinyl ester (Hetron) resin. Different sizes of powders were used as described in Table 3.1.

Figures 5.23 -5.26 graphically show the integral results of the mechanical and electrical tests for the composites made of graphite powders of different particle sizes. In these plots, the xaxis represents strain and the major y-axis (left side) represents electric resistance of the sample, while the secondary y-axis (right side) represents tensile stress. Multiple replications were carried out for each particle size and all the data were presented so as to observe the reproducibility of the results.

$10 \%$ of GP44-B in Vinyl Ester

Relationship between stress \& resistance w.r.t strain

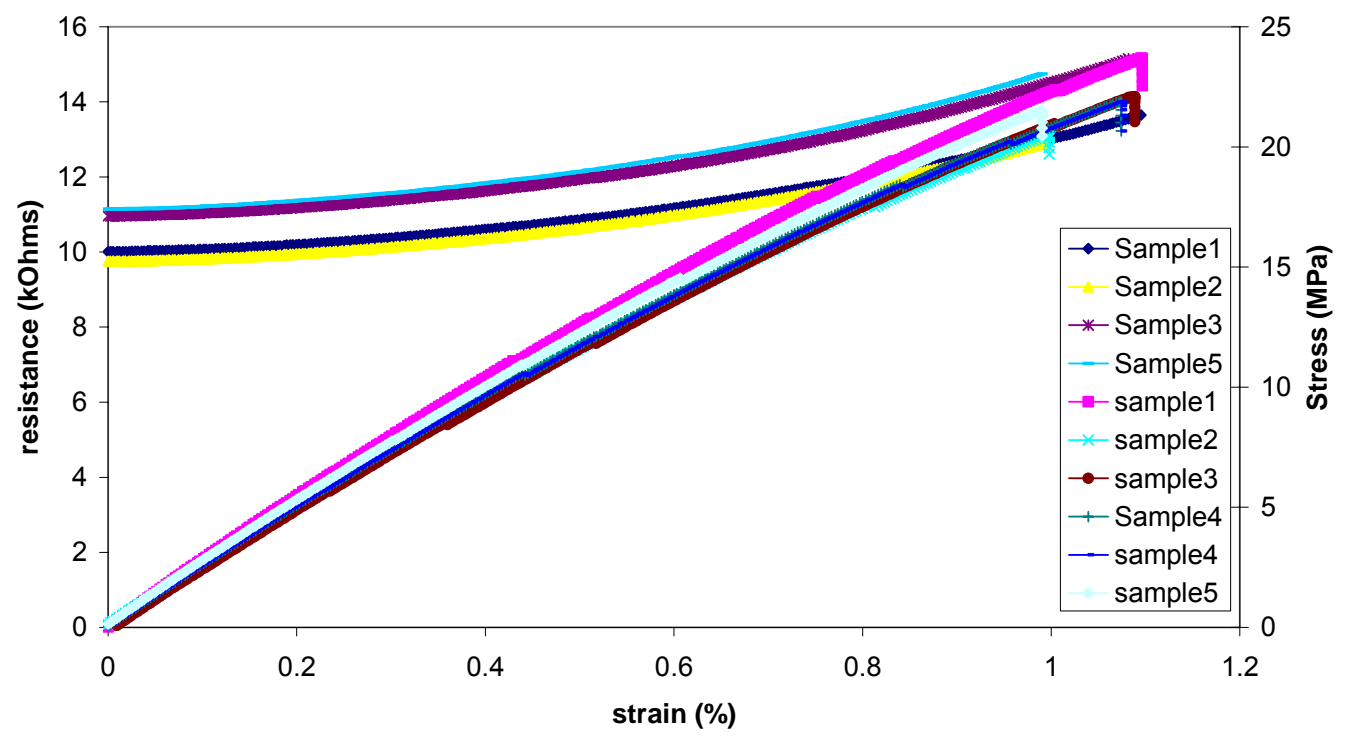

Figure 5.23 Stress \& resistance vs strain for 10\% GP44-B in Vinyl ester 
$10 \%$ of GP55-B in Vinyl ester

Relationship between resistance \& stress w.r.t. strain

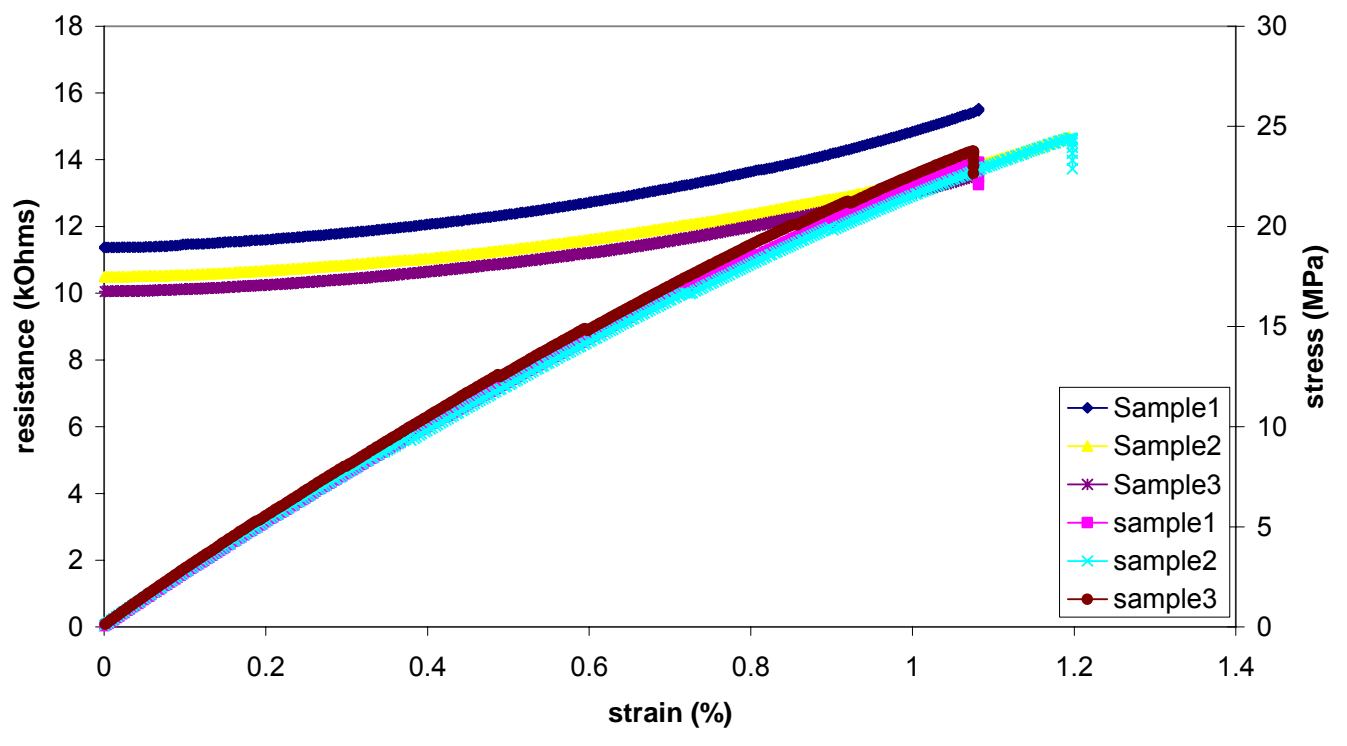

Figure 5.24 Stress \& resistance w.r.t. strain for 10\% GP55-B in Vinyl ester

10\% GS75-E in Vinyl Ester

Relationship between resistance \& strain w.r.t strain

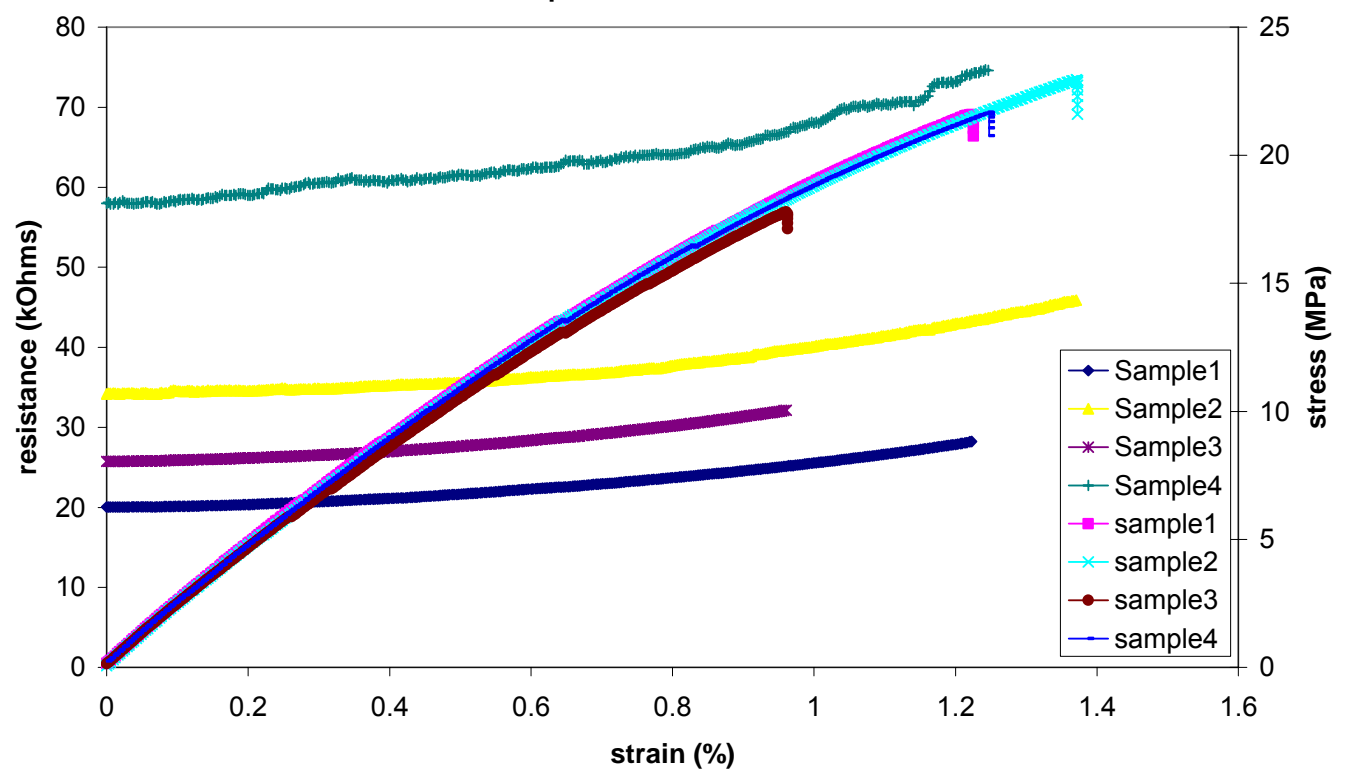

Figure 5.25 Stress and resistance w.r.t. strain for 10\% GS75-E in Vinyl ester 


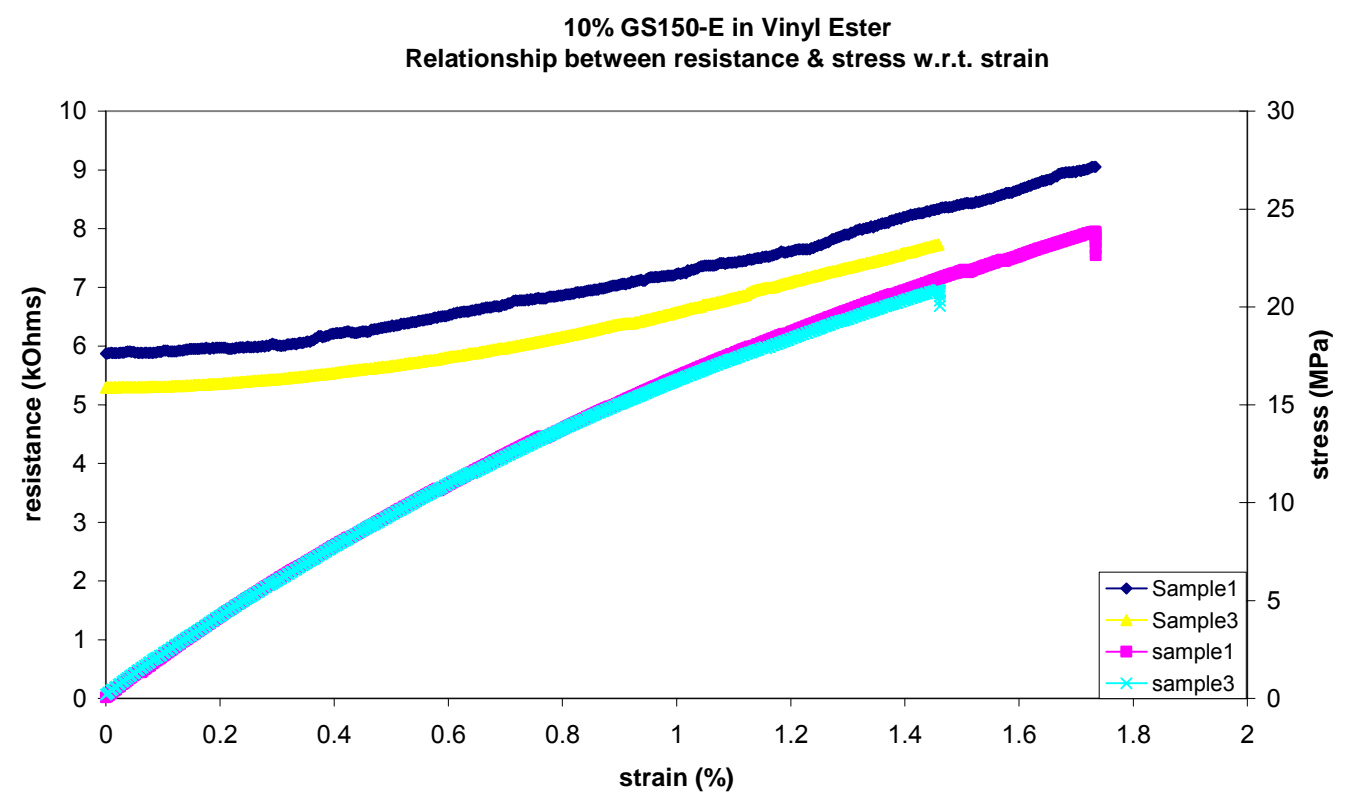

Figure 5.26 Stress and resistance w.r.t strain for 10\% GS150-E in Vinyl ester

From Figures 5.23-26, it can be observed that the resistance increases monotonically with strain until failure. The stress versus strain curves of replication samples overlap with each other and show good consistency for all composites with different particle sizes. However, the curves of resistance versus strain show good consistency for the composites with GP44-B and GP55-B, but a scatter for the composites with GS75-E. There is an anomaly in the GS150-E/vinyl ester composites where the resistance was lower than that of GP44-B and GP55-B systems. This may be due to the fact that the huge GS150-E graphite particles might have formed a conductive chain due to their humongous size when compared to other particles, resulting in the lowest resistance. It could also be attributed to GS150-E's different surface properties.

A summary of tension and electrical test results for the conducting composites with different graphite particle sizes at a concentration of $10 \mathrm{wt} \%$ is listed in Table 5.7. It turns out that the composite with GP44-B graphite powder has the highest sensitivity among the composites of four different particle sizes. Figure 5.27 gives a the relationship between particle size and the sensitivity of the sensor.

It can be seen from Figure 5.28 that the final elongation to failure of the conducting composite samples increased with increase in the particle size of the graphite powder dispersed 
in them. This can be explained as follows: since all the composite samples have the same graphite concentration by weight percentage in the vinyl ester resin, the sample with greater graphite particle size will have fewer particles, with the density of all the graphite particles being the same. A composite made of fillers of particle size 150 microns would have about 30 times less number of particles than that made of fillers of particle size 50 microns. Neat vinyl ester has an elongation to failure of about 5\%. Therefore, for the composite with GS150-E, the graphite particles are not able to deteriorate the ductility as much as those of smaller graphite particles such as the composite with GP44-B, as schematically shown in Figure 5.29. However, this explanation conflicts the observation that the composite with GS150-E has the lowest electrical resistance.

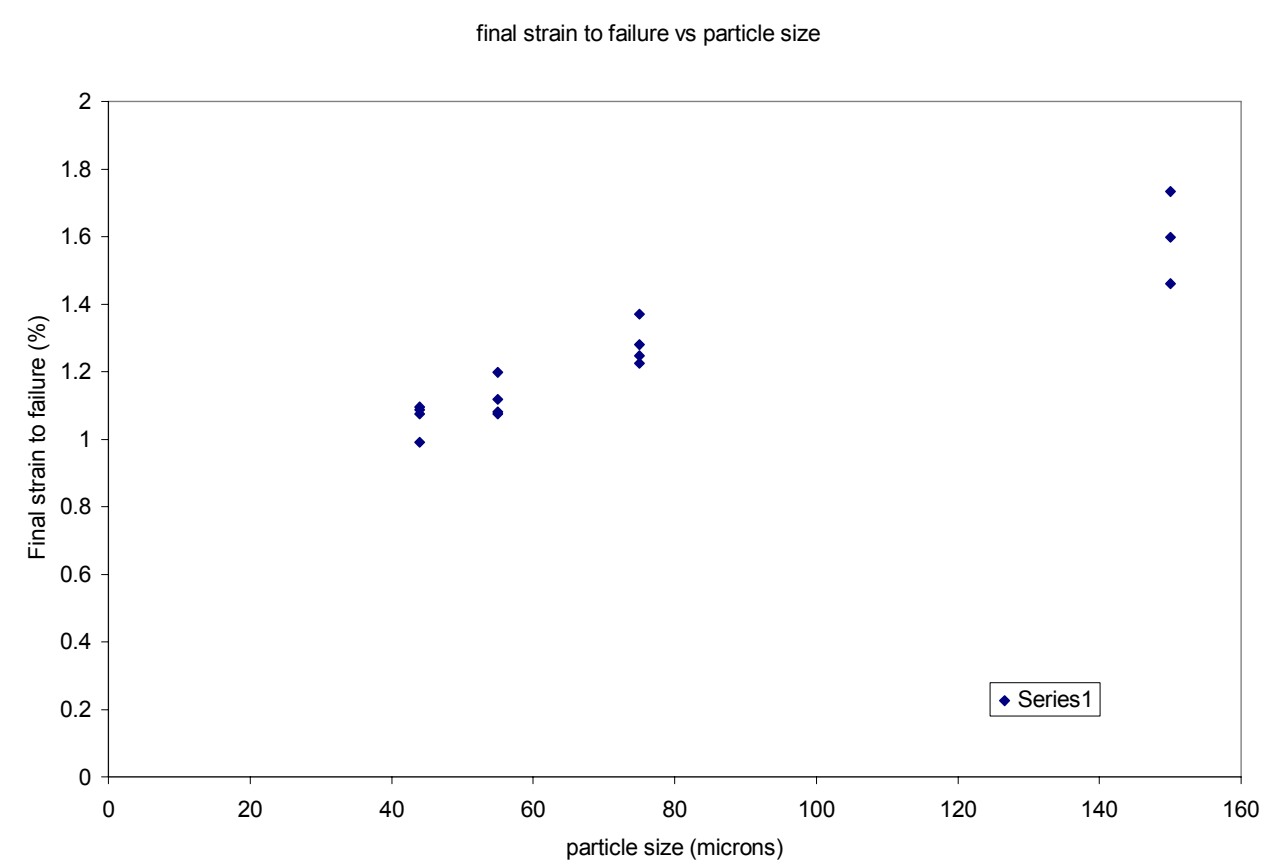

Figure 2.28 Final elongation to failure vs graphite particle size for $10 \%$ graphite concentration in Hetron 922

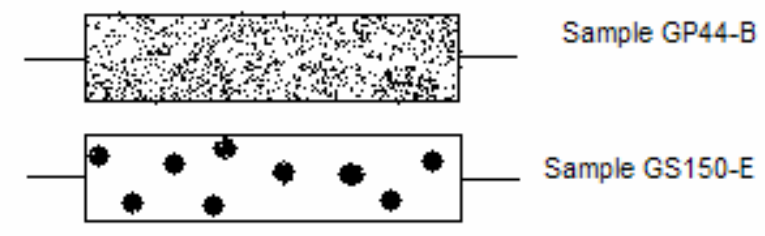

Figure 5.29 A schematic of graphite powder dispersion in the composites with graphite powder GP44-B \& GS150-E 
Table 5.7 Tension and electrical test results of conducting composites with different graphite particle sizes at a concentration of $10 \mathrm{wt} \%$

\begin{tabular}{|c|c|c|c|c|c|c|}
\hline & $\begin{array}{c}\text { Sample } \\
\text { replications }\end{array}$ & $\begin{array}{c}\text { Initial } \\
\text { resistance } \\
(\mathrm{kOhms})\end{array}$ & $\begin{array}{c}\text { Resistance } \\
\text { at } 0.5 \% \\
\text { strain } \\
(\mathrm{kOhms}) \\
\end{array}$ & $\begin{array}{l}\text { Change } \\
\text { in } \\
\text { resistance } \\
(\mathrm{kOhms})\end{array}$ & $\Delta \mathrm{R} / \mathrm{R}$ & $\begin{array}{c}\text { Sensitivity } \\
\text { (gage } \\
\text { factor) }\end{array}$ \\
\hline \multirow[b]{6}{*}{ GP44-B } & Sample \# 1 & 10.01 & 10.86 & 0.85 & 0.084915 & 16.98 \\
\hline & Sample \# 2 & 9.75 & 10.65 & 0.9 & 0.092308 & 18.46 \\
\hline & Sample \# 3 & 10.96 & 11.95 & 0.99 & 0.090328 & 18.06 \\
\hline & Sample \# 4 & 10.16 & 11.22 & 1.06 & 0.104331 & 20.86 \\
\hline & Sample \# 5 & 11.14 & 12.28 & 1.14 & 0.102334 & 20.46 \\
\hline & Mean & 10.4 & 11.392 & 0.988 & 0.094843 & 18.96 \\
\hline \multirow[b]{4}{*}{ GP55-B } & Sample \# 1 & 11.37 & 12.37 & 1 & 0.087951 & 17.59 \\
\hline & Sample \# 2 & 10.49 & 11.3 & 0.81 & 0.077216 & 15.44 \\
\hline & Sample \# 4 & 10.05 & 10.9 & 0.85 & 0.084577 & 16.91 \\
\hline & Mean & 10.64 & 11.523333 & 0.886667 & 0.083248 & 16.64 \\
\hline \multirow[b]{5}{*}{ GS75-E } & Sample \# 1 & 20.03 & 21.65 & 1.62 & 0.080879 & 16.17 \\
\hline & Sample \# 2 & 34.17 & 35.58 & 1.41 & 0.041264 & 8.25 \\
\hline & Sample \# 3 & 25.74 & 27.64 & 1.9 & 0.073815 & 14.76 \\
\hline & Sample \# 4 & 58 & 61.1 & 3.1 & 0.053448 & 10.68 \\
\hline & Mean & 34.485 & 36.4925 & 2.0075 & 0.062352 & 12.47 \\
\hline \multirow{3}{*}{$\begin{array}{l}\text { GS150- } \\
\text { E }\end{array}$} & Sample \# 1 & 5.87 & 6.35 & 0.48 & 0.081772 & 16.35 \\
\hline & Sample \# 2 & 5.29 & 5.67 & 0.38 & 0.071834 & 14.36 \\
\hline & Mean & 5.58 & 6.01 & 0.43 & 0.076803 & 15.36 \\
\hline
\end{tabular}

variation of gage factor vs particle size

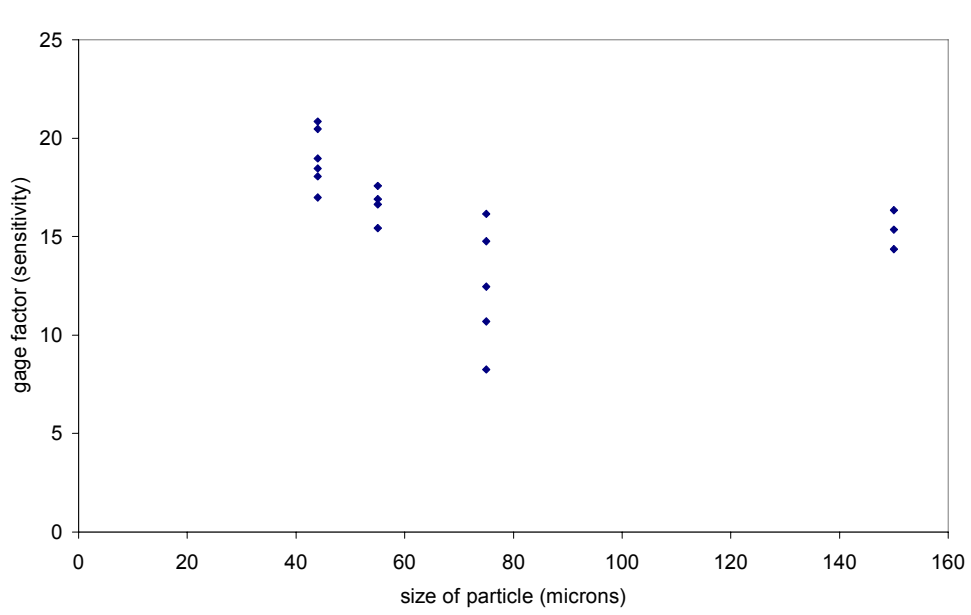

Figure 5.27 Variation of gage factor with particle size in Hetron 922 vinyl ester 
From figures 5.22, 5.28 and 5.27, we can choose the particle size and particle concentration of the graphite powders that will give us the best sensitivity and a better elongation to failure for Hetron 922 vinyl ester resin.

\subsubsection{A comparison between vinyl ester based and epoxy based samples}

A typical stress versus strain curve was shown in Figure 5.30 for $10 \mathrm{wt} \%$ graphite in epoxy resin along with $10 \mathrm{wt} \%$ graphite in vinyl ester. The result demonstrates a significant difference in elongation-to-failure between these two composites, with graphite/ epoxy showing about $30 \%$ strain to failure and graphite/ vinyl ester of about $1 \%$ strain to failure.

Ebond \& Vinyl ester with 10\% graphite powder (GP 44B) with a

loading rate of $.1 \mathrm{~mm} / \mathrm{min}$

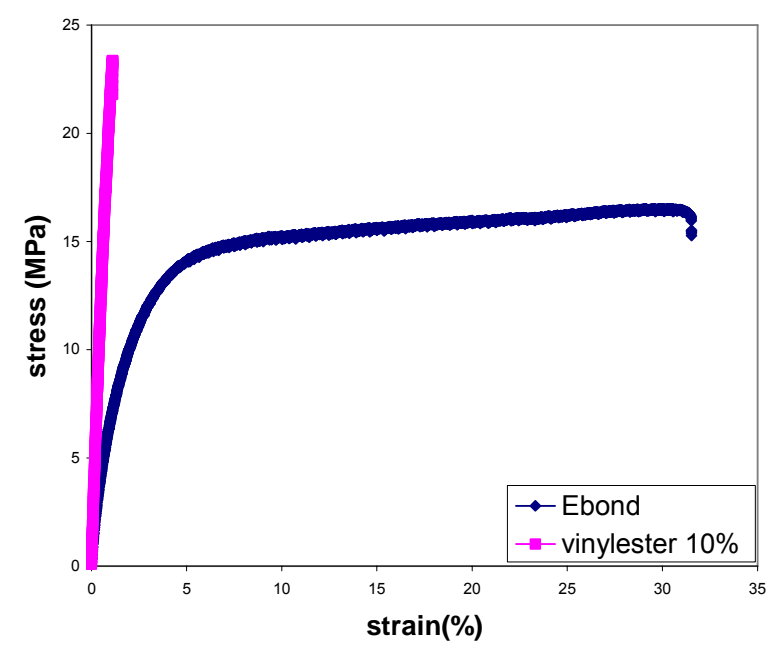

Figure 5.30 A comparison in stress versus strain curve between vinyl ester based and epoxy based samples

Therefore, a resin system is very much desired that will have properties intermediate to both the above resins, that is, a large elongation to failure and a semi-conducting property.

\subsubsection{Derakane 8084 based samples}

Derakane 8084 has better electric insulating property as Hetron 922 resin but has a larger elongation to failure, and thus appears to be a good candidate for formulating conductive composites. 
The stress versus strain plots are shown in Figures 5.31 and 5.32 respectively for Batch I and Batch II samples. Note that there is a slight difference in experimental set up between Batch I and Batch II samples. The $1 \mathrm{KN}$ load cell was selected for Batch I samples while 50KN load cell for Batch II samples. Therefore, experimental data in Figures 5.28 were limited to loads below $1 \mathrm{KN}$ for Batch I samples, and discussions hereafter are mainly based on data shown in Figures 5.29 of Batch II samples.

The results show that the tensile strength and failure strain generally decrease with increase in graphite concentration but the tensile stiffness increases with graphite concentration. The failure strain for Derakane 8084 based conducting composites is 2 to 4 times larger than those of Hetron 922 L25 based conducting composite samples. This is an important improvement.

stress strain behaviour of samples with different graphite concentrations (run I)

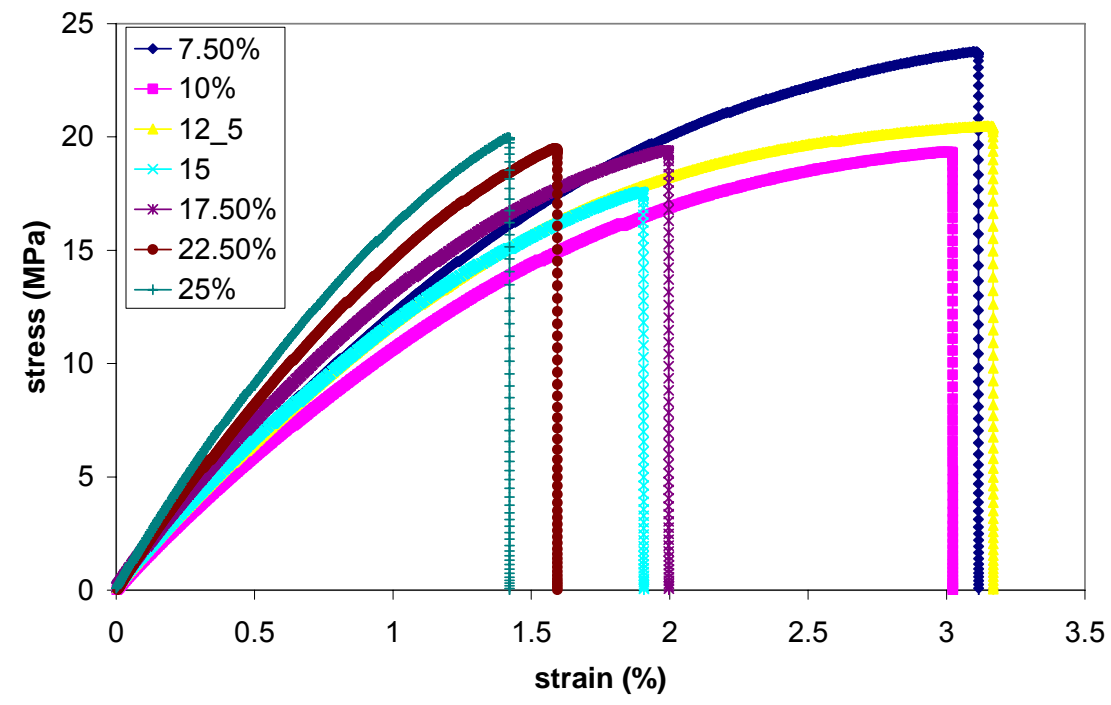

Figure 5.31 Stress versus strain curves for Batch I Derakane 8084 based composite samples with different graphite concentrations. 
variation of stress and strain for different graphite concentrations (run

II)

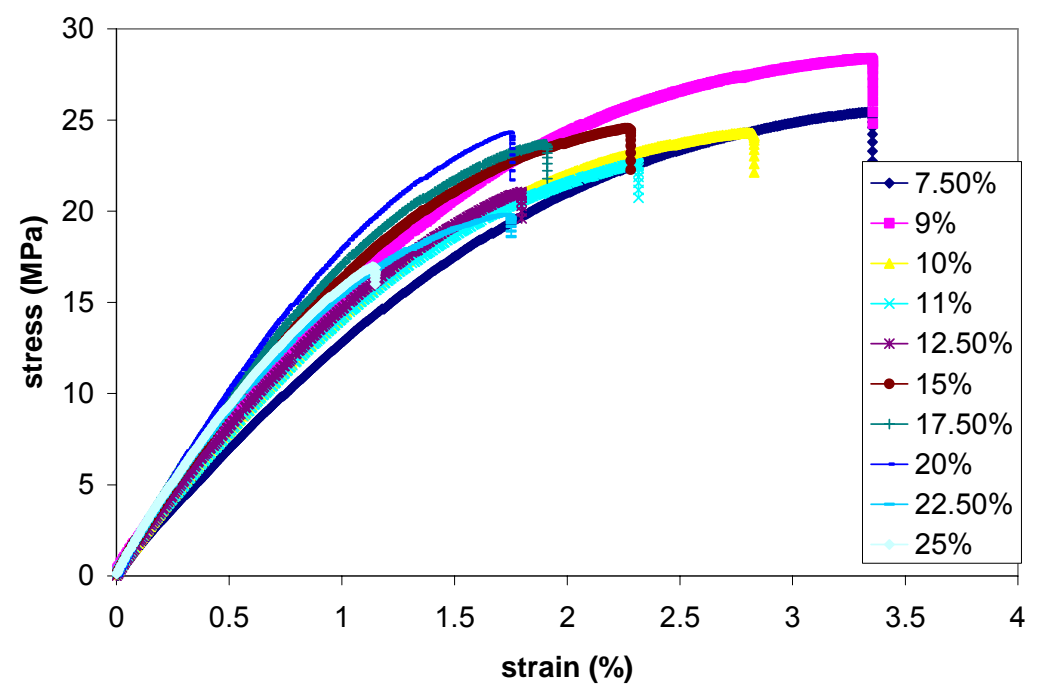

Figure 5.32 Stress versus strain curves for Batch II Derakane 8084 based composite samples with different graphite concentrations.

The stress and the resistance data as a function of tensile strain are plotted in Figures 5.33 to 5.42 for all Derakane 8084 based composite samples with graphite concentrations ranging from $7.5 \%$ to $25 \%$ by weight except $5 \%$ graphite sample that shows infinitely large resistance. As seen from those figures, a general trend is that the resistance first increases gradually with strain; as the strain further increases to a point where the sample begins to rupture, the resistance increases remarkably.

It has also been found that the variation of resistance with strain can be described well by fitting the data into a polynomial model. Data fit curves and corresponding equations for resistance versus strain plot are also shown in Figures 5.33 to 5.42. The fitting model can be expressed as follows:

$$
\mathrm{R}=\mathrm{R} 0+\mathrm{R} 1(\varepsilon)+\mathrm{R} 2(\varepsilon)^{2}+\mathrm{R} 3(\varepsilon)^{3}
$$

Where $\mathrm{R}$ is resistance, $\mathrm{R} 0$ is initial resistance, $\mathrm{R} 1, \mathrm{R} 2$, and $\mathrm{R} 3$ are coefficients, and $\varepsilon$ is train.

Sensitivity $\left(\mathrm{S}_{\mathrm{A}}\right)$, i.e identical to Gauge factor $(\mathrm{GF})$ for a strain gage, is defined as the ratio of fractional change in electrical resistance to the fractional change in length (strain), i.e.

$$
S_{A}=\frac{\Delta R / R}{\Delta L / L}=\frac{\Delta R / R}{\varepsilon}
$$


We are only interested in operating our sensor in the linear range (stress vs strain linear) instead of operating it in the entire range till failure. This is because we want the sensor to be in the elastic region so that it would come back to its original state after releasing the load on the sensor. Since we have taken $0-0.5 \%$ of strain as the linear region in the case of Hetron 922 based samples, we have taken the same range for Derakane 8084 based samples. We therefore model the resistance as a linear equation instead of modeling it as a polynomial with an order 3 as shown in Equation 5.2. Therefore the new equation for the resistance is as follows:

$$
R=R_{0}+R_{1}(\varepsilon \%)
$$

Where, $\mathrm{Z}$ is the slope of the resistance vs strain curve. $\mathrm{Z}$ tells us the rate of change of resistance with respect to strain. A sample graph in which the resistance is modeled as a linear equation is shown in Figure 5.43. The stress vs strain is linear in the region of $0-0.5 \%$ strain. The following equations were established:

$$
\begin{aligned}
& R-R_{0}=R_{1}(\varepsilon \%) \\
& R-R_{0}=\Delta R
\end{aligned}
$$

From Equations $5.5 \& 5.6$, we have

$$
\frac{\Delta R}{R_{0}}=\frac{R_{1}(\varepsilon \%)}{R_{0}}
$$

Therefore

$$
\frac{\Delta R / R_{0}}{\varepsilon}=100 \frac{R_{1}}{R_{0}}
$$

We know that the left hand side of equation 5.7 is the sensitivity (gauge factor) of the sensor

So, $\quad$ Gauge Factor $=$ Sensitivity $=100 \frac{R_{1}}{R_{0}}$

We can therefore conclude that the sensitivity of a conducting composite sensor in the linear range is directly proportional to the rate of change of resistance with strain and inversely proportional to the initial resistance. 
correlation of stress strain and change in resistance (7.5\%)

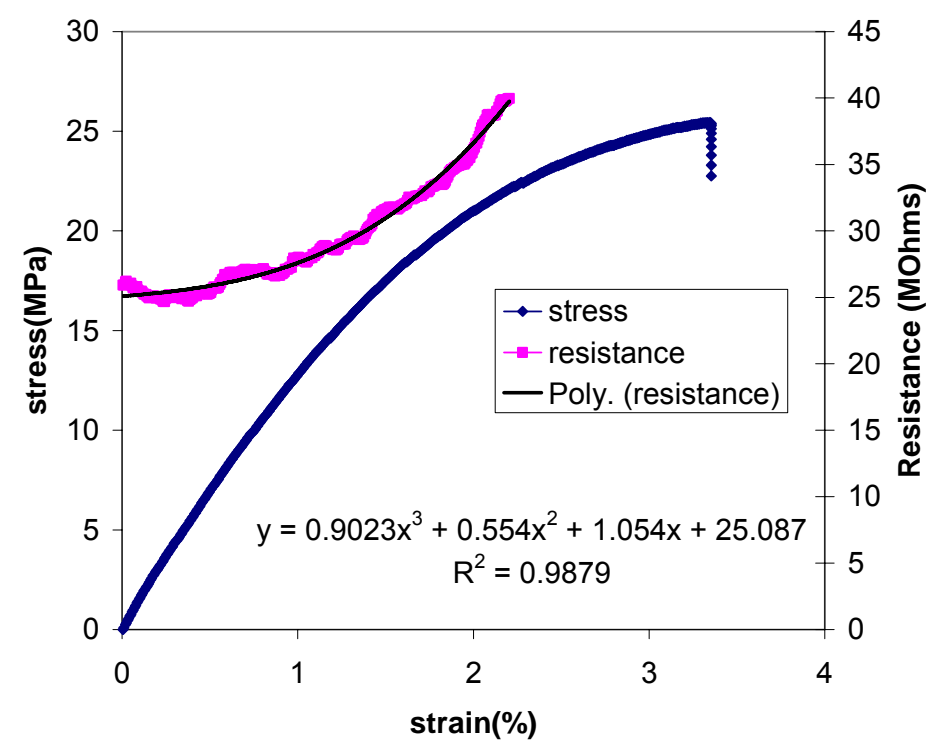

Figure 5.33 Tensile stress and electric resistance versus strain for $7.5 \%$ graphite in Derakane 8084 resin

stress vs resistance vs stress (9\%)

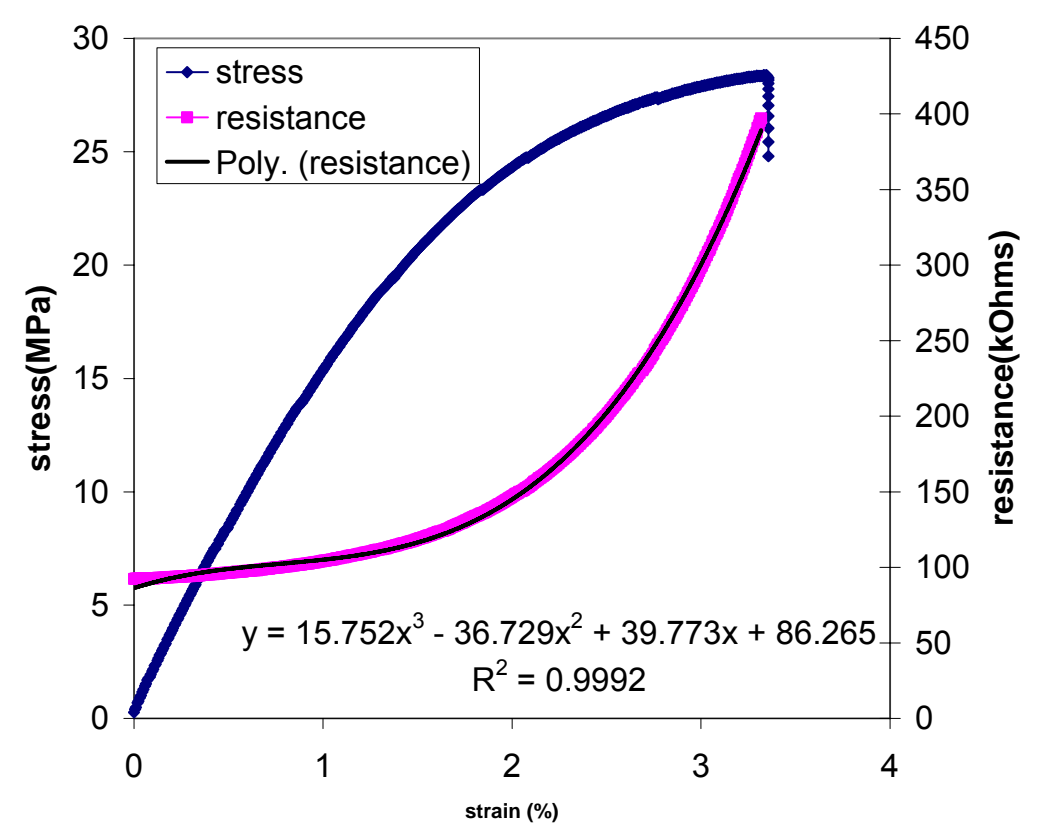

Figure 5.34 Tensile stress and electric resistance versus strain for 9\% graphite in Derakane 8084 resin 


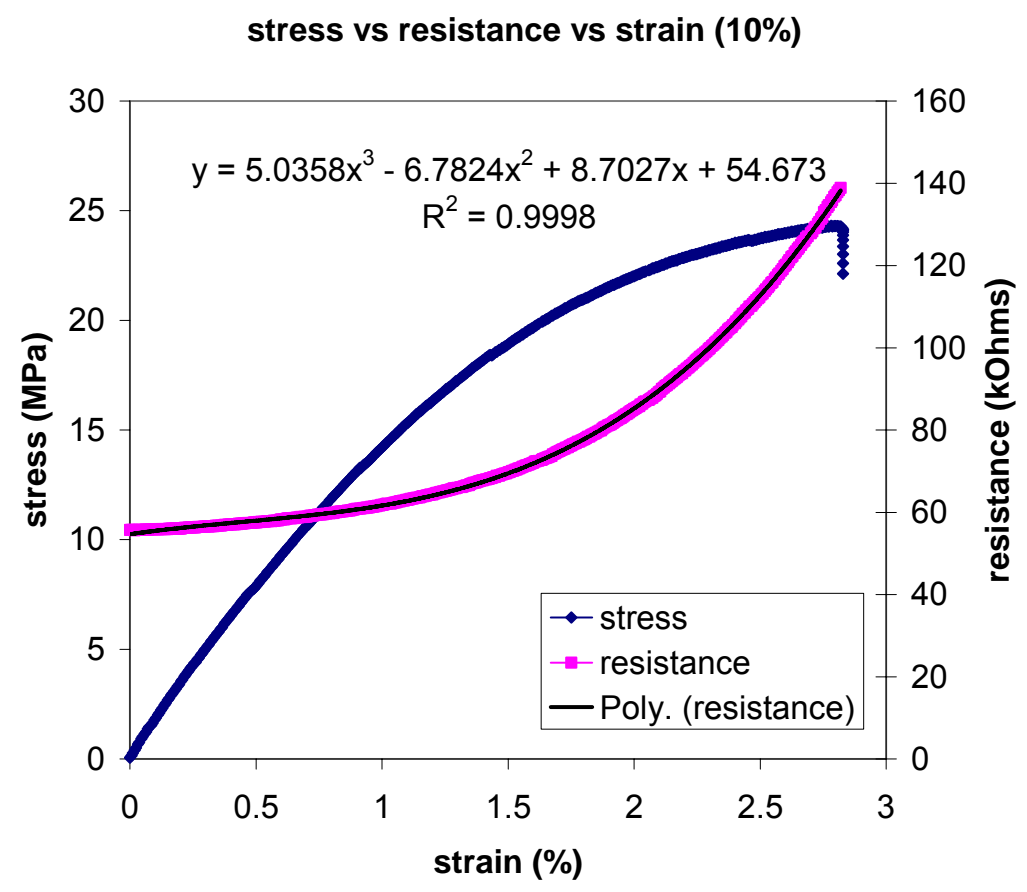

Figure 5.35 Tensile stress and electric resistance versus strain for $10 \%$ graphite in Derakane 8084 resin

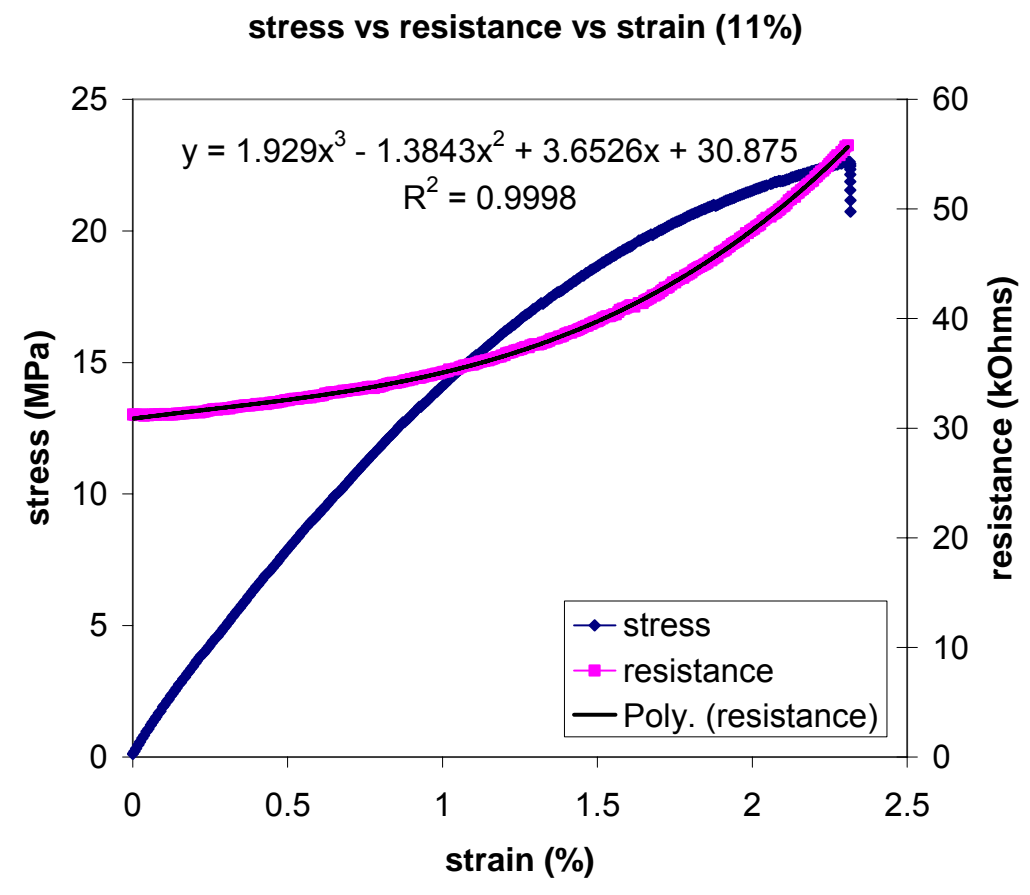

Figure 5.36 Tensile stress and electric resistance versus strain for $11 \%$ graphite in Derakane 8084 resin 
stress vs resistance vs strain (12.5\%)

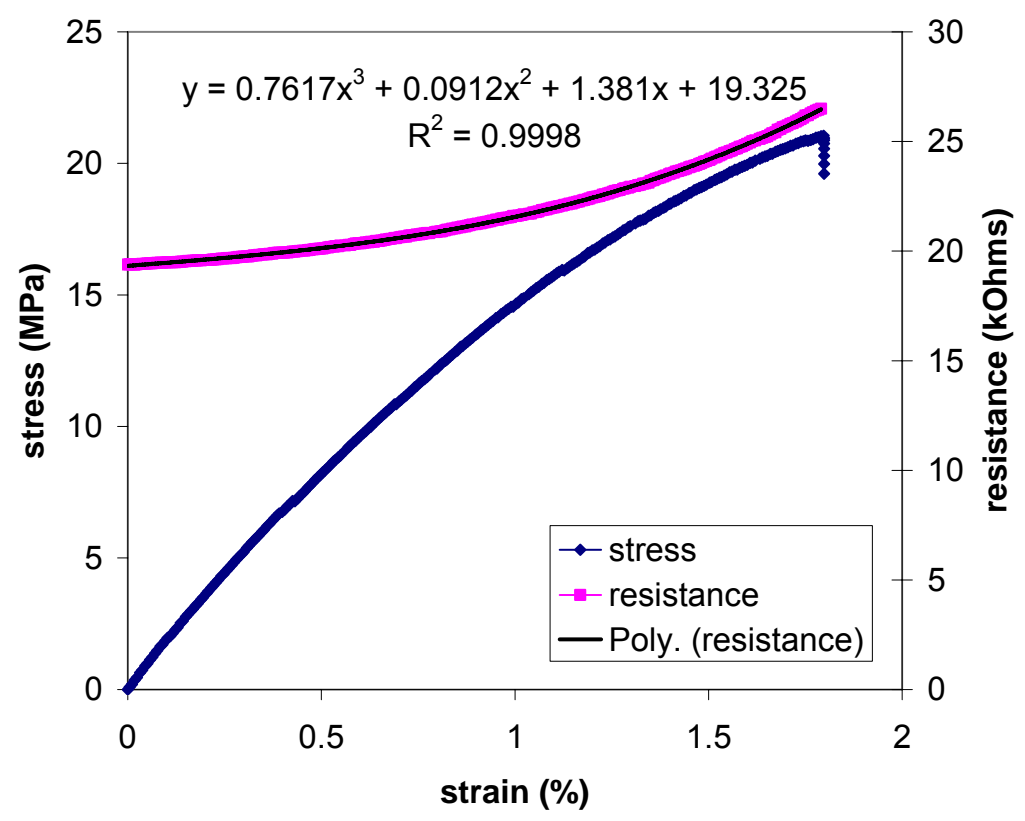

Figure 5.37 Tensile stress and electric resistance versus strain for $12.5 \%$ graphite in Derakane 8084 resin

stress vs resistance vs strain (15\%)

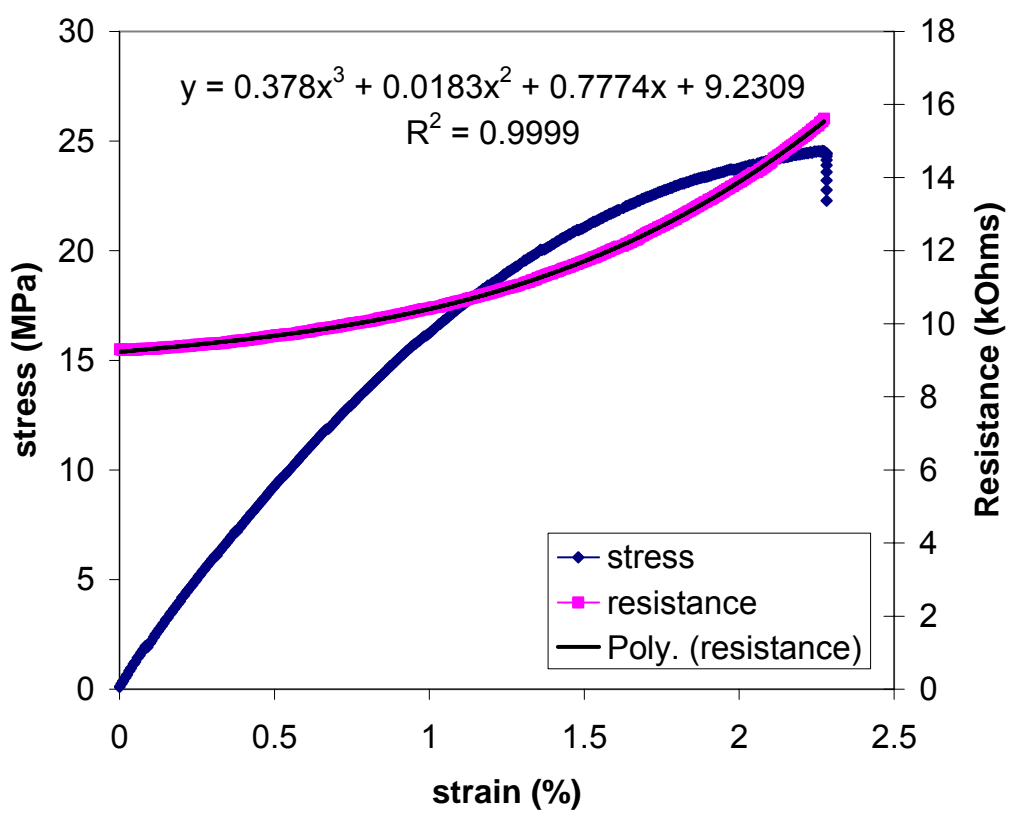

Figure 5.38 Tensile stress and electric resistance versus strain for $15 \%$ graphite in Derakane 8084 resin 
stress vs resistance vs strain $(\mathbf{1 7 . 5 \% )}$

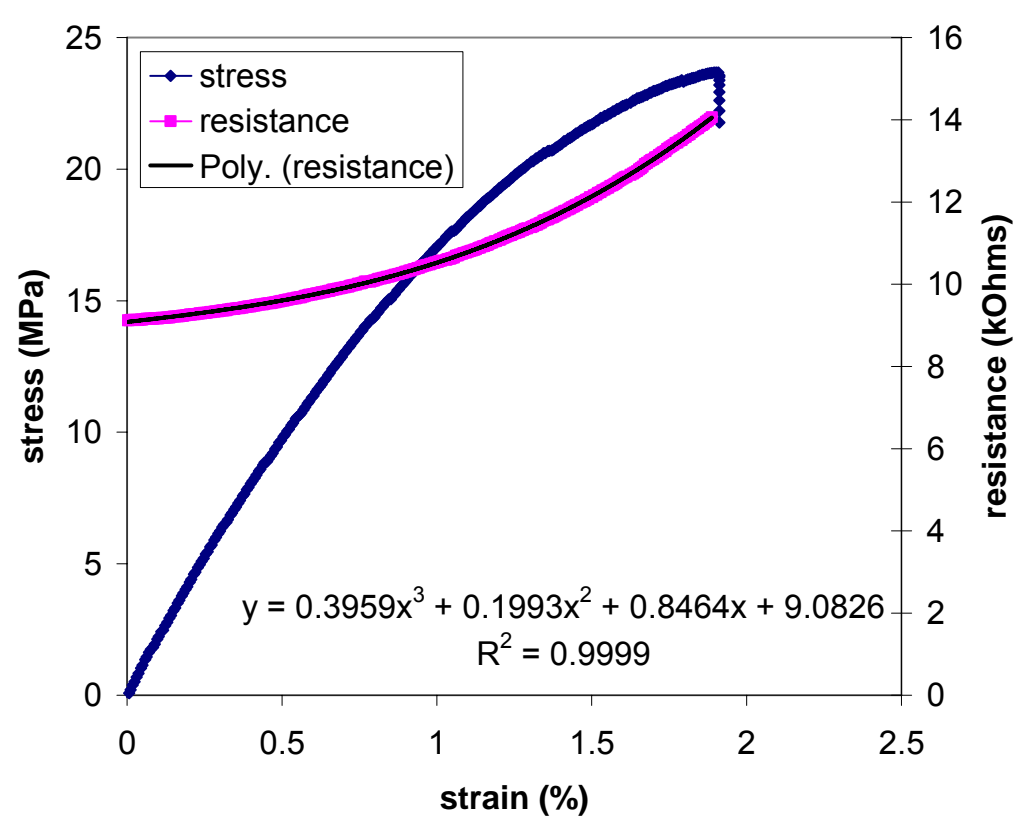

Figure 5.39 Tensile stress and electric resistance versus strain for $17.5 \%$ graphite in Derakane 8084 resin

stress vs resistance vs strain (20\%)

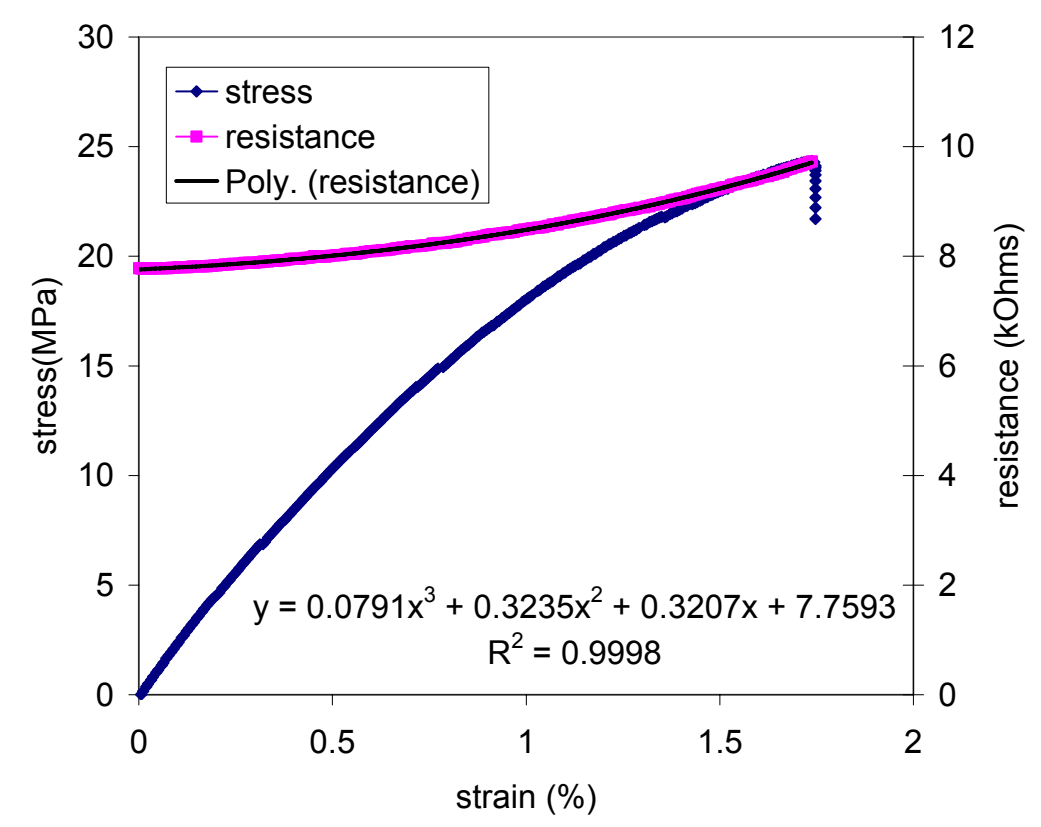

Figure 5.40 Tensile stress and electric resistance versus strain for $20 \%$ graphite in Derakane 8084 resin 
stress vs resistance vs strain $(22.5 \%)$

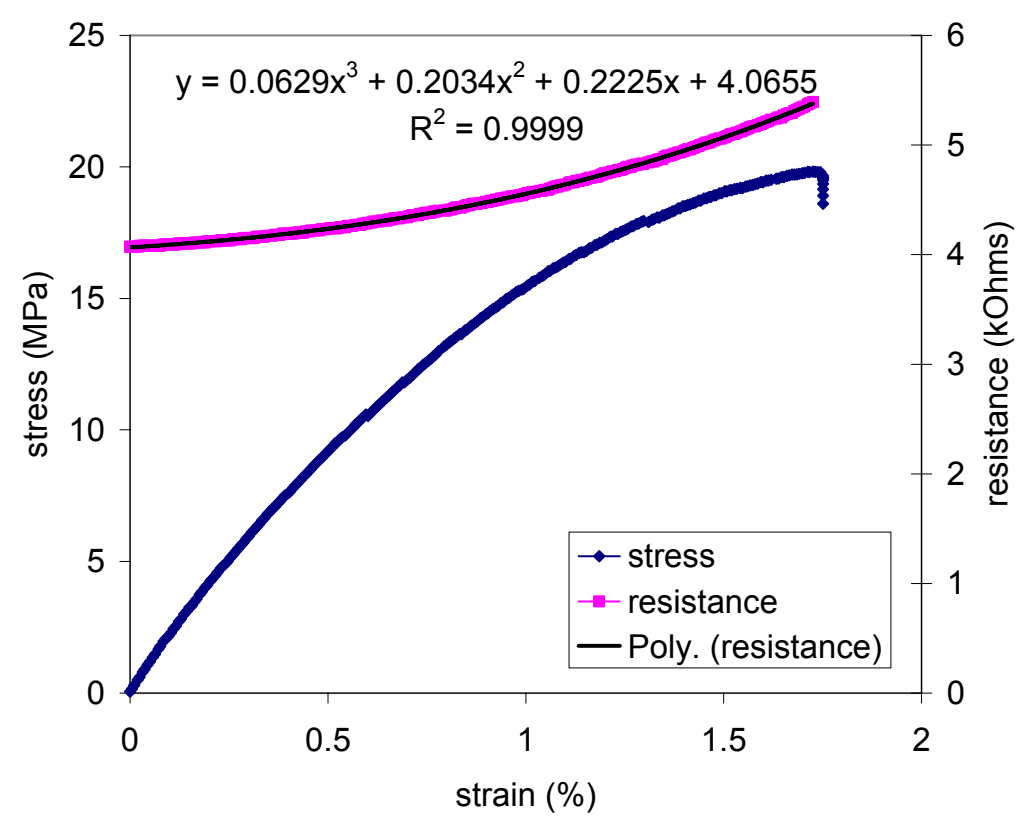

Figure 5.41 Tensile stress and electric resistance versus strain for $22.5 \%$ graphite in Derakane 8084 resin

\section{variation of resistance and stress with strain}

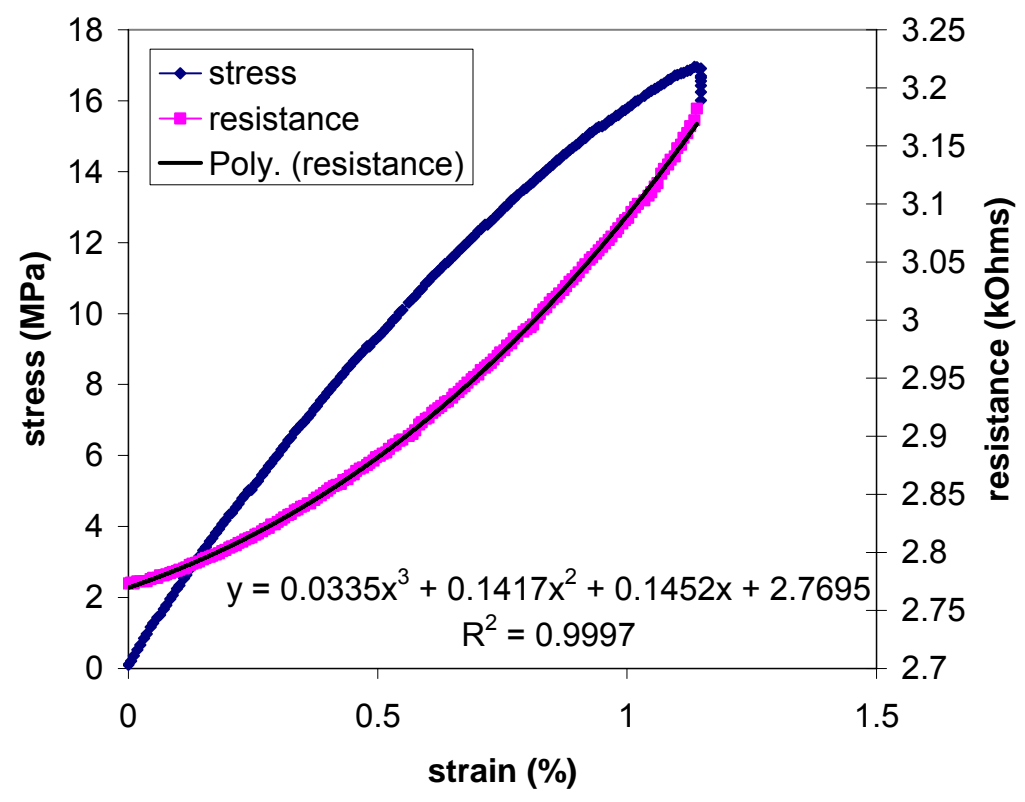

Figure 5.42 Tensile stress and electric resistance versus strain for $25 \%$ graphite in Derakane 8084 resin 


\section{Linear modelling of stress and resistance vs strain}

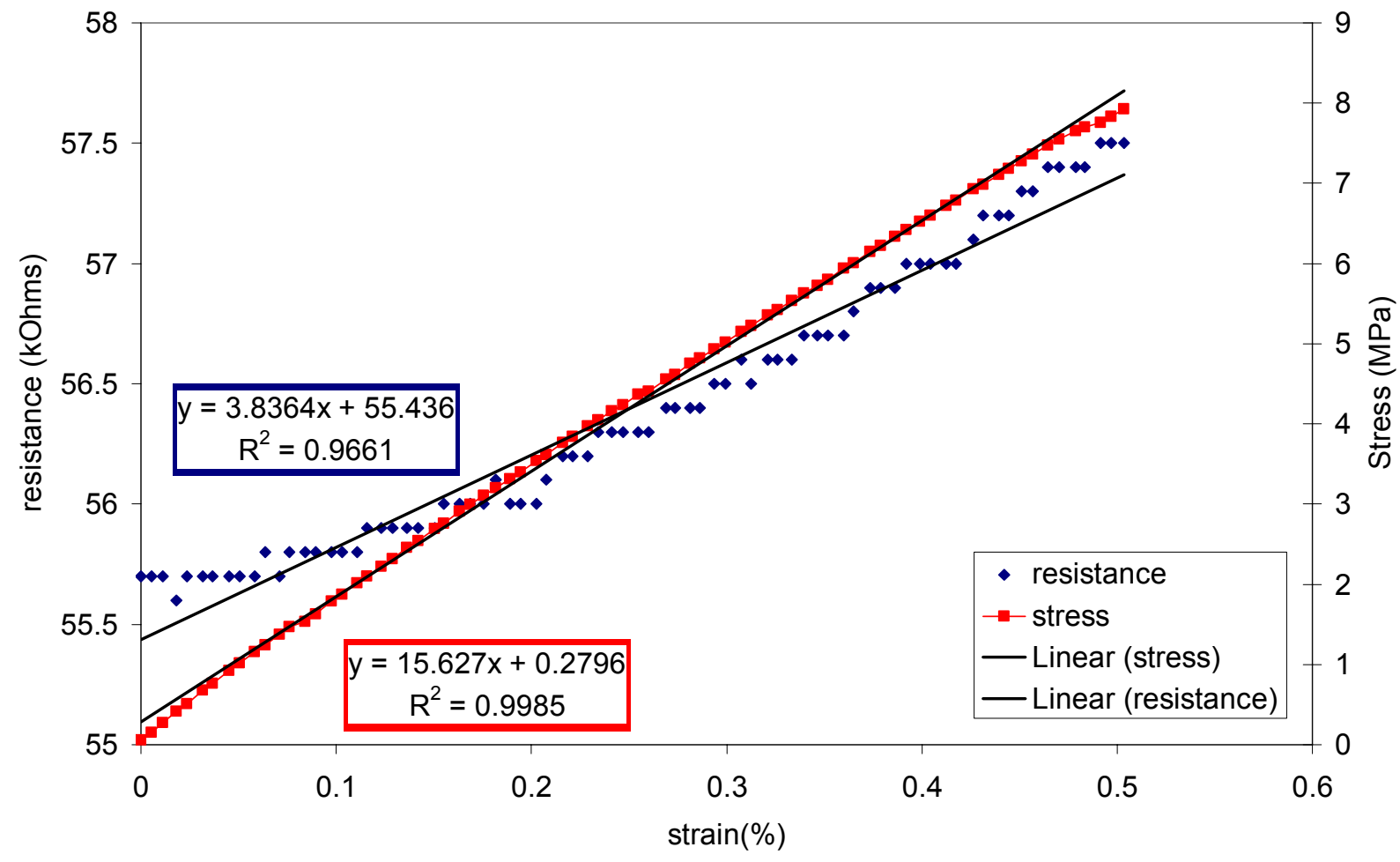

Figure 5.43 Linear modeling of stress and resistance vs strain

Some typical and representative values are extracted from Figures 5.31 to 5.40 and listed in Table 5.8 for Derakane 8084 based composite samples. The properties are listed as a function of graphite concentration, including failure load, failure strain, initial resistance, and final resistance at rupture. Gage factor is also calculated and listed in the table.

The following statements can be concluded from Table 5.8: 1) the failure load almost remains the same till the graphite reaches high concentrations (around $25 \%$ by weight); 2) the failure strain decreases and the material becomes less ductile as the graphite concentration increases, but the failure strain is still 2 to 4 times larger than those of conductive composites using Hetron 922 L 25 vinyl ester resin; 3) the initial resistance decreases with increase in graphite concentration ( as described in Figure 5.11, the resistance is the $3^{\text {rd }}$ power of reciprocal of graphite concentration); and 4) Conductive composites yield a much larger gage factor. Note that a conventional strain gauge (metallic) has a gage factor of 2. Conductive composites have a Gage factor as high as 8 . 
Table 5.8 Typical properties of Derakane 8084 based composite samples

\begin{tabular}{|c|c|c|c|c|c|}
\hline $\begin{array}{c}\text { wt\% of } \\
\text { Graphite }\end{array}$ & $\begin{array}{c}\text { Max } \\
\text { load } \\
(\mathrm{N})\end{array}$ & $\begin{array}{c}\text { Strain } \\
\text { to } \\
\text { failure } \\
(\%)\end{array}$ & $\begin{array}{c}\text { Initial } \\
\text { resistance } \\
\text { R0 (no } \\
\text { strain) } \\
(\mathrm{kOhms})\end{array}$ & $\begin{array}{c}\text { Final resistance } \\
\text { Rf(0.5\% strain } \\
\text { applied)(kOhms) }\end{array}$ & $\begin{array}{c}\text { Factor } \\
\text { (GF) }\end{array}$ \\
\hline 7.5 & 1181 & 3.35 & 24690 & 25360 & 5.4273 \\
\hline 9 & 1318 & 3.35 & 92.3 & 96.4 & 8.88407 \\
\hline 10 & 1129 & 2.82 & 55.7 & 57.5 & 6.4632 \\
\hline 11 & 1051 & 2.31 & 31.26 & 32.57 & 8.38132 \\
\hline 12.5 & 977 & 1.79 & 19.38 & 20.12 & 7.63674 \\
\hline 15 & 1140 & 2.28 & 9.3 & 9.68 & 8.17204 \\
\hline 17.5 & 1099 & 1.91 & 9.12 & 9.45 & 7.23684 \\
\hline 20 & 1130 & 1.74 & 7.78 & 8.01 & 5.9126 \\
\hline 22.5 & 920 & 1.75 & 4.07 & 4.24 & 8.35381 \\
\hline 25 & 787 & 1.14 & 2.773 & 2.883 & 7.93365 \\
\hline
\end{tabular}

The final strain to failure for the conducting composites decreased with increased graphite powder concentration. This can be observed from the Figure 5.44. The ductility of the resin is definitely affected by the increasing the amount of additives in the resin. Therefore, considering the mechanical and electrical properties of the sensors using Derakane 8084 resin, we can conclude that an optimum concentration from $9-13 \%$ by weight of graphite powder would give us maximum sensitivity as well as a better elongation to failure.

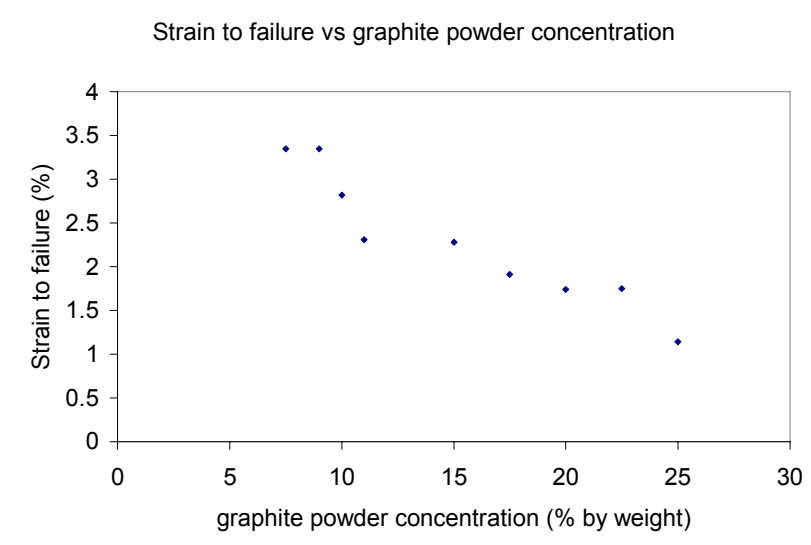

Figure 5.44 Failure strain versus graphite concentration

From the Figure 5.45 we could not observe any relationship between the guage factor and the concentration of graphite powder in the dearakane samples. We should have more 
replications to observe a trend between the two parameters. From the figure we can conclude that the maximum guage factor can be obtained when we have a wt $\%$ of graphite powder around $9-12 \%$.

variation of GF with wt\% in Derakane 8084

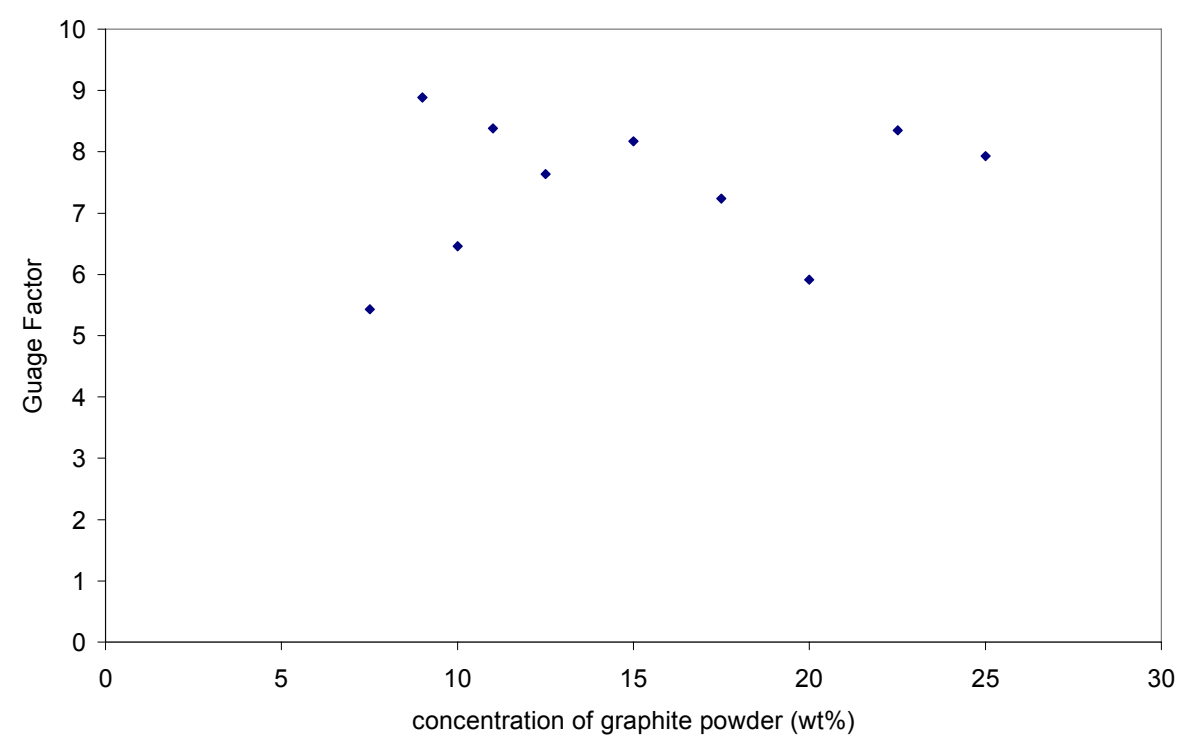

Figure 5.45 Guage factor versus graphite concentration

\subsubsection{Effect of Particle size on Derakane 8084 samples}

In order to study the effect of particle sizes on both the mechanical and electrical properties, the samples were cast at $10 \%$ by weight of graphite powder in vinyl ester (Derakane 8084) resin. Different sizes of powders were used as described in Table 3.1.

Mechanical and electrical tests for the composites made of graphite powders of different particle sizes were conducted as described in section 5.2.3. Multiple replications were carried out for each particle size and all the data were presented in Table 5.9 so as to observe the reproducibility of the results.

It was observed that the resistance increased monotonically with strain until failure. The stress versus strain curves of replication samples overlap with each other and show good consistency for all composites with different particle sizes. Unlike in the case of Hetron based samples, the GS150-E showed a very huge resistance and could not be measured by the instruments. (see Figure 5.12). 
Table 5.9 Tension and electrical test results of conducting composites with different graphite particle sizes at a concentration of $10 \mathrm{wt} \%$ in Derakane 8084

\begin{tabular}{|l|c|r|r|r|r|r|r|}
\hline & $\begin{array}{c}\text { Sample } \\
\text { Replications }\end{array}$ & $\begin{array}{c}\text { Resistance } \\
\text { (kOhms) }\end{array}$ & $\begin{array}{c}\text { Resistance } \\
\text { (at 0.5\% } \\
\text { strain) } \\
\text { (kOhms) }\end{array}$ & $\begin{array}{c}\text { Ultimate } \\
\text { strain to } \\
\text { failure (\%) }\end{array}$ & $\begin{array}{c}\text { Change in } \\
\text { Resistance } \\
\text { (kOhms) }\end{array}$ & \multicolumn{1}{|c|}{ R/R } & Sensitivity \\
\hline $\begin{array}{l}\text { GP44- } \\
\text { B }\end{array}$ & Sample \# 1 & 21.52 & 22.50 & 2.42 & 0.98 & 0.045 & 9.12 \\
\hline & Sample \# 2 & 32.59 & 34.02 & 2.16 & 1.43 & 0.044 & 8.83 \\
\hline & Sample \# 3 & 26.43 & 27.65 & 2.34 & 1.22 & 0.046 & 9.24 \\
\hline & Sample \# 4 & 29.15 & 30.46 & 2.08 & 1.31 & 0.044 & 8.99 \\
\hline & Mean & $\mathbf{2 7 . 4 2}$ & $\mathbf{2 8 . 6 6}$ & $\mathbf{2 . 2 5}$ & $\mathbf{1 . 2 3}$ & $\mathbf{0 . 0 4 5}$ & $\mathbf{9 . 0 4 5}$ \\
\hline GP55- & Sample \# 1 & 34.29 & 35.58 & 2.45 & 1.29 & 0.037 & 7.54 \\
\hline & Sample \# 2 & 29.3 & 30.51 & 2.37 & 1.21 & 0.041 & 8.32 \\
\hline & Sample \# 3 & 29.45 & 30.65 & 2.69 & 1.205 & 0.0409 & 8.19 \\
\hline & Sample \# 4 & 31.9 & 33.16 & 2.21 & 1.26 & 0.039 & 7.94 \\
\hline & Mean & $\mathbf{3 1 . 2 3 5}$ & $\mathbf{3 2 . 4 8}$ & $\mathbf{2 . 4 3}$ & $\mathbf{1 . 2 4}$ & $\mathbf{0 . 0 3 9}$ & $\mathbf{7 . 9 9 7 5}$ \\
\hline GS75- & Sample \# 1 & 205.2 & 209.29 & 3.04 & 4.093 & 0.019 & 3.99 \\
\hline E & Sample \# 2 & 100.4 & 103.22 & 2.78 & 2.82 & 0.028 & 5.63 \\
\hline & Sample \# 3 & 150.8 & 154.094 & 2.65 & 3.29 & 0.021 & 4.37 \\
\hline & Sample \# 4 & 154.6 & 157.908 & 2.91 & 3.308 & 0.021 & 4.28 \\
\hline & Mean & $\mathbf{1 5 2 . 7 5}$ & $\mathbf{1 5 6 . 1 3}$ & $\mathbf{2 . 8 4}$ & $\mathbf{3 . 3 8}$ & $\mathbf{0 . 0 2 2}$ & $\mathbf{4 . 5 6}$ \\
\hline
\end{tabular}

The samples containing graphite powder GS150-E are not mentioned in the table since they had high resistance values and were not recorded on the multimeter. However, the mechanical tests were performed and they showed a maximum strain to failure of $\sim 3 \%$. Three main conclusions can be drawn from the experiments that were conducted varying the particle sizes.

Firstly, the initial resistance of the conducting composites increases with increase in particle size as seen in Figure 5.12. For the same concentration of $10 \%$ by weight of graphite powder, the particle size of 44 microns has the most number of particles. This results in a larger surface area and as a result in more number of effective conducting channels. This makes the resistance of the samples prepared by 44 microns size graphite powder lower than the others.

Secondly, as seen in Figure 5.46, the ultimate strain to failure of the conducting composite samples was higher for particle sizes of 150 microns. This can be also explained on the basis of less number of particles per given volume of 150 micron sized graphite powder. 
Ultimate strain to failure vs particle size

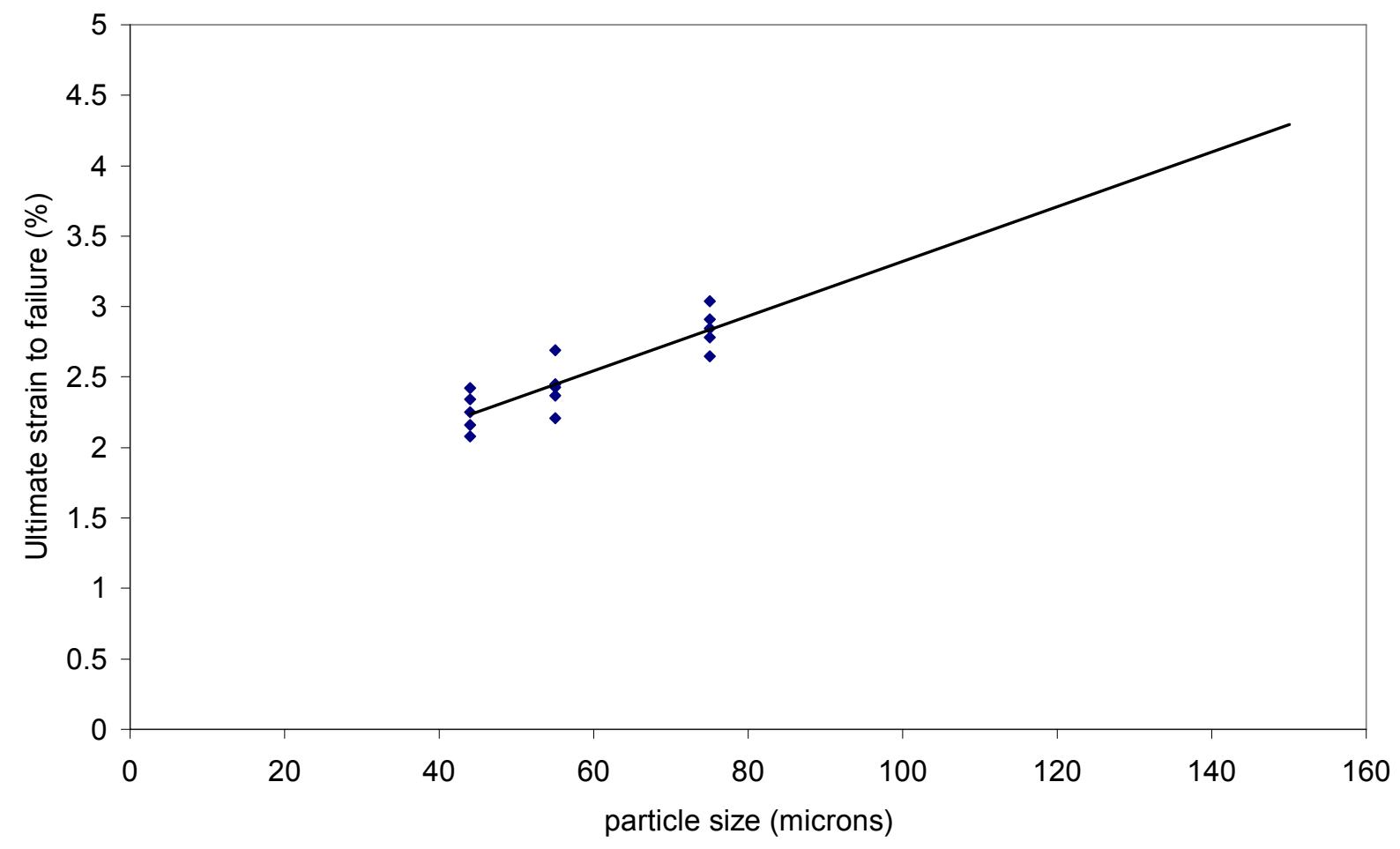

\section{Figure 5.46 Relationship between ultimate failure strain and particle size}

Finally, the sensitivity of the sensor is inversely proportional to the initial resistance as explained in equation 5.9 and it can be clearly seen from figure 5.47 that the powders with 44 microns have greater sensitivity. 
Sensitivity vs particle size

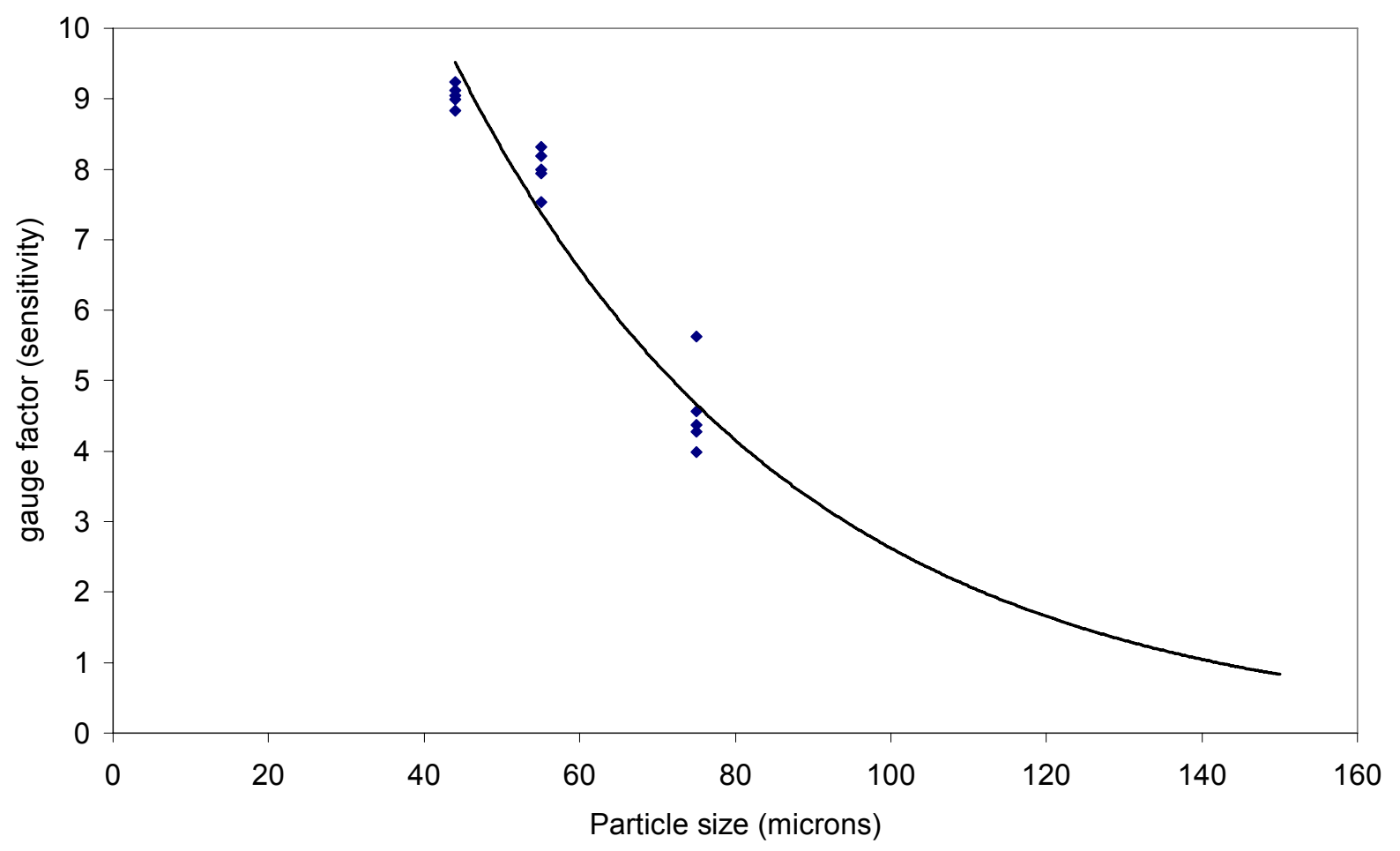

Figure 5.47 variation of sensitivity w.r.t particle size

\subsubsection{CNT based samples}

CNT's dispersed in styrene at a concentration of $0.5 \%$ was used to mix with Derakane 8084 resin and cast moldings of a CNT concentration $\sim 0.25 \%$. The samples were tested for their electrical resistance first and then for the correlation between electrical and mechanical properties. Figure 5.48 shows the relationship between strain, resistance and stress. Only two replications were tested with a significant difference due to presence of cracks with the samples.

Further work is needed to establish the advantages of CNT fillers over graphite fillers. It appears that $0.25 \%$ of CNT is giving similar results which are obtained from $\sim 9-15 \%$ of graphite fillers. This will reduce the amount of additives in the resin, thereby keeping the properties of the resin intact. 


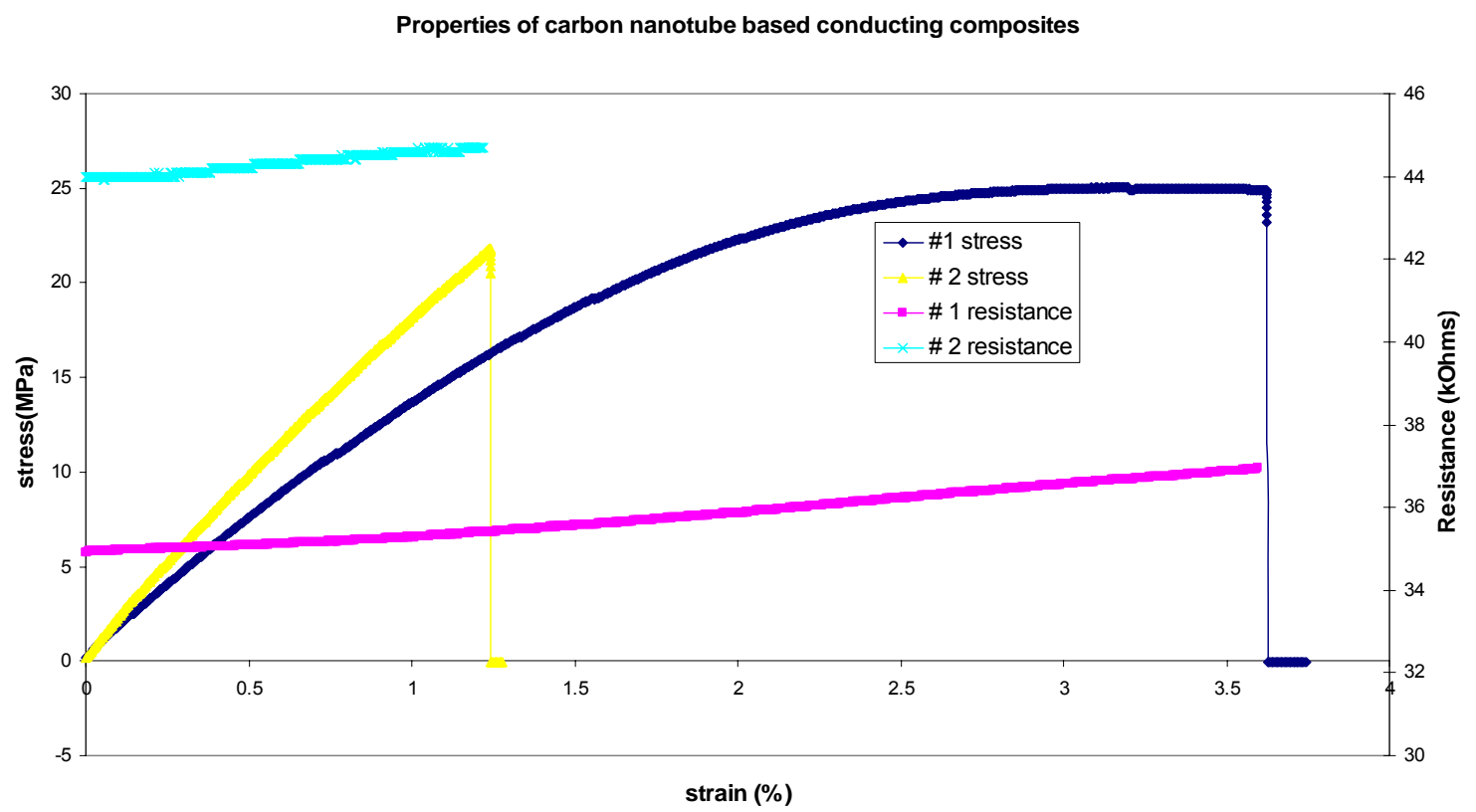

Figure 5.48 Relationship between stress, strain and resistance data for $0.25 \% \mathrm{CNT}$ in Derakane 8084 resin.

\subsection{Static multi-run test}

The conductive composites are further extensively tested in the region of our interest, by performing a static multi-run test. The samples were all made of $10 \% \mathrm{wt}$ graphite powder GP 44 - B in Derakane 8084 vinyl ester resin. The test procedure is explained in Section 4.3. Figures $5.49 \& 5.50 \mathrm{how}$ the results of 2 samples with each of them being tested 5 times until a strain of $0.5 \%$ was achieved and then the sample was relaxed. We can observe that all the samples show good repeatability during the runs. We operated only in the linear region (elastic) of the samples. The stress versus strain curves for a specific sample were straight lines with approximately equal slopes for all the runs. This tells us that the potential sensor has good repetitiveness in the region of interest. The resistance was also simultaneously monitored throughout the experiment. The resistance of the samples also showed good repetitiveness. The quantitative results for the experiment were shown in Table 5.10. The standard deviations for all the runs were calculated and some of the samples showed good repetitiveness. 
Table 5.10 Static Multi-run test results

\begin{tabular}{|c|c|c|c|c|c|c|c|}
\hline $\begin{array}{l}\text { Sample \# } \\
1\end{array}$ & & $\begin{array}{l}\text { Final } \\
\text { Strain (\%) }\end{array}$ & $\begin{array}{l}\text { Final } \\
\text { Stress } \\
\text { (Mpa) }\end{array}$ & $\begin{array}{l}\text { Initial } \\
\text { Resistance } \\
\text { (kOhms) }\end{array}$ & $\begin{array}{l}\text { Final } \\
\text { Resistance } \\
\text { (kOhms) }\end{array}$ & $\begin{array}{l}\text { Change in } \\
\text { resistance } \\
\text { (kOhms) }\end{array}$ & $\begin{array}{l}\text { Guage } \\
\text { Factor }\end{array}$ \\
\hline & run \#1 & 0.50 & 11.65 & 17.17 & 17.73 & 0.56 & 6.52 \\
\hline & run \#2 & 0.49 & 11.51 & 17.78 & 18.06 & 0.28 & 3.21 \\
\hline & run \#3 & 0.49 & 11.45 & 16.88 & 17.22 & 0.34 & 4.11 \\
\hline & run \#4 & 0.50 & 11.86 & 16.72 & 17.09 & 0.37 & 4.43 \\
\hline & run \#5 & 0.49 & 11.76 & 16.66 & 16.85 & 0.19 & 2.33 \\
\hline & Average & 0.49 & 11.65 & 17.04 & 17.39 & 0.35 & 4.12 \\
\hline & Std. Dev. & 0.01 & 0.17 & 0.46 & 0.49 & 0.14 & 1.57 \\
\hline \multirow[t]{7}{*}{$\begin{array}{l}\text { Sample \# } \\
2\end{array}$} & run \#1 & 0.50 & 12.71 & 21.70 & 22.32 & 0.62 & 5.72 \\
\hline & run \#2 & 0.50 & 12.79 & 21.83 & 22.39 & 0.56 & 5.14 \\
\hline & run \#3 & 0.50 & 12.88 & 21.93 & 22.53 & 0.60 & 5.48 \\
\hline & run \#4 & 0.50 & 12.79 & 21.96 & 22.46 & 0.50 & 4.56 \\
\hline & run \#5 & 0.50 & 13.09 & 21.81 & 22.24 & 0.43 & 3.92 \\
\hline & Average & 0.50 & 12.85 & 21.85 & 22.39 & 0.54 & 4.97 \\
\hline & Std.Dev. & 0.00 & 0.14 & 0.10 & 0.11 & 0.08 & 0.73 \\
\hline \multirow[t]{7}{*}{$\begin{array}{l}\text { Sample \# } \\
3\end{array}$} & run \#1 & 0.50 & 12.55 & 21.93 & 22.56 & 0.63 & 5.76 \\
\hline & run \#2 & 0.50 & 12.70 & 22.18 & 22.77 & 0.59 & 5.33 \\
\hline & run \#3 & 0.50 & 12.86 & 21.67 & 22.26 & 0.59 & 5.42 \\
\hline & run \#4 & 0.50 & 12.80 & 20.61 & 21.28 & 0.67 & 6.51 \\
\hline & run \#5 & 0.50 & 12.94 & 20.41 & 20.92 & 0.51 & 5.01 \\
\hline & Average & 0.50 & 12.77 & 21.36 & 21.96 & 0.60 & 5.60 \\
\hline & Std.Dev. & 0.00 & 0.15 & 0.80 & 0.81 & 0.06 & 0.57 \\
\hline \multirow[t]{7}{*}{$\begin{array}{l}\text { Sample \# } \\
4\end{array}$} & run \#1 & 0.50 & 12.59 & 24.79 & 25.12 & 0.33 & 2.67 \\
\hline & run \#2 & 0.50 & 12.90 & 23.53 & 24.13 & 0.60 & 5.07 \\
\hline & run \#3 & 0.50 & 12.66 & 22.90 & 23.17 & 0.27 & 2.36 \\
\hline & run \#4 & 0.50 & 12.96 & 22.61 & 23.15 & 0.54 & 4.75 \\
\hline & run \#5 & 0.50 & 12.87 & 23.02 & 23.36 & 0.34 & 2.96 \\
\hline & Average & 0.50 & 12.80 & 23.37 & 23.79 & 0.42 & 3.56 \\
\hline & Std.Dev. & 0.00 & 0.16 & 0.86 & 0.85 & 0.14 & 1.25 \\
\hline
\end{tabular}




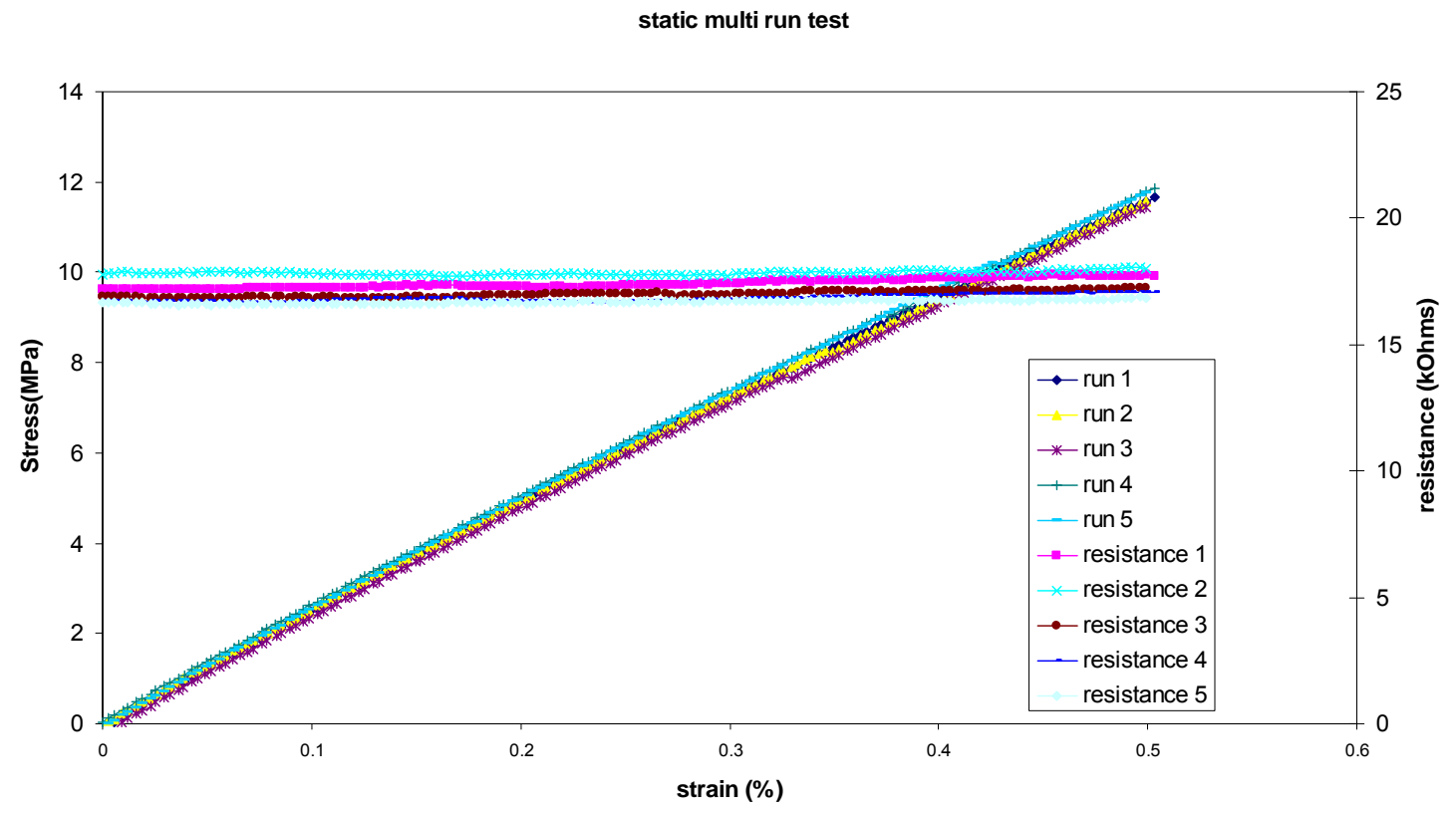

Figure 5.49 Multi-run static test curves for sample \# 1 till $0.5 \%$ strain is achieved

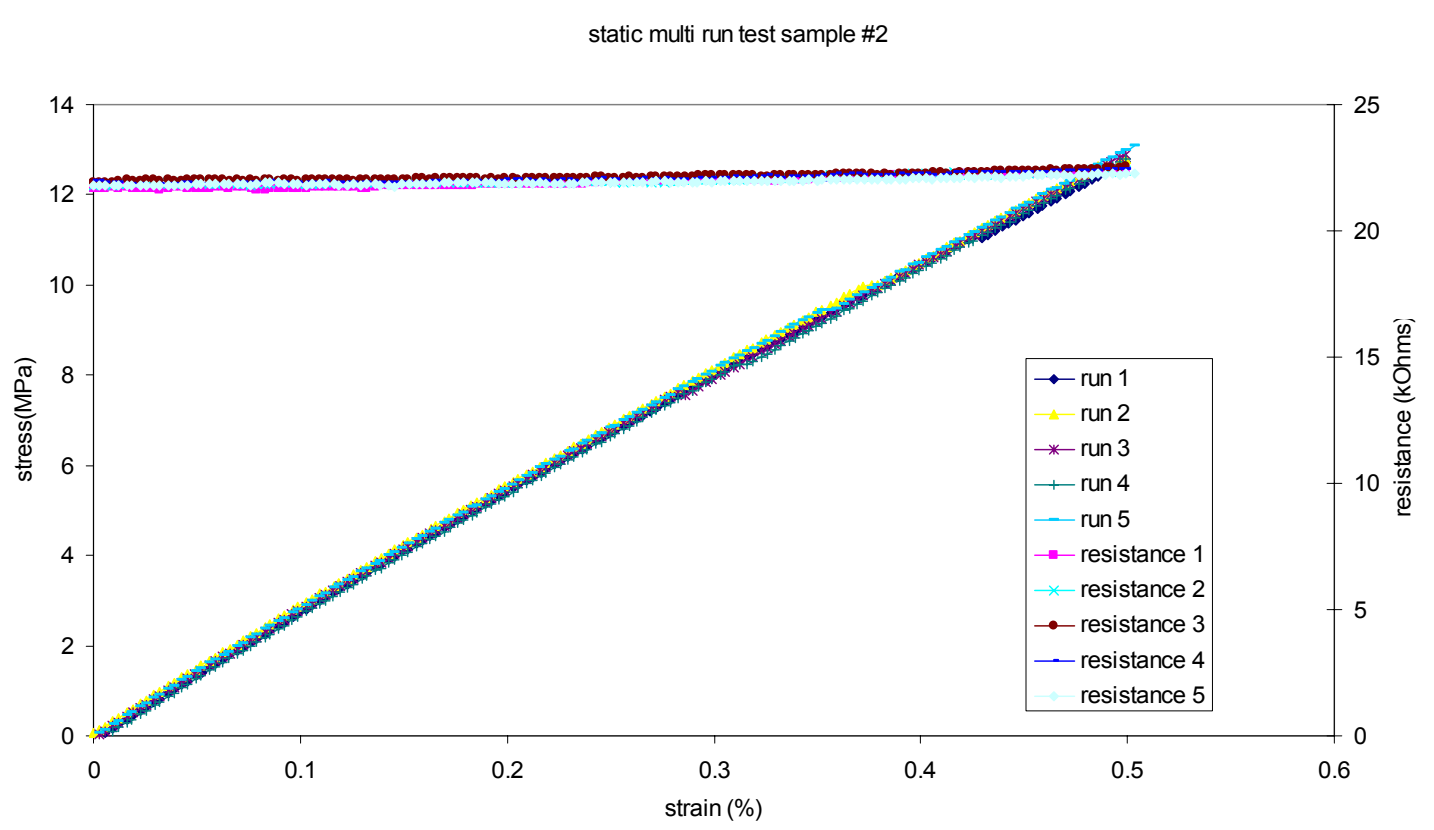

Figure 5.50 Multi-run static test curves for sample \# 2 till $0.5 \%$ strain is achieved

\subsection{Application of conductive composites as heating elements}

The application of conductive composites as heating elements is preliminarily studied and the results are discussed in this section. A typical infrared camera image is shown in Figure 4.10 for $25 \%$ graphite composite sample. The image provides information on global temperature 
profiles over the entire sample surface. It can be seen from Fig. 4.10 that the temperature profile of the sample is completely symmetrical about the central axis. The observations indicate that graphite particles have been uniformly dispersed within the Derakane vinyl ester resin.

The temperature profiles are summarized in Table 5.11 for all conductive composite samples that are subjected to an $\mathrm{AC}$ voltage for 10 minutes. The data show that the final temperature of the sample increases with the graphite concentration. According to Equation 4.8 the temperature increment is inversely proportional to the resistance. This relation has been verified in Figure 5.51

The results have demonstrated that the developed conductive composites function well as fast and effective heating elements.

Table 5.11 Temperature profiles of Derakane 8084 based conductive composites subjected to an AC voltage for 10 minutes

\begin{tabular}{|c|c|c|c|c|c|}
\hline $\begin{array}{c}\text { \% of } \\
\text { Graphite }\end{array}$ & $\begin{array}{c}\text { Resistance } \\
\text { kOhms }\end{array}$ & $\begin{array}{c}\text { Min. temp. } \\
\text { at two ends } \\
\mathrm{F}\end{array}$ & $\begin{array}{c}\text { Max. temp. } \\
\text { at the center } \\
\mathrm{F}\end{array}$ & $\begin{array}{c}\text { Average } \\
\text { temperature } \\
\mathrm{F}\end{array}$ & $\begin{array}{c}\text { Standard } \\
\text { Deviation } \\
\mathrm{F}\end{array}$ \\
\hline 12.5 & 19.38 & 80 & 108 & 96 & 6 \\
\hline 15 & 9.29 & 87 & 142 & 121 & 13 \\
\hline 17.5 & 9.12 & 89 & 143 & 125 & 13 \\
\hline 20 & 7.78 & 96 & 150 & 133 & 11 \\
\hline 22.5 & 4.07 & 109 & 204 & 162 & 22 \\
\hline 25 & 2.773 & 115 & 243 & 180 & 30 \\
\hline
\end{tabular}




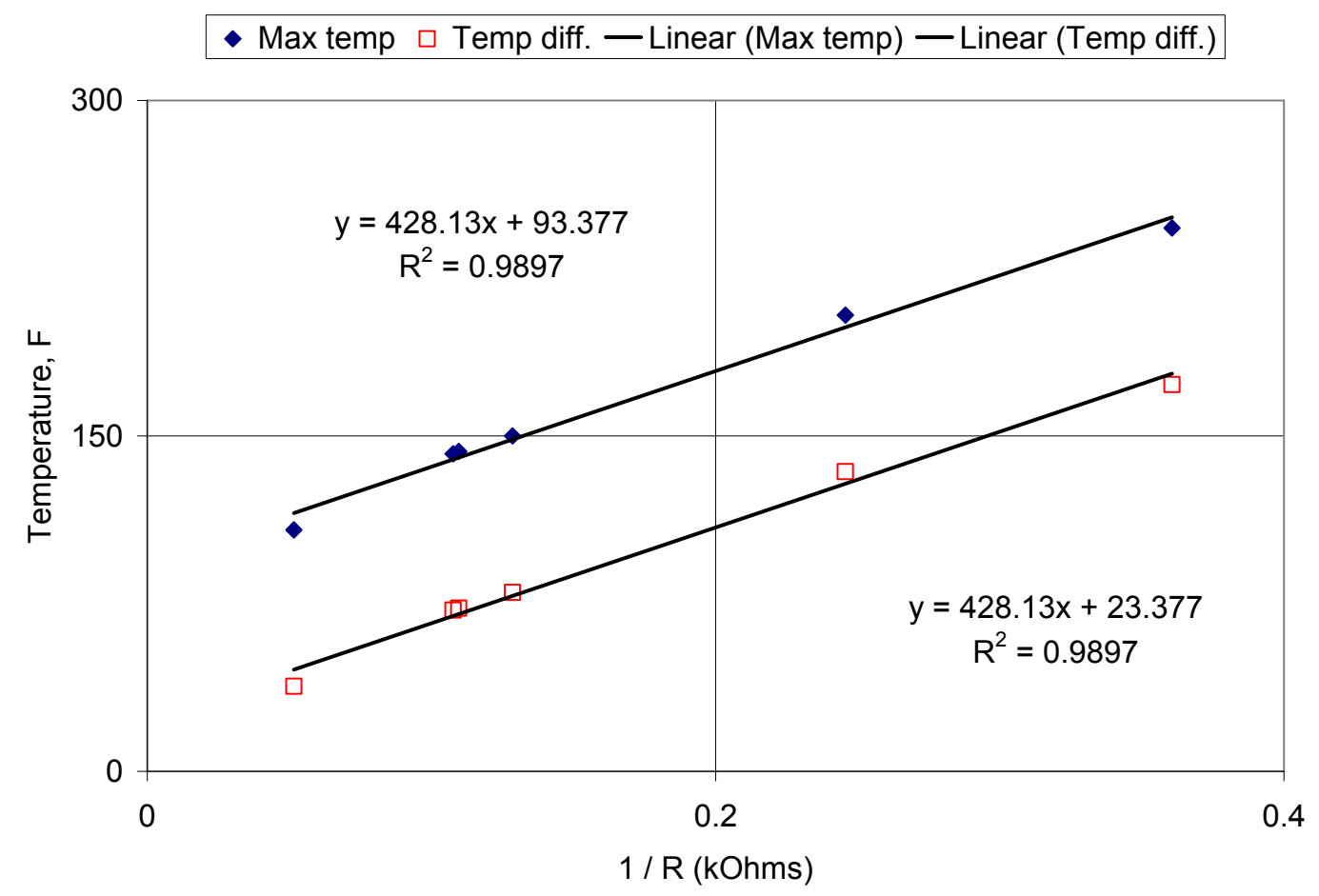

Figure 5.51aximum temperature and temperature difference at the center versus reciprocal of resistance for graphite/ 8084 composite samples

\subsection{Thermal conductivity}

The thermal conductivity of the electrically conducting composites is measured in comparison with that of neat resin on a guarded heat flow meter as described in Section 4.5. The measurement results are given in Table 5.12.

The addition of graphite powder significantly increases the thermal conductivity approximately by $88 \%$ at a concentration of $10 \mathrm{wt} \%$ and $170 \%$ at a concentration of $12.5 \mathrm{wt} \%$, respectively, as compared to that of neat resin.

In the case of carbon nano-tubes, there is a slight increase in thermal conductivity at the temperature segment of $60^{\circ} \mathrm{C}$ when compared to neat vinyl ester resin, but the thermal conductivity almost remains unchanged at the temperature segments of $80^{\circ} \mathrm{C}$ and $100^{\circ} \mathrm{C}$. It appears that the addition of nano-tubes has not enhanced the thermal conducting property as much as expected. The reasons are to be further explored. 
Table 5.12 Thermal conductivity values of vinyl ester 8084 with and without additives

\begin{tabular}{|c|c|c|c|c|}
\hline \multirow[b]{2}{*}{ Sample } & \multirow{2}{*}{$\begin{array}{c}\text { Thickness } \\
\text { mm } \\
\text { (inch) }\end{array}$} & \multicolumn{3}{|c|}{ Thermal conductivity, W/m K } \\
\hline & & $\begin{array}{c}\text { Segment } 1 \\
\text { at } 140^{\circ} \mathrm{F} \\
\left(60^{\circ} \mathrm{C}\right)\end{array}$ & $\begin{array}{c}\text { Segment } 2 \\
\text { at } 140^{\circ} \mathrm{F} \\
\left(80^{\circ} \mathrm{C}\right)\end{array}$ & $\begin{array}{c}\text { Segment } 3 \\
\text { at } 212^{0} \mathrm{~F} \\
\left(100^{\circ} \mathrm{C}\right)\end{array}$ \\
\hline Neat Resin* & $\begin{array}{c}4.594 \\
(0.18085) \\
\end{array}$ & 0.1775 & 0.184 & 0.1915 \\
\hline $\begin{array}{c}10 \% \\
\text { Graphite } \\
\text { powder }\end{array}$ & $\begin{array}{c}16.021 \\
(0.6307)\end{array}$ & 0.358 & 0.368 & 0.361 \\
\hline $\begin{array}{c}12.5 \% \\
\text { Graphite } \\
\text { powder }\end{array}$ & $\begin{array}{c}16.186 \\
(0.6372)\end{array}$ & 0.496 & 0.536 & 0.515 \\
\hline $\begin{array}{c}0.25 \% \mathrm{CNT} \\
\text { Carbon } \\
\text { nano-tubes }\end{array}$ & $\begin{array}{c}8.528 \\
(0.3357)\end{array}$ & 0.239 & 0.198 & 0.192 \\
\hline
\end{tabular}

* an average of two replications

\subsection{Effect of water \& moisture on the resistance}

The conductive composite sample comprising of $10 \%$ graphite powder in Derakane vinyl ester was kept in water amd moisture to study their effect as described in Section 4.6. In the case of immersing them in water, the resistance of the sample was measured on a daily basis. The readings of resistance are plotted in Figure 5.52. Two samples were reported in the figure. One of the samples has $10 \mathrm{wt} \%$ of graphite powder GP44-B while the other has $15 \mathrm{wt} \%$ of the same powder. Surprisingly, the resistance of the samples kept on increasing. The resistance of the sample increases with increase in time that it is in water. A linear data fit was done for both samples

Pure water is not a conductor of electricity. Only when it is mixed with salts or acids or bases water becomes conductive. It appears that when the sample is kept in the pure water, the water does diffuse into the sample. The resistance of water is more than the resistance of the sample. The resistance of water is $\sim 10^{10} \mathrm{Ohm}-\mathrm{m}$. So the resultant resistance of the sample with water would be greater than the resistance of the sample without water (original sample). Figure 5.53 shows a sample under water with air bubbles on the surface. 
variation of resistance on exposure to moisture

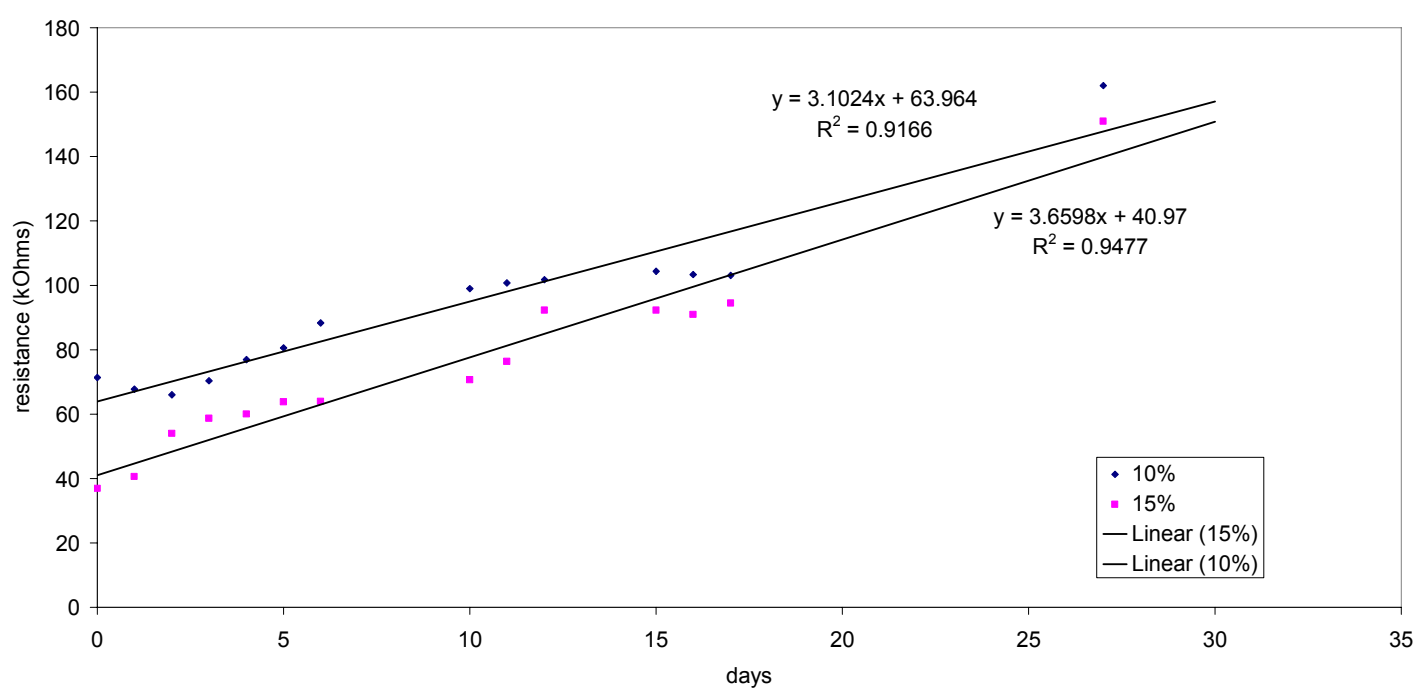

Figure 5.52 The variation of resistance with the number of days the sample was kept in

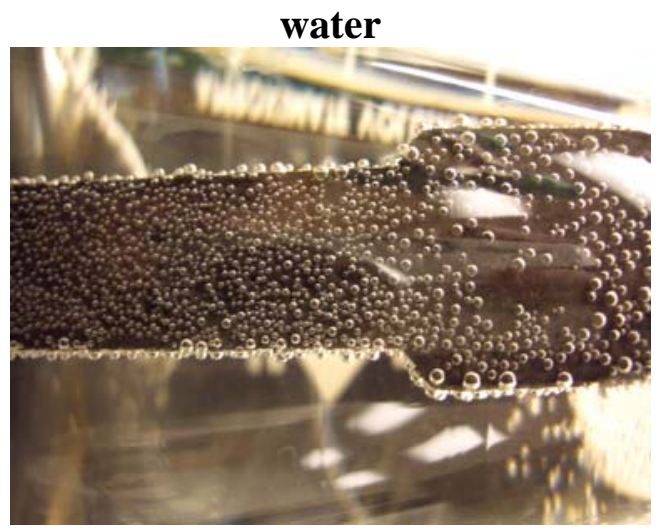

Figure 5.53 A sample under water with air bubbles on the surface

The effect of moisture was further studied as described in section 4.6. The results were plotted in a graph as shown in Figure 5.54. Initially the Relative Humidity $(\mathrm{RH})$ of the chamber was equal to that of the room at $45 \%$. The sample was then placed inside the air tight chamber. The $\mathrm{RH}$ in the chamber was then decreased to $0 \%$, gradually increased it to $90 \%$ and then decreased back to $0 \%$. While the chamber was being regulated at different $\mathrm{RH}$ levels at different times, the resistance of the sample was also measured. 


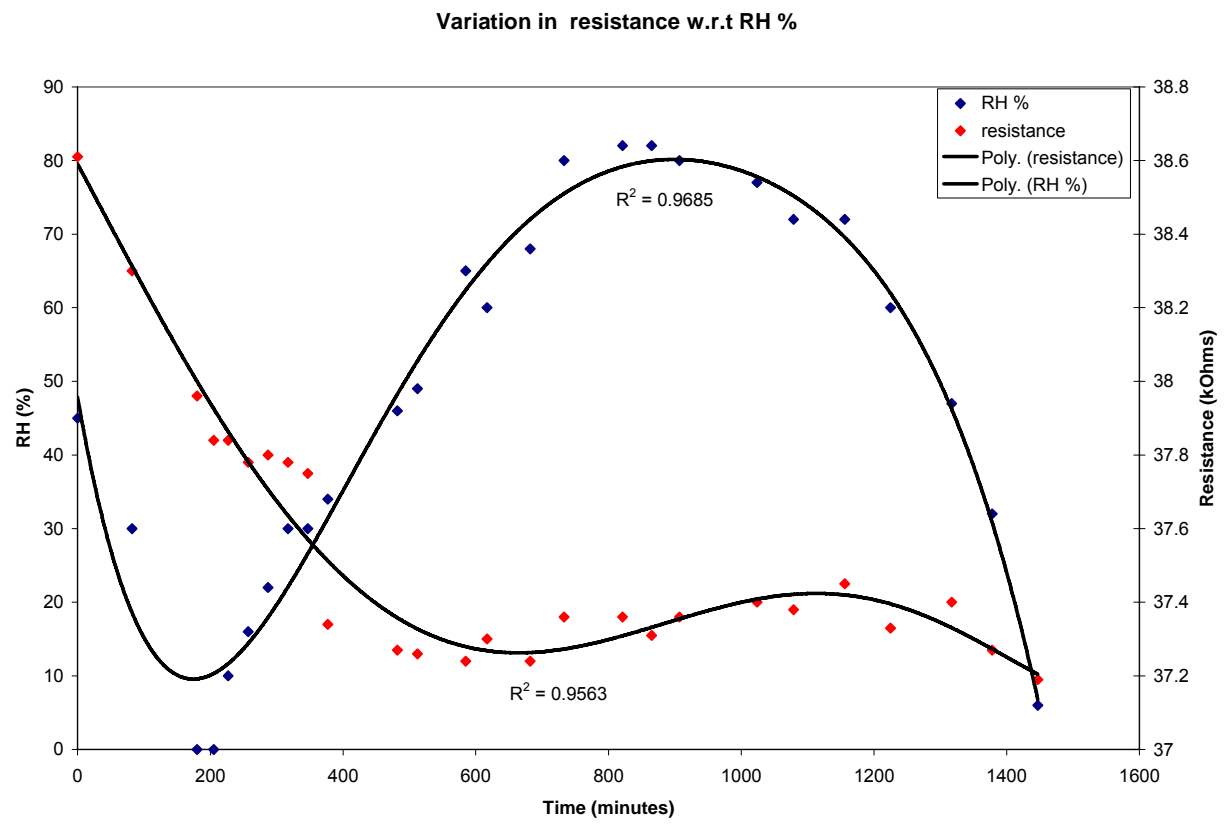

Figure 5.54 Graph shows the variation of resistance when the sample is subjected to a variation in moisture with time

It can be observed from the figure that the resistance clearly follows the same trend as the relative humidity curve but with some amount of a delay. If we had regulated the RH from 45 to $0 \%$ in a greater period of time ( $\sim 600$ minutes) instead of 200 minutes, the resistance curve would have followed the RH curve much closely without any delay. This is due to the reason that the sample takes some time to achieve the steady state resistance when exposed to a particular level of moisture. In this experiment we have not given enough time for the sample to reach that steady state resistance. The experiment definitely concludes that the sensor responds to a change in the surrounding moisture level.

\subsection{Effect of temperature on the resistance}

The resistance of a conductive composite sensor as a function of temperature is plotted in Figure 5.55. It appears that our sample falls into the semiconductor category, that is, its resistance decreases exponentially with increase in temperature [Wikipedia 2006]. As shown in Figure 5.55, an exponential data fit can be used to represent the variation of resistance with temperature. The fit agrees to the original data as per the $\mathrm{R}^{2}$ value. The deviation of the $\mathrm{R}^{2}$ value might be due to the following reason. The heating of the sample is done in a compression 
molding machine whose plates heat the top and bottom surface of the sample instead of uniform atmosphere.

Variation of resistance with temperature

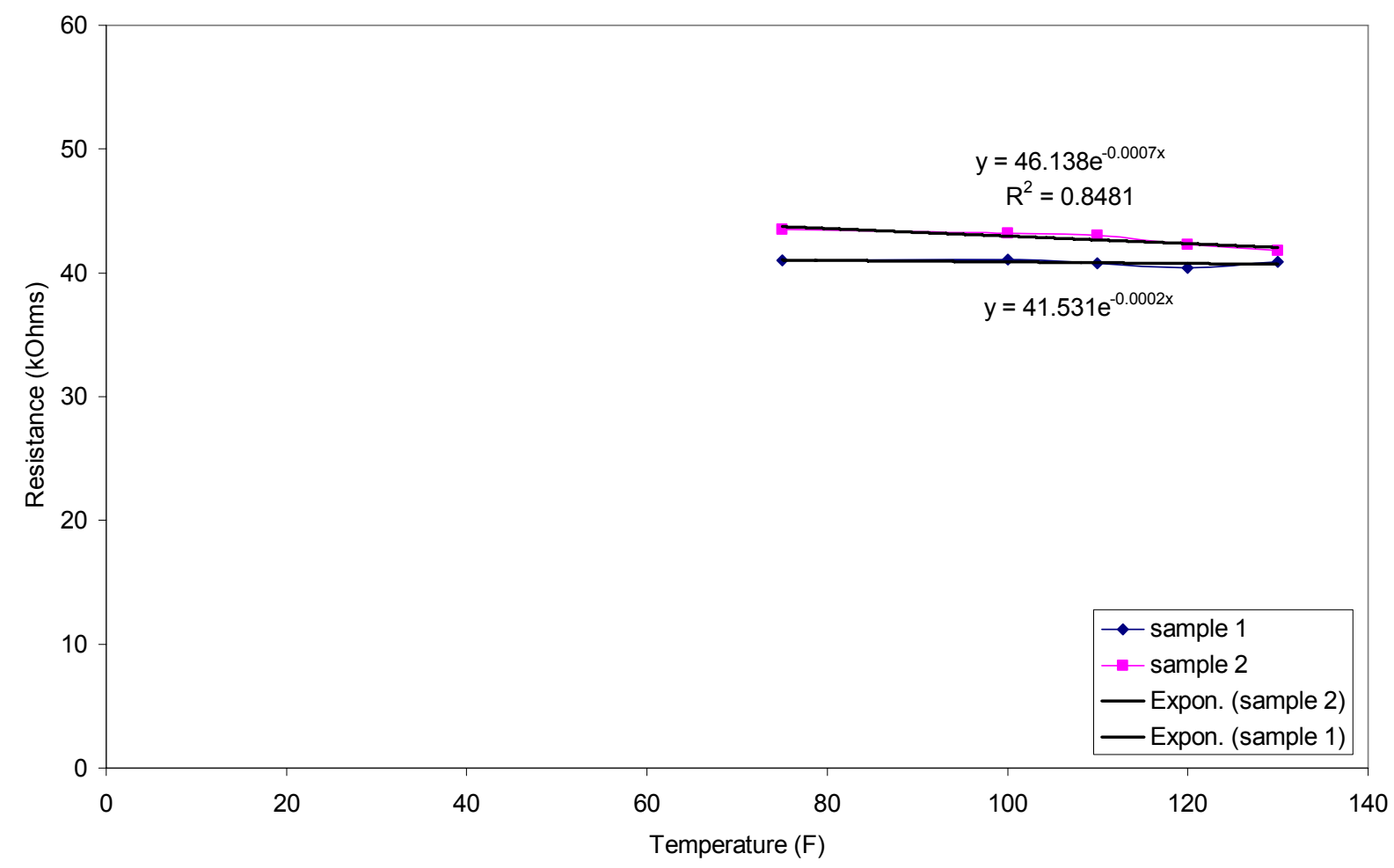

Figure 5.55 The variation of resistance with temperature 


\section{CHAPTER 6}

\section{CONCLUSIONS AND FUTURE WORK}

\subsection{Conclusions}

Most neat polymers, including thermoplastics and thermosets are electrical insulators. However, conductive additives or fillers can be incorporated as a second phase into these materials to produce composite materials, which exhibit electrical conductivity. The objective of our study is to develop conductive polymer composites as sensors in terms of change in electrical resistance as a function of deformation for health monitoring of civil structures and in particular, fiber reinforced polymer (FRP) composites structures.

In this study, a variety of conductive fillers have been examined for their applicability as additives to produce semi-conductive composites. On the other hand, a number of thermosetting resins have been investigated for their applicability as polymer matrices. In particular, different sizes of graphite powder and chopped carbon fiber were used as the conductive fillers and dispersed in the vinyl ester resins including Hetron 922 L25 and Derakane 8084.

Conductive composite samples of dog bone shapes were cast using in-house made molds. All the samples were first tested for their electrical properties and their electrical resistance data were correlated as a function of additive concentration and or particle size. The conductive composite samples were then tested under tension to establish the relationship between the stress and /or strain and the resistivity. The sensitivity (gauge factor) that is defined as an index of change in resistance in response to strain over the sensor's original resistance, was calculated for each sample.

The three main parameters involved in the preparation of conducting composite samples/sensors are the filler particle concentration, filler particle size and the polymeric resin. By varying these three parameters we have found optimum values for these parameters at which the sensitivity/guage factor for these sensors is a maximum. Guage factors of 16 and 8 were achieved using Hetron 922 and Derakane 8084 vinyl ester based resins. This sensitivity achieved is larger than existing strain gauges. The typical sensitivity of a metallic type strain guage is around 2. 
We have established a relationship between the resistance of the sensor and its mechanical deformation. The variation of resistance with strain was linear in the linear range of operation of the sensor. Since the relationship is linear, we should be able to determine the strain and stress acting on the sensor and in a way the structure on which the sensor is mounted.

The sensor shows good repeatability in the region of interest (elastic region). The static multi run test concludes that when the sample is loaded, provided the load stays within the limits of the elastic bound, it gets back to its original state (size, shape and resistance).

Preliminary tests demonstrate that the sensor can be effectively used as a heating element for de-icing FRP bridge decks during winter when these smart composites are embedded onto FRP bridge decks. The resistance of the conductive composite sensor is also able to reflect the influence of moisture and temperature within the range studied, but more quantitative data are needed to establish the relationship between those parameters and the change in resistance.

\subsection{Future work}

We would like to establish solid results for the variation of resistance with moisture and temperature. In addition, other natural weathering parameters such as UV radiation and thermal cycling effects on the resistance will be studied. The above results would then help us to calibrate the sensor for outdoor use under harsh environmental conditions.

The shape of the composite sensor used in this work was a dog bone shape. In order to use the sensor for different applications, we should try to consider different shapes and perform all the tests that were performed on the dog bone shaped specimen to study the feasibility.

The under development conductive composite sensor will be grafted on a bridge deck and evaluated at a deck level when the deck is subjected to fatigue with $20 \%$ of final load. The responses from the sensor will be co-related to the responses of conventional sensors.

We would like to examine the feasibility of embedding the conductive composite sensor in-line with production process while pultruding bridge deck modules. 


\section{REFERENCES}

1. Angelopoulos, Marie. Conducting polymers in microelectronics, IBM Journal of Research and Development (2001), Vol.45, No.1, pp.57-76.

2. Clingerman, Matthew, L., Weber, Eric, H., King, Julia A., Schulz, Kirk, H. Development of an additive equation for predicting the electrical conductivity of carbon filled composites, Wiley Interscience (2003), pp.2281-2298.

3. Dally, James, W., Riley, William, F. Experimental Stress Analysis, $3^{\text {rd }}$ edition, McGrawHill (1978).

4. Danescu, R. I., Zumbrunnen, D. A. Computational simulation of controllable structure formation among particle additives in a continuous-flow chaotic mixer, Journal of Powder Technology (2002), Vol. 125, pp. 251-259.

5. eSMART, Smart materials, (2005), http://www.cs.ualberta.ca/ database/MEMS/sma_mems/smrt.html

6. Gaier, J.R. Intercalated graphite fiber composites as EMI shields in aerospace structures, IEEE Trans. Electromag. Compat. (1992), vol. 34, issue 3, pp. 351-356.

7. Instron, Instron 8500 Two-Column Load Frame Operating Manual (1999).

8. Krueger, Quinton, J., King, Julia, A. Synergistic effects of carbon fillers on shielding effectiveness in conductive nylon 6,6, and polycarbonate based resins, Advances in Polymer technology (2003), Vol.22, No.2, pp.96-111.

9. Kumar, Anil and Gupta, Rakesh, K. Fundamentals of Polymer Engineering, $2^{\text {nd }}$ edition, Marcel Dekker Inc. (2003).

10. Law, S.S., Shi, Z.Y., Zhang, L.M. Structural damage detection from incomplete and noisy modal test data, Journal of Engineering Mechanics, ASCE (1998), Vol. 124, No. $11,1280-1288$.

11. Park, Jong, S., Kang, Phil, Hyun and Chang, Young, Nho. Characterization of carbon black filled polymer composites for strain sensor, J. Ind. Eng. Chem. (2003), Vol.9, No.5, pp.595-601.

12. Poirier, P.E., Page, D.J.Y.S., and Bates, P.J. Compounding of conductive polypropylene/graphite composites, ANTEC (2005), pp.1549-1552. 
13. PTM\&W, Urethanes, (2005), http://www.ptm-w.com/index.asp?pgid=9

14. Schueler, R., Joshi, Shiv, P., Schulte, Karl. Conductivity of CFRP as a tool for health and usage monitoring, SPIE (1997), vol.3041, pp.417-426.

15. Tamiatto, C., Krawczak, P., and Pabiot, J. Integrated sensors for in-service health monitoring of glass/resin composites, Journal of Advanced Materials (1998), pp.32-37.

16. Tang, Benjamin. Fiber reinforced polymer composites applications in USA, DOT Federal Highway Administration (1997).

17. Temperatures, Resistance temperature detectors, (2005), http://www.temperatures.com/rtds.html

18. Wang, S., Kowalik, Daniel, P and Chung, D. D. L. Self-sensing attained in carbon fiber polymer matrix structural composites by using the inter laminar interface as a sensor, Smart Mater. Struct. (2004), Vol.13, pp.570-592.

19. Wikipedia, Resistivity, (2006), http://en.wikipedia.org/wiki/Electrical_resistivity 